\title{
Maurice Halbwachs (1913)
}

\section{La classe ouvrière et les niveaux de vie Recherches sur la hiérarchie des besoins dans les sociétés industrielles contemporaines}

\section{Livre I}

Un document produit en version numérique par Mme Marcelle Bergeron, Professeure à la retraite de l'École Dominique-Racine de Chicoutimi, Québec et collaboratrice bénévole

Courriel: mailto:mabergeron@videotron.ca

Site web: http://www.geocities.com/areqchicoutimi_valin

Dans le cadre de la collection: "Les classiques des sciences sociales" dirigée et fondée par Jean-Marie Tremblay, professeur de sociologie au Cégep de Chicoutimi

Site web: http://www.uqac.uquebec.ca/zone30/Classiques des_sciences_sociales/index.html

Une collection développée en collaboration avec la Bibliothèque

Paul-Émile-Boulet de l'Université du Québec à Chicoutimi

Site web: http://bibliotheque.uqac.uquebec.ca/index.htm 
Un document produit en version numérique par Mme Marcelle Bergeron, bénévole, professeure à la retraie de l'École Dominique-Racine de Chicoutimi, Québec courriel: mailto:mabergeron@videotron.ca

site web: http://www.geocities.com/areqchicoutimi_valin

à partir de :

\section{Maurice Halbwachs (1913)}

\section{La classe ouvrière et les niveaux de vie. Recherches sur la hiérarchie des besoins dans les sociétés industrielles contemporaines}

\section{Livre I}

Une édition électronique réalisée du livre de Maurice Halbwachs, La classe ouvrière et les niveaux de vie. Recherches sur la hiérarchie des besoins dans les sociétés industrielles contemporaines. Thèse de doctorat présentée à la Faculté des lettres de l'Université de Paris. $1^{\text {re }}$ édition, Félix Alcan, 1913, 495 pages.

Polices de caractères utilisée :

Pour le texte: Times, 12 points.

Pour les citations: Times 10 points.

Pour les notes de bas de page : Times, 10 points.

Édition électronique réalisée avec le traitement de textes Microsoft Word 2001 pour Macintosh.

Mise en page sur papier format

LETTRE (US letter), 8.5' x 11',)

Édition complétée le 13 février 2003 à Chicoutimi, Québec.

Tableaux réalignés correctement le 15 février 2003. 


\section{Table des matières}

Introduction

\section{Livre I \\ Les limites et l'unité de la classe ouvrière}

Chapitre I. - Les groupements ruraux.

I. Les groupements ruraux et la classe ouvrière. - II. La technique du travail agricole. - III. La condition juridique des paysans. - IV. Vie urbaine et vie rurale.

Chapitre II. - Les conditions techniques et juridiques du travail ouvrier.

I. La classe ouvrière et les industries. - II. Les métiers et la division du travail. - III. La notion de salarié. - IV. Résumé.

\section{Livre II Les dépenses dans la classe ouvrière}

Chapitre I. - Les deux aspects de la vie ouvrière : travail et consommation.

Chapitre II. - Les sources. - Choix et examen critique des données.

I. Préparation des livrets et contrôle. - II. La durée de l'enquête. - III. Le nombre des budgets. IV. Les différentes espèces de dépenses. - V. Moyennes fictives et moyennes valables. - VI. L'expression de la grandeur des familles. - VII. Employés et ouvriers.

Chapitre III. - Les dépenses dans les villes et dans les métiers différents.- La composition des revenus suivant les métiers.

I. Les influences locales et la répartition des dépenses. - II. Les métiers et la répartition des dépenses. - III. Les diverses sources du revenu.

Chapitre IV. - La répartition des dépenses dans les ménages ouvriers de composition et de dépense totale différentes.

A. - L'enquête de l'Office impérial allemand de statistique. - I. L'élaboration des données. - II. La grandeur des familles et la répartition des dépenses. - III. Le chiffre de la dépense totale et la répartition des dépenses. - 
B. - L'enquête de la Fédération des ouvriers des métaux en Allemagne. - IV. L'état des données. - V. La grandeur des familles et la répartition des dépenses. - VI. La dépense totale et la répartition des dépenses. -VII. Les résultats des deux enquêtes.

Chapitre V. - La nourriture et le logement des ouvriers.

I. Le détail de la dépense nourriture. - II. La valeur absolue du prix du loyer. - III. Résumé.

\section{Livre III \\ Les tendances consommatrices}

Chapitre I. - Les tendances consommatrices. - Contribution à une théorie sociologique des besoins.

I. La théorie individualiste. -

II. Les besoins et la société.

- A. - La forme des besoins.

- B - La matière des besoins. $-1^{\circ}$ Les objets des besoins. $-2^{\circ}$ Les principes des besoins. -

III. Conclusion. - La famille et la classe ouvrière.

ANNEXE I. - Les enquêtes par budgets de familles, - Bibliographie et remarques critiques.

A. - Les budgets proprement dits (réellement tenus). $1^{\circ}$ Les budgets tenus spontanément. $-2^{\circ}$ Les budgets tenus sur la demande de l'enquêteur. $-3^{\circ}$ Les budgets tenus une année ou plus. _ $4^{\circ}$ Les budgets tenus moins d'une année. -

B. - Les budgets établis sur indications verbales. $1^{\circ}$ Les budgets établis par approximation. $2^{\circ}$ Les budgets établis par questionnaire (méthode extensive). $-3^{\circ}$ Les budgets établis par la méthode monographique.

ANNEXE II. - Tableau établi d'après les données de l'enquête de l'Office impérial allemand de statistique. - Les ménages ouvriers, classés d'après leur composition, le chiffre de leur revenu, et la répartition de leurs dépenses. 


\title{
LA CLASSE OUVRIÈRE ET LES NIVEAUX DE VIE
}

\section{RECHERCHES SUR LA HIÉRARCHIE DES BESOINS DANS LES SOCIÉTÉS INDUSTRIELLES CONTEMPORAINES}

\author{
Thèse pour le doctorat \\ présentée à la Faculté des Lettres de l'Université de Paris \\ PAR
}

\section{Maurice HALBWACHS \\ GORDON \& BREACH}

PARIS LONDRES NEW YORK

Première édition : 1912 Félix Alcan

P. Halbwachs et Gordon \& Breach 1970 


\section{Introduction}

$\underline{\text { Retour à la table des matières }}$

Que faut-il entendre par classe? Cette notion semble déborder l'économie sociale. Il y a ou il y a eu, en effet, des classes au sens juridique, en particulier sous le régime de l'esclavage : esclaves, affranchis, hommes libres représentent bien de tels groupes. En France, sous l'ancien régime, les trois ordres : noblesse, clergé et tiers état comprenaient des catégories d'hommes dont les droits politiques étaient inégaux : les ouvriers, bien que confondus parmi le tiers, ne participaient pas au vote pour les élections aux états généraux, et constituaient une quatrième classe, définie par cela même. La constitution du clergé en ordre indépendant prouve qu'il y a eu aussi des classes religieuses ; et dans certaines sociétés à régime de castes, les séparations sociales ne sont rien d'autre. Enfin on conçoit qu'il existe encore des classes guerrières et jusqu'à des classes intellectuelles. Mais, même si on s'en tient aux classes économiques, plusieurs divisions se réalisent. Les auteurs du XVIII ${ }^{\mathrm{e}}$ siècle opposaient déjà les classes disponibles aux classes industrieuses, les classes possédantes aux classes salariées, les classes riches aux classes pauvres. Ces trois séries d'opposition correspondent à des distinctions fondées sur la considération de l'attitude prise par ces classes, soit dans la 
production, soit dans la répartition, soit enfin dans la consommation ${ }^{1}$. » - Nous croyons que toutes ces définitions de classes, des points de vue juridique, politique, économique, etc., expriment une même réalité, et s'inspirent toutes d'un même principe : c'est lui que nous allons d'abord rechercher.

Il nous paraît contradictoire de supposer qu'une classe existe sans prendre conscience d'elle-même. Rien n'empêche un historien ou un sociologue de distinguer dans une société beaucoup de groupes, en tenant compte des ressemblances et des différences extérieures ou apparentes entre leurs membres : mais de tels « rangements » ont chance d'être le plus souvent artificiels, si on ne se préoccupe pas avant tout de l'attitude et des dispositions collectives des hommes. Appeler classe un ensemble d'hommes dans lequel une conscience de classe ne s'est point développée et ne se manifeste pas, c'est ne désigner aucun objet social, ou c'est désigner une classe en voie de formation, qui n'existe pas encore, bien que ses éléments se trouvent là, mais qui existera: c'est-à-dire qu'elle se constituera autour d'une représentation collective dont il faut bien donner au moins une idée.

Voici un autre point, sur lequel il ne peut, croyons-nous, y avoir de désaccord : il n'y a de classes, par définition, que dans une société hiérarchisée, à quelque degré, d'ailleurs, et sous quelque forme qu'elle le soit. Prendre conscience de soi, pour une classe, c'est reconnaître à quel niveau social elle se trouve, et c'est par suite se représenter par rapport, à quoi, à quels privilèges, à quels droits, à quels avantages, se mesurent ces niveaux et se détermine cette hiérarchie Toute représentation de classe implique un double jugement de valeur: l'estimation du bien ou des biens les plus importants et les plus appréciés dans la société considérée - l'estimation du degré jusqu'où il est permis aux membres de la classe de satisfaire les besoins qui s'y rapportent. - On conçoit que, suivant les époques et les pays, la première espèce d'estimation puisse varier. Dans une société profondément religieuse, le bien suprême sera d'entrer en rapports le plus directement avec la divinité par l'accomplissement de certains rites, dont le privilège se trouvera réservé au groupe le plus élevé : dans une telle société, le rang des divers groupes serait déterminé par le degré de leur participation à la vie religieuse. Si une société a surtout pour raison d'être son organisation et sa puissance politique, l'objet principal des désirs ses membres sera de remplir des fonctions administratives, ou de direction, et de se mêler en tous cas le plus possible à la vie publique : à mesure qu'on s'élèvera dans la hiérarchie des classes, c'est le nombre et l'étendue des droits politiques qui augmentera. Ailleurs, les préoccupations de lucre peuvent passer au premier plan : alors la puissance pécuniaire des citoyens, c'est-àdire en même temps l'argent qu'ils possèdent, et la faculté qu'ils ont d'en acquérir,

Picard (Roger). La théorie de la lutte des classes à la veille de la Révolution française. Revue d'économie politique, septembre-octobre 1911, p. 624. 
fixera la place de chaque classe dans la société. Il y a encore des sociétés purement guerrières, comme il pourrait y avoir des sociétés purement intellectuelles. C'est toujours par rapport aux biens regardés comme les plus importants dans chaque espèce de société que les classes se définiront.

Cherchons maintenant ce qu'il y a de commun à toutes ces références, et s'il est possible d'exprimer par une formule générale tout cet ensemble de jugements sur la valeur des diverses activités et des divers biens. - Quel que soit le type de société que nous considérions, l'idéal, le bien par excellence, c'est sans doute une forme déterminée de vie sociale, mais c'est, en même temps, la vie sociale la plus intense qu'on puisse se représenter.

Dans une société où les cérémonies religieuses, l'accomplissement des rites, sont l'occasion principale pour les hommes de se rattacher entre eux par la communauté des pensées et des sentiments, où la transmission des dogmes et des mystères constitue la tradition sociale unique, on comprend que ceux qui en sont plus ou moins écartés, qui n'y participent qu'à de longs intervalles, et de plus loin que les autres, se sentent surtout diminués en ce que l'accès de la vie sociale proprement dite leur est plus ou moins interdit. Dans une société avant tout orientée vers un idéal politique, et d'ailleurs fortement organisée, les membres d'un groupe souffriront plus de se voir privés du droit de vote ou de délibération que de subir une perte matérielle quelconque : c'est que la richesse pure et simple ne permet pas alors de prendre sa part des émotions, des joies et des peines collectives les plus intenses en une telle cité, et d'élargir sa pensée et son action en les confondant ou les confrontant avec celles des hommes assemblés. Inversement, dans une « société lucrative », le mal essentiel sera, par sa faiblesse pécuniaire, d'être empêché de se manifester aux yeux des autres, de compter pour eux, de compter parmi eux des amis, des associés, des adversaires, et de multiplier avec les autres les rapports d'affaires, c'est-à-dire de ne point participer à l'activité sociale par excellence. Mais il en est sans doute de même en toute société. Qu'un homme, ou quelques hommes isolés, puissent diriger toutes leurs pensées et leurs désirs vers ce qui laisse indifférents les autres, on le conçoit. Mais qu'un groupe puisse avoir un autre objet en vue, et d'autres préférences, qu'un objet et des préférences sociales, ce serait contradictoire. Or, vers quoi tend toute société, si ce n'est à intensifier de plus en plus en elle-même la vie collective?

Lorsqu'on envisage de ce point de vue la hiérarchie des classes, on constate, à mesure qu'on s'élève de l'une à l'autre, que les groupes sont de plus en plus intégrés, c'està-dire que leurs membres se trouvent de plus en plus pris dans un réseau de relations sociales, religieuses, politiques, d'affaires, etc., suivant le type de société. On peut, interpréter cela de deux façons : ou bien on dira que la société dans son ensemble tend à se dépasser, que la vie sociale d'abord diffuse, éparpillée, soumise à l'action de 
beaucoup de forces de dispersion, petit à petit se concentre, se ramasse comme autour d'un foyer qu'elle a elle-même allumé et qu'elle alimente ; ou bien on dira que la société fait un effort, et un effort pénible et constant, pour se distendre, comme s'il lui fallait écarter d'elle beaucoup de forces d'oppression, qui l'enserrent et l'étouffent, et que les parties d'elle-même les plus voisines de sa périphérie se trouvent de plus en plus éloignées du foyer central, de plus en plus en contact avec le «dehors », qu'elles perdent en même temps de leur souplesse et de leur élasticité, qu'elles se durcissent et qu'elles se figent. Au fond, il ne faut pas croire que ces deux interprétations s'opposent entièrement, comme si l'on se représentait la société tantôt comme une création artificielle des hommes, et tantôt comme leur nature même. Il demeure incontestable que, lorsque les hommes se sont élevés au prix d'un effort, ou se sont trouvés par chance le plus près du foyer, c'est-à-dire dans la partie de la société où la vie collective est la plus intense, il leur est très pénible de s'en éloigner, et ils gardent toujours le désir d'y rentrer. Cela suffit pour qu'on puisse poser que plus la vie est sociale, plus elle est conforme à la nature de l'homme. Il en résulte qu'une classe occupera un niveau d'autant plus élevé que ses membres participeront davantage à la vie collective, telle qu'elle est organisée dans leur société.

Ces observations générales permettent, et permettent seules, de surmonter la plus grosse difficulté où se sont heurtés les théoriciens des classes. Leurs discussions, en effet, avaient pour résultat d'opposer nettement deux thèses. L'une explique les classes par la profession, et veut que les hommes se distinguent socialement en raison des fonctions différentes qu'ils occupent dans la société : ces fonctions sont plus ou moins difficiles, elles exigent tout un ensemble d'aptitudes plus ou moins rares, et elles modifient l'organisme aussi bien que la nature morale de ceux qui s'en acquittent: ces aptitudes et ces modifications, transmises par l'hérédité et fortifiées par l'éducation, expliquent que les séparations de classes tendent à se conserver ${ }^{2}$. L'autre met au premier plan les différences de revenu ; la diversité des fonctions n'en serait qu'une conséquence secondaire ; c'est parce que les hommes ont telle «force pécuniaire » qu'ils peuvent choisir telles professions, et se préparer à les remplir ; les hommes des professions les plus diverses se trouvent réunis dans les mêmes classes; mais ce que l'on se représente surtout, lorsqu'on parle du rang social d'un groupe d'hommes, c'est leur richesse, c'est-à-dire l'ensemble de leurs dépenses habituelles, les biens que leurs revenus leur permettent de se procurer ${ }^{3}$.

C'est la thèse soutenue par Schmoller (Gustave), dans son Grundrisse der, Allgemeinen Volkswirtschafslehre, 1904, $1^{\mathrm{er}}$ Teil, p. 424-450, $2^{\mathrm{e}}$ Teil, p. 196 sqq. Dans son cours à l'Université de Berlin, en 1910 Schmoller insiste à nouveau sur l'importance, ici, de l'hérédité. Ce qui a empêché, suivant lui, la constitution d'une classe de prêtres catholiques progressive et capable d'assurer toujours la direction spirituelle des peuples, c'est la règle du célibat...

Bücher (Karl) s'est placé à ce point de vue, dans die Entstehung der Volkwirtschaft (Arbeitsteilung und soziale Klassenbildung), 1893. 
Ainsi la classe peut être définie soit par la profession, soit par la fortune, et ces deux points de vue semblent aussi différents, aussi irréductibles l'un à l'autre que ceux où se sont placés les théoriciens de la valeur, qui l'expliquent, les uns par la quantité de travail contenue dans un objet, les autres par l'utilité de cet objet, c'est-à-dire par les satisfactions qu'il apporte. Travail et consommation, profession et dépense, l'opposition est symétrique. Plus on y réfléchit, plus il paraît difficile, pour définir une classe, de ne pas faire leur part à chacun de ces deux termes. Mais comment cela serait-il possible, s'ils sont distincts entièrement?

De fait, comment passer de l'un à l'autre ? De ce que les hommes s'acquittent de telle espèce de travail, et de cela seul, s'ensuit-il qu'ils effectueront telle quantité de dépenses de telle nature ? Suffit-il d'analyser le niveau de vie d'un groupe, pour découvrir quelles sont les professions de ses membres ? - Il nous est loisible de formuler deux hypothèses dans lesquelles il en serait ainsi. On peut supposer ceci : à mesure qu'augmente la quantité de travail fournie par les membres d'un groupe, à mesure aussi ils peuvent consommer davantage; tel serait le cas pour un individu isolé tel que Robinson. Mais on peut supposer l'inverse : plus on travaille, moins on satisfait ses besoins: sous un régime d'esclavage particulièrement rigoureux, il pourrait en être ainsi. Dans ces deux cas, l'un des termes exprimerait l'autre. Mais nous sommes loin de la réalité, de ce qui se passe dans nos sociétés. - Si, maintenant, nous admettons qu'entre la quantité de travail fournie et la quantité ou l'espèce de biens consommés dans les groupes, le rapport est indéterminé, il faudrait, pour tenir compte de l'un et de l'autre, les comprendre ensemble dans la représentation de classe. Mais qui ne voit qu'on communiquerait alors à celle-ci un caractère d'obscurité, qu'elle deviendrait à la fois équivoque et confuse ? La représentation de classe ne se ramène pas plus à celle d'un groupe de professions qu'à celle d'une catégorie de revenus. Mais elle ne se ramène pas non plus à la juxtaposition pure et simple, et non motivée, de l'une et de l'autre. Si l'on n'y trouvait rien d'autre, il faudrait reconnaître qu'elle n'a pas de contenu propre et convenir qu'elle n'est qu'une fiction.

La difficulté nous paraît naître de ce qu'on oppose ainsi l'occupation et la dépense, le travail et la consommation, exactement comme la peine et plaisir. Cela est très obscur. Pour un homme qui travaillerait et consommerait seul, qu'on supposerait tout à fait dégagé de toutes habitudes et façons de penser sociales, le contraste serait net, sans doute, entre les heures de labeur, où la fatigue du corps et de l'esprit se traduit en sentiments pénibles, et les heures où il jouit, sans arrière-pensée, des produits de son travail. Même alors, la séparation des deux termes ne sera cependant pas entière. Il pourra éprouver un plaisir physique à exercer ses muscles, il éprouvera certainement de la joie à surmonter les obstacles, à réussir, inventer, etc. D'autre part des circonstances diverses (rareté du gibier, sécheresse, épuisement de ses provisions) vont l'obliger à s'alimenter autrement, moins et moins bien; sa cabane peut brûler : le voilà 
réduit à se réfugier dans un trou de rocher : par comparaison, son dénuement lui apparaîtra : aux actes par lesquels il satisfera ses besoins, au sentiment de les satisfaire, se mêlera bien de l'amertume. Mais il ne s'ensuit pas qu'il y ait une commune mesure entre la consommation et le travail. C'est encore en termes de travail, si l'on peut dire, que s'expriment les joies qui y sont liées (suppression, dans le travail, de l'élément monotonie, ou difficulté, ou tâtonnement, etc.), et c'est en termes de consommation que s'exprime le sentiment pénible qui s'y mêle parfois (lacunes de la consommation actuelle, regret de la plénitude des satisfactions consommatrices antérieures, etc.). Peu importe d'ailleurs qu'en définitive Robinson établisse une correspondance entre la peine que demandent certains travaux, et le plaisir qu'apportent tels biens, puisqu'il diffère ou entreprend les travaux suivant le prix qu'il attache aux biens : nous défions de l'expliquer autrement que par une série de décrets arbitraires, et qui ne l'enchaînent qu'autant qu'il le veut bien, ou qu'en réintroduisant dans son île, d'une façon ou de l'autre, la société. La ligne qui sépare l'occupation et la satisfaction des besoins reste bien marquée.

Mais tournons le dos à cette fantaisie. Rentrons dans la société. Entre les biens et les travaux, celle-ci va établir des rapports, puisque les uns et les autres ont des prix. Nous ne chercherons pas (ce n'en est pas le lieu) comment elle met ainsi en équations telle quantité de travail (de telle espèce) et telle quantité de biens. Il nous suffit d'avoir rappelé que ce n'est pas dans les besoins et appréciations de l'individu comme tel qu'elle en pourra trouver le principe. Mais nous nous en tenons maintenant à des ensembles, ensembles de travaux que représente une occupation, une profession, une fonction, ensemble de consommations que représente un niveau de vie. Et nous nous demandons : peut on envisager ces deux ensembles de faits sociaux d'un point de vue tel qu'on aperçoive entre l'un et l'autre une ressemblance, dans l'un et l'autre un aspect ou un caractère commun, qui serait le centre et le contenu original de toutes les représentations de classes? Il s'agit approfondissant ces deux termes : occupation et consommation, d'y découvrir un élément positif, qui serait tout ce qu'en retient la conscience sociale, quand elle devient conscience de classe.

Mais si notre définition générale des classes est exacte, s'il est vrai qu'une classe doit occuper un rang d'autant plus élevé que ses membres participent davantage à la vie sociale telle qu'elle est organisée dans leur société, nous apercevons une solution de ce problème, et nous n'en apercevons qu'une. - Comme consommateurs, les hommes se procurent les divers biens et satisfont leurs besoins essentiels. Or les besoins peuvent être considérés comme d'autant plus sociaux que leur satisfaction s'accompagne d'un plus grand nombre de pensées et de sentiments collectifs. S'il y a dans la société des classes, il faut s'attendre à ce que, dans chacune d'elles, les divers besoins ne soient ni aussi pleinement satisfaits, ni « hiérarchisés » de la même manière : c'est une partie essentielle de l'étude de ces groupes, que la détermination de «niveaux de 
vie » classés d'après la satisfaction et le développement inégal des besoins sociaux et non sociaux. - L'échelle des professions (en admettant qu'on les puisse ranger d'après le degré de leur « désirabilité ») ne correspond pas à l'ordre des fatigues, des efforts, des préoccupations plus on moins pénibles qu'elles comportent. Mais elles ne sont quand même pas rangées ainsi au hasard, ni pour des raisons de tradition ou, de mode. Par leurs occupations, les hommes plongent dans la vie sociale, mais plus ou moins profondément. Il en résulte qu'à tous leurs genres d'activité se mêlent aussi des pensées et des sentiments collectifs. Si donc la société classe les professions (c'est-à-dire les groupes qui les exercent) au nom de son idéal propre, elle les appréciera d'autant plus que leur exercice engage l'homme dans un plus grand nombre de relations sociales. - Ainsi il est très concevable que, dans la représentation de classe, on retrouve l'idée d'une profession, et l'idée d'un ensemble de dépenses, puisque ces deux termes expriment à la fois l'un et l'autre, quoique de façon diverse, la situation de l'homme dans la société, et le degré de sa participation à la vie collective.

On comprend dès lors que, nous proposant d'étudier la classe ouvrière, nous ayons été conduits à déterminer comment se répartissent les dépenses des ouvriers, quelles sont leurs habitudes consommatrices et jusqu'à quel « niveau de vie » ils s'élèvent ou tendent à s'élever, Mais en même temps, et d'abord, quelle est leur place dans l'organisme industriel, et leur fonction à titre de producteurs. Car si, extérieurement, la vie de ces hommes semble coupée, comme par autant de cloisons, par les moments où ils passent de l'intérieur de l'usine au dehors, et inversement, ce n'est sans doute qu'une apparence. La profession et la consommation n'ont tout leur sens, on n'en aperçoit bien l'importance et le rôle, que quand on les rapproche, et qu'on les étudie dans leurs rapports. Nous ne voulons pas, dès maintenant, dire en quoi elles sont solidaires : ce sera l'objet du premier chapitre de notre deuxième livre. Mais puisque, comme nous l'avons vu, les travaux exercés, de même que les biens consommés, en dehors de leur nature physique et de leur action sur l'organisme, sont l'objet d'une appréciation de la part de la société, et ont pour elle une valeur qui se communique aux hommes euxmêmes, il n'est pas indifférent que ceux-ci, avant d'entrer à l'usine, aient séjourné dans telle zone du milieu social où l'on consomme, et, encore moins, qu'avant de dépenser leurs revenus ils les aient obtenus par telle espèce de travail ou par telle autre. En particulier, comment comprendre l'ordre et l'espèce des dépenses des ouvriers par rapport à celles des autres classes, si l'on ne sait comment leur nature physique et morale a été affectée, comment leur faculté d'apprécier les divers biens sociaux a été influencée par les conditions de leur travail ? L'examen de la fonction des ouvriers est l'introduction nécessaire à la mesure de leurs besoins. 
$* * *$

Nous avons, dans les pages qui précèdent, présenté une définition très générale et théorique des classes sociales; nous avons expliqué quel est, de ce point de vue, l'intérêt d'une étude des habitudes de consommation des hommes, et de leurs niveaux de vie; et nous avons enfin montré que cette étude ne peut pas se séparer d'une analyse des conditions de leur travail, ou de leur fonction dans l'organisme producteur. Tel étant notre objet, il nous reste à indiquer les limites où nous avons dû nous enfermer, pourquoi nous avons choisi de restreindre d'abord nos recherches en ne sortant pas du domaine que nous dirons, et jugé opportun de nous en tenir à la classe ouvrière, et à l'époque toute contemporaine.

Nous nous en tenons à la classe ouvrière. - À cela, il y a certainement, d'abord, des raisons de commodité. Nous possédons, sur les conditions de travail des ouvriers et sur leur consommation, des données que nous n'avons pas pour les autres classes. La plus importante partie de notre travail est consacrée à l'analyse des dépenses des ouvriers et des rapports où sont entre eux leurs divers besoins. Il serait tout à fait impossible d'étudier en ce moment par les mêmes méthodes les besoins et les dépenses dans les autres groupes. Si la science sociale veut demeurer inductive, il lui faut bien renoncer provisoirement à poser les problèmes qu'elle ne pourrait résoudre par l'étude des faits.

D'autre part, nous reconnaissons volontiers que les questions ouvrières sont d'un intérêt plus actuel que les autres, et que c'était encore une raison pour que la classe ouvrière sollicitât davantage notre attention. Non que la science ait, à s'inspirer en quelque mesure de préoccupations pratiques : nous ne nous soucions pas, en tant que sociologue, des arguments que les amis des ouvriers ou leurs adversaires pourraient tirer de notre livre. Mais nous constations que beaucoup d'économistes, d'hommes d'action, d'hommes de toutes professions et de tous partis, parlent depuis moins d'un siècle de la classe, ouvrière comme d'une réalité. Bien entendu nous ne pouvons provisoirement regarder ces déclarations individuelles que comme des opinions ou des suppositions. Mais ce n'est certainement point par hasard qu'elles se sont produites si nombreuses, et imposées à l'attention publique, précisément dans le cours et surtout à la fin du XIX ${ }^{\mathrm{e}}$ siècle. Cela est en rapport indiscutable avec une vaste évolution, qui s'est poursuivie dans cette période, et qui a modifié profondément la contexture du corps social, savoir qu'une quantité d'hommes qui exerçaient un métier agricole et vivaient à la campagne sont allés dans les grandes villes et sont devenus ouvriers d'industrie, c'est-à-dire ont changé à la fois de lieu d'habitation et de profession. Avant cela, il y avait déjà beaucoup d'ouvriers d'industrie, et peut-être formaient-ils une classe : en tout cas, en même temps qu'il s'accroissait dans des proportions considéra- 
bles, ce groupe s'est présenté de plus en plus sous un aspect d'unité. C'est le fait social sans doute le plus ample qu'il nous soit donné d'observer. La science sociale est dès maintenant assez sûre de sa méthode, assez consciente de son objet propre, pour ne pas craindre de s'occuper des faits les plus récents, et qui sont les plus capables de passionner les hommes contemporains : quand des expériences aussi importantes et variées sont à sa portée, elle ne peut plus se dérober.

Mais, à ces deux raisons, commodité relative de la recherche, et importance ou ampleur du phénomène, s'en ajoutait une troisième, qui était pour nous la plus décisive, d'aborder l'étude des classes par la classe ouvrière : les faits que nous allons rencontrer sont beaucoup plus simples que ceux que nous présenteraient les autres classes.

De même que la sociologie religieuse a avantage à étudier d'abord la religion sous ses formes primitives, et dans les sociétés encore peu évoluées, de même la sociologie économique a été nécessairement conduite à s'occuper d'abord et surtout des conditions de travail et de vie des ouvriers. Bien entendu, nous ne considérons point la classe ouvrière comme un groupe ou un ensemble de groupes plus primitifs que les autres parties de la société. Si certains observateurs ont pu relever des rapports entre les coutumes et les façons de penser des couches les plus basses de la population ouvrière, et celles de certaines peuplades sauvages, il n'en reste pas moins que l'existence d'une classe ouvrière de l'industrie, établie le plus souvent dans les grandes villes, est un phénomène entièrement moderne. Mais plus nous avons étudié cette classe, plus nous avons reconnu l'uniformité et la simplicité de ses tendances, et à quel point les réactions de ces groupes sont mécaniques et limitées. Les diversités locales, si apparentes dans les coutumes des paysans, n'exercent pas une influence très essentielle sur les conditions de vie des ouvriers. On pourrait penser que la diversité des métiers, et la diversité des revenus séparent la classe ouvrière en une quantité de groupes, déterminent en eux les habitudes collectives les plus diverses, si bien que la classe ouvrière serait elle-même une société très complexe, et qu'on ne pourrait pas la définir à l'aide de quelques tendances ou représentations relativement simples. Mais toute notre étude prouve le contraire. Si nous nous étions proposé d'étudier les besoins sociaux et les activités sociales sous leur forme les plus achevées, nous aurions dû les observer dans les parties les plus hautes de la société. Mais nous voulions étudier les classes : or il n'y a sans doute pas de classe plus homogène, précisément parce que la vie sociale y est plus réduite, moins compliquée, et aussi parce que l'intervalle qui la sépare des autres groupes, sous ce rapport, est très marqué, que la classe ouvrière. C'était une raison suffisante pour nous y attacher d'abord.

Mais pourquoi nous en tenir au présent, à l'époque toute contemporaine ? Pourquoi ne point nous appuyer d'abord, et principalement, sur l'histoire ? Est-ce que la division actuelle de la société en groupes hiérarchisés ne s'explique pas surtout par le 
passé ? Nous avons tous le sentiment que la classe dont nous faisons partie est un groupe où notre place, comme celle de ses autres membres, se trouvait fixée dès avant notre naissance, et que des forces indépendantes de notre volonté et difficiles à vaincre nous y retiennent. Sans doute, dans la répartition des hommes en classes, comme dans tout le domaine des faits économiques, il y a des changements brusques et radicaux, qu'il faut bien accepter : les hommes subissent l'action des institutions économiques actuelles plus que des anciennes. Malgré tout, ils ne réussissent pas tout de suite à faire table rase des croyances, des traditions et même des institutions du passé. Lorsque Marx soutient que les institutions juridiques, politiques, religieuses, et tout le mouvement des idées, ne sont que l'expression, et comme l'apparence phénoménale d'une réalité plus profonde, savoir de l'évolution économique, peut-être ne veut-il pas dire autre chose. Les hommes n'aperçoivent pas tout de suite l'infrastructure : le passé encore vivant sous ces formes juridiques, politiques, religieuses, intellectuelles, les empêche de prendre conscience du présent économique. Ainsi les divisions sociales, anciennes se prolongent dans les classes d'aujourd'hui.

Il faut répondre à cette objection en tant qu'elle porte contre une méthode générale d'études, contre ceux qui croient pouvoir expliquer la nature et les propriétés des classes sociales sans s'appuyer principalement sur l'histoire. - L'histoire elle-même nous apprend que les rapports de puissance des classes se transforment souvent. Une classe qui depuis longtemps s'est distinguée par ses aptitudes rares soudain décline. D'une masse d'hommes sans tradition, sans éducation, sans passé, les nécessités économiques font, en moins d'une génération, une classe puissante, originale, admirablement adaptée aux fonctions d'entreprise et de commandement. Une classe unique se divise. Des classes, ou des groupes détachés d'autres classes, se fondent ${ }^{4}$. Or, pour expliquer ces changements, et, aussi, que les classes soient tantôt fermées et exclusives, tantôt s'ouvrent, accueillent et absorbent quantité d'éléments nouveaux, c'est l'état social tout entier, et l'état actuel, non l'évolution antérieure de ces classes, qu'il faut surtout envisager. En effet la division des groupes en classes se modifie sous la pression de besoins ressentis non dans une classe, mais dans le corps social tout entier : la société se décompose alors et se réorganise suivant le plan qui permet de les satisfaire le mieux. Ces besoins prennent naissance en dehors des cadres sociaux préexistants. Expliquer l'état actuel des classes par leur passé, c'est s'enfermer dans ces cadres et se condamner à ignorer ces nouveaux principes. - Mais, même si l'on s'en tient aux périodes de stabilité, où les divisions sociales ne se modifient pas, comment en rendre compte, sinon par la subsistance des besoins de la société en général ? et comment

En voici un exemple: « $\mathrm{Au} \mathrm{XV}^{\mathrm{e}}$ siècle acheva de se constituer, entre la haute noblesse et le peuple, une classe moyenne, où les parvenus et les anoblis se mêlèrent aux gentilshommes campagnards. Formée ainsi d'éléments hétérogènes, cette partie de la société française avait cependant, au temps de Charles VII et de Louis XI, des mœurs et des idées communes : elle formait vraiment une classe. » Histoire de France (Ernest Lavisse), tome IV, par Petit-Dutaillis, p. 152 sqq. 
savoir que ces besoins continuent d'exister, sinon par l'analyse de l'organisation actuelle de la société et l'observation des faits sociaux contemporains ? L'hérédité et l'éducation n'expliquent rien, car ce ne sont que des moyens. Elles supposent l'existence et la subsistance des classes, loin d'en rendre compte. Il importe peu que les individus, ou les familles, dominées surtout par la tradition et qui obéissent à leur passé, s'efforcent de diriger l'évolution, d'en ralentir le rythme. Elles doivent bien se plier assez vite aux conditions nouvelles. - Ainsi le passé des classes peut nous renseigner sur des résistances passagères que rencontre la société en train d'évoluer, sur des traditions tenaces, des survivances autrement inexplicables; sur les causes profondes de la distribution actuelle de la société en groupes hiérarchisés, il nous apprendra moins que le présent.

Mais la classe ouvrière en particulier pouvait être étudiée sans qu'il fût nécessaire de connaître et de rapporter toute son évolution, car elle n'a point, proprement, de passé. - Il pourrait en être autrement. L'organisation corporative des métiers sous l'ancien régime groupait les artisans en des « corps sociaux » relativement stables : tout un ensemble de traditions, de connaissances pratiques, de coutumes morales et sociales, se transmettant d'une génération à l'autre, assurait, à travers bien des changements, la continuité de ces groupes. Chaque «métier » avait son histoire, qu'il faut connaître pour s'expliquer la situation de ses membres, et, surtout, l'idée qu'ils se faisaient d'euxmêmes et de leur rang. Au reste, si les corporations jouaient ce rôle, c'est sans doute grâce aux familles des « maîtres », solidement organisées, et élargies jusqu'à comprendre en elles les compagnons et les apprentis : car les traditions et les habitudes de vie se consolident à l'intérieur des familles, et se transmettent surtout par elles de génération en génération. Aujourd'hui, alors même que le régime corporatif n'existe plus, la famille ouvrière ne peut-elle pas conserver cette fonction? Encore faudrait-il que l'ouvrier moderne fût, dès sa naissance, et durant la plus grande partie de sa vie, encadré dans un groupe domestique fortement constitué ; mais on peut penser qu'il n'en est rien, et que si l'esprit de famille tend à fortifier les sentiments de classe des groupes non ouvriers, il n'exerce pas ici une influence appréciable. Enfin il n'y a pas lieu d'invoquer l'histoire du mouvement ouvrier : les ouvriers ne paraissent pas encore assez organisés, leurs groupements professionnels et locaux ont été le plus souvent trop isolés ou trop éphémères, pour qu'une tradition ouvrière ait pu s'imposer de façon durable à la conscience de leurs groupes. En réalité, qu'il soit venu de la campagne à la ville, ou, à l'intérieur de la société urbaine, qu'il ait pris un autre métier que celui de son père (ce qui arrive le plus fréquemment), ou qu'il ait adopté le même, en raison du changement incessant des conditions techniques et économiques de l'industrie, l'ouvrier ne plonge point de racines bien profondes dans un passé d'ailleurs très vite enveloppé pour lui d'obscurité. Il tient par des rapports autrement nombreux, par des liens autrement étroits à toute l'organisation sociale contemporaine. 
En somme s'il s'agissait d'expliquer les habitudes et les idées d'un groupe très « organisé », d'une classe guerrière aristocratique, ou même d'une bourgeoisie très traditionaliste, la méthode dite historique, pourrait être féconde. Ainsi, pour rendre compte des propriétés d'une espèce vivante, en biologie, il est utile de comparer les diverses formes à travers lesquelles, au cours d'une évolution continue, elle est parvenue à son état présent. Mais la classe ouvrière ressemble bien plus, croyonsnous, à une masse mécanique et inerte qu'à un organisme vivant et souple. Or croit-on qu'il suffit, pour comprendre la nature et le rôle des instruments et des machines actuelles, de comparer ceux dont les hommes se sont servis aux diverses époques, et de suivre leurs perfectionnements successifs ? Ne convient-il pas plutôt, pour expliquer l'outillage de l'industrie moderne, de considérer l'état actuel de la société, les connaissances, les ressources, les coutumes, les institutions et les besoins des hommes d'aujourd'hui ? Si nous parvenons à démontrer que cette comparaison est une expression approchée de la réalité, nous aurons du même coup justifié notre méthode. C'est dans le présent, et non dans l'histoire, qu'il sera légitime et nécessaire d'étudier d'abord la classe ouvrière, puisque, de toutes les parties de la société, c'est elle qui subit le moins l'influence et l'impulsion de son passé. 
La classe ouvrière et les niveaux de vie

Livre I

Les limites et l'unité de la classe

$\underline{\text { Retour à la table des matières }}$ 
Livre I : les limites et l'unité de la classe

\section{Chapitre I}

Les programmes ruraux

\section{I \\ Les groupements ruraux et la classe ouvrière}

Lorsqu'on parle de la classe ouvrière, on croit s'entendre. Quelles sont ses limites? Se confond-elle avec la classe pauvre, ou faut-il en distinguer les couches les plus basses du « prolétariat », population flottante et misérable qui vit presque en marge de la société? Comprend-elle tous ceux qui travaillent de leurs mains, non seulement les ouvriers de la grande industrie, mais les petits producteurs encore indépendants au moins en apparence, et les travailleurs à domicile empêchés, par leur dispersion habituelle, d'entrer en contact les uns avec les autres, et avec les travailleurs en général ? Ces questions sont fondamentales, et nous essaierons d'y répondre. En tout cas, de notre temps, et dans les contrées civilisées, on croit que dans une partie au moins de la masse des ouvriers se développe une conscience de classe. L'expression classe ouvrière 
s'emploie couramment comme si, quelle que soit la réalité qu'elle recouvre, on était sûr, en tout cas, qu'elle en recouvre une.

Mais, par classe paysanne ou rurale, pense-t-on désigner rien d'autre qu'une catégorie d'hommes semblables ? Est-ce, à ce moment, l'observateur qui classe, en tenant compte de caractères communs et faciles à discerner, ou est-ce l'objet, c'est-à-dire le groupe considéré, qui se classe spontanément? Nous bornons-nous à enregistrer une attitude psychologique de la masse paysanne, un jugement ou un sentiment collectif, ou bien imposons-nous à une réalité sociale mouvante nos cadres administratifs, scientifiques, ou philologiques?

On entrevoit en effet trois hypothèses possibles, si on admet qu'il y a une classe ouvrière, sur l'attitude des paysans vis-à-vis de celle-ci.

Ou bien il y aurait, en effet, une classe paysanne qui, par ses intérêts, son genre de vie, ses traditions, s'opposerait nettement à la classe ouvrière, se distinguerait d'elle en tout cas (malgré certains points de contact inévitables). On a souvent observé que l'ouvrier est moins prévoyant, plus indépendant, moins routinier, plus " avancé » que le paysan. D'autre part, la concentration croissante de la population dans les villes, en diminuant la main-d'œuvre agricole, rend plus précaire la situation des fermiers et petits propriétaires. Que ces conflits d'intérêt, cette diversité de tendances se traduisît en un antagonisme conscient de deux groupes, cela n'étonnerait point. - Ou bien, au contraire, les deux classes ouvrière et paysanne n'en feraient, en réalité, qu'une ${ }^{5}$. Car, des luttes et divergences de cette nature, il s'en produit à l'intérieur de la classe ouvrière elle-même, entre ouvriers appartenant à la grande, ou à la petite industrie (artisans), ou à des industries d'espèces différentes. Les motifs d'opposition seraient, d'ailleurs, accidentels et temporaires, et passeraient au second plan. Leur attention se porterait sur la ressemblance de leurs travaux, sur leur relation générale de dépendance vis-à-vis de la classe riche, c'est-à-dire sur des traits communs à la fois essentiels et durables. Surtout, il y aurait des passages fréquents d'un groupe dans l'autre. On interprète souvent le mouvement de migration des campagnes dans les villes comme un retranchement brutal d'une partie de la classe paysanne, et son annexion par la classe ouvrière. Mais, d'abord, la transplantation n'est pas toujours définitive. Bien des ouvriers redeviennent paysans pendant la morte-saison. Plus de la moitié des émigrants italiens aux États-Unis reviennent dans leur pays. Le nombre, ici, importe peu : il suffit qu'il apparaisse que les relations ne sont pas interrompues à jamais, que l'émigrant ne se ferme pas le chemin du retour. En ce sens, le groupe paysan serait subordonné au

Turgot, dans ses Réflexions sur la formation et la distribution des richesses, réunit dans une première et même classe les cultivateurs et les artisans qui se ressemblent, " en ce qu'ils ne possèdent aucun revenu et vivent également de salaires qui leur sont payés sur les produits de la terre... » Picard (Roger), article cité, p. 629. 
groupe ouvrier comme, dans celui-ci, les manœuvres aux ouvriers qualifiés; mais ils feraient partie de la même classe. Il n'y aurait pas entre paysans et ouvriers la même solution de continuité qu'entre ouvriers et employés. Ou, enfin, en face et en dehors de la classe ouvrière, les ruraux formeraient une masse sociale confuse et inorganique, caractérisée précisément par l'absence d'une conscience collective ${ }^{6}$. Isolés, éparpillés, ils n'auraient d'autre horizon que celui de leur terre natale et ne connaîtraient d'autres liens que ceux qui rattachent les habitants d'un même village ou d'une même province. Entre le propriétaire terrien et le fermier ou même l'ouvrier journalier, on trouverait beaucoup plus de similitudes qu'entre ceux-ci et l'ouvrier des villes. C'est ce qui empêcherait les paysans de constituer un prolongement et comme une frange indécise et très divisée de la classe ouvrière. Pour la même raison, et surtout parce que les petits propriétaires sont très nombreux, que les grandes exploitations collectives propres à mettre en relief l'opposition du patron et du salarié ici sont rares, et que tout paysan désire s'approprier une parcelle du sol, ils auraient surtout en commun l'idée qu'ils vivent tous de la terre. Mais c'est là plutôt un élément encore de division et d'éloignement : car la terre, en tous les endroits, n'est pas aussi fertile ; elle est d'ailleurs inégalement répartie. Dans une région restreinte, ces conditions pourraient être les mêmes pour presque tous ; cela ne suffirait pas pour leur donner conscience d'appartenir à une classe qui doit s'étendre au moins jusqu'aux limites de la nation. Passer de l'agriculture à l'industrie ne serait donc pas s'élever d'une classe à l'autre, mais quitter un groupement local qui repose surtout sur des traditions et coutumes domestiques, pour entrer dans un groupe organique, et au moins national.

On pourrait nous répondre, il est vrai : il n'y a pas lieu de choisir entre ces hypothèses, puisque, suivant les régions considérées, et aux différentes époques, elles se réalisent en même temps, ou l'une après l'autre. Considérons, par exemple, la France, terre classique de la petite propriété ; on y trouvera sans peine des régions (la Lorraine entre autres) où, à proximité de campagnes dont le sol est possédé par de petits paysans, de situation économique très voisine et généralement médiocre, se développent de grands centres industriels, habités par une nombreuse population d'ouvriers d'usine. L'ouvrier, réduit à son salaire, mais indépendant et insouciant, le paysan, attaché à la terre « comme le serf à la glèbe », quoique par des liens d'autre nature, qui ne peut combiner le travail industriel avec celui de la culture, qui limite ses besoins et craint les mauvaises récoltes, vivent très près l'un de l'autre; ils se confrontent et se comparent. Alors même que des fils ou des filles de paysans vont à l'usine, cette

Ce pourrait être l'opinion de Marx. Il range sans doute les paysans, ainsi que les artisans, dans la petite bourgeoisie, qui, avec la noblesse féodale, représente une classe en décadence. Mais «les paysans ne sont pas néanmoins une classe entièrement développée, parce qu'il ne suffit pas d'additionner des hommes de même condition «comme des pommes de terre dans un sac ». L'identité des intérêts n'ayant engendré chez les «paysans aucune solidarité, aucun lien national, aucune organisation politique », ils ne forment pas, en ce sens, une classe ». Andler (Charles). Introduction au Manifeste communiste, p. 83. Bibliothèque socialiste, Paris, 1901. 
proximité dans l'espace, cette différence de situation économique, et cette impossibilité de réunir les deux métiers créent des sentiments de défiance, d'envie, d'hostilité, chez les moins favorisés : n'existe-t-il pas alors deux classes ? On peut même ajouter que l'opposition dépasse ici le cercle de la région où elle se précise : les paysans se représentent sous forme universelle et humaine cette dualité de genre de vie. - Il n'en serait plus de même, sans doute, en des pays de grande propriété et d'exploitation en grand. Dans plusieurs régions, la culture est presque industrialisée, les cultivateurs produisent pour des industriels (culture des betteraves) ou pour des commerçants (culture viticole) dont ils doivent accepter les conditions, et à la merci de qui ils se trouvent; ici, la terre est fortement hypothéquée au bénéfice de personnes que leur occupation principale éloigne de la culture ${ }^{7}$; là, enfin, les grands propriétaires profitent de la misère et du grand nombre des cultivateurs pour élever extrêmement le prix des fermages, comme en Irlande. En tous ces cas, les paysans auront le sentiment confus de dépendre d'un ensemble d'hommes plus riches qu'eux, et à qui ils doivent céder régulièrement une part mal définie du produit de leur travail. C'est une raison pour qu'en eux se développe une conscience de groupe. On ne peut dire, sans doute, qu'en même temps, et en toutes circonstances, il s'établira entre eux et les ouvriers industriels de la même région des relations de solidarité assez étroites pour qu'ils se confondent tous en une classe : du moins on n'aperçoit pas, dans leur situation économique, de raisons suffisantes pour qu'une barrière isole ces paysans de la classe ouvrière. - Enfin, en d'autres régions encore, les conditions anciennes de l'exploitation agricole se sont maintenues; entre le maître ou les fermiers et les ouvriers journaliers, les rapports restent fréquents et sont encore empreints d'un caractère patriarcal; le taux des fermages ne se modifie que lentement et sans que les fermiers se sentent pressurés ; enfin, l'influence de la grande industrie ne s'y est pas encore exercée. Alors les paysans ne s'opposent collectivement ni aux ouvriers, ni à la classe riche : il y a bien des paysans, mais il n'existe pas une classe paysanne. C'est sans doute le cas en Basse-Bretagne. Isolés des centres industriels par l'éloignement, les paysans voient dans leurs maîtres sinon des égaux, du moins des hommes de même espèce qu'eux. Aucun intérêt commun ne les amène à se grouper; aucune vie sociale intense n'entraîne les relations multiples, les comparaisons, et ces courants de pensée collective d'où naît une conscience commune.

Au reste, puisque les classes semblent se définir surtout à l'occasion d'un conflit, il faut s'attendre à ce que, suivant les circonstances, un même groupe se comporte ou ne se comporte pas comme une classe. En période de prospérité, quand les récoltes sont bonnes, quand les travailleurs sont bien payés, les préventions éventuelles des paysans contre les ouvriers, selon toute vraisemblance, s'atténueront; leur attention pourra se porter de préférence sur les liens de solidarité qui existent entre l'agriculture

Il en est ainsi de plus en plus dans la Basse-Normandie. Voir là-dessus Sion (Jules), les Paysans de la Normandie orientale, Pays de Caux, Bray, Vexin normand, Vallée de la Seine. Paris, 1909. 
et l'industrie. Sans se rattacher, du même coup, à la classe ouvrière, ils ne seront pas fondés à former bloc contre elle. - D'autre part, qu'en une région où les agriculteurs trouvent un supplément de gain dans un métier industriel pratiqué à domicile (industrie domestique) vienne s'établir une usine où l'on fabrique les mêmes produits. Sans doute une partie des cultivateurs, s'ils y trouvent avantage, se transformeront en ouvriers d'usine et quitteront les champs. Mais ceux qui seront restés attachés au sol, privés de ce travail accessoire, sentiront d'autant plus l'intervalle qui les sépare des ouvriers qu'ils auront refusé de passer dans leurs rangs. Ce sera une cause de plus, à côté de leur rancune et de leur détresse commune, pour qu'à ce moment ils se posent comme classe en face d'eux. D'une façon générale, il se peut que les mouvements de migration qui dépeuplent certaines campagnes, loin d'établir des rapports nouveaux entre paysans et ouvriers, contribuent à creuser entre eux un fossé ; en particulier, les paysans devenus ouvriers, et qui reviennent de temps à autre dans leur pays, s'ils décident quelques paysans à les imiter, inspirent à la masse des autres des sentiments d'autant plus hostiles que leur changement de situation apparaît plus net. - Remarquons tout de suite que l'opposition de la classe paysanne à la classe ouvrière, là où elle se produit, est difficile à constater : deux tendances contraires se développent: certains envient et, pour cette raison, imitent ; d'autres envient et, pour cette raison, s'entêtent. Nulle psychologie ne pourra, a priori, déterminer quelle voie ils choisiront; et, en l'absence de signes objectifs, on en est réduit à induire, du fait de leur pauvreté accrue, et de certaines observations empiriques, une hostilité de classe.

On peut mieux déterminer des cas où les paysans en viennent à s'opposer aux riches, et, par cette attitude, se trouvent rapprochés de la classe ouvrière jusqu'à s'y incorporer. En Bretagne, par exemple ${ }^{8}$, dans la seconde moitié du XVIII ${ }^{\mathrm{e}}$ siècle, les propriétaires nobles étendirent de façon abusive les obligations imposées aux tenanciers : corvées extraordinaires, réclamation des arrérages des rentes à un taux arbitraire ; d'autre part, ils afféagèrent à de nouveaux tenanciers, en particulier à des bourgeois ou à des paysans aisés, des portions des bois seigneuriaux et des terres vagues, sur lesquels les paysans exerçaient jusqu'ici des droits d'usage (affouage, pâturage). Il en résulta, nous dit $M$. Sée, un sérieux mouvement de protestation (procès, violences, etc.); et on doit regretter qu'il ne nous indique pas quelles catégories de la population se sont les premières, et se sont le plus énergiquement soulevées, dans quelle mesure et dans quel ordre les autres les ont suivies, si ces rébellions ou ces protestations furent isolées, ou s'étendirent à des groupes étendus, si elles furent spontanées ou concertées : elles restent toutefois l'indice d'une conscience de classe naissante. Cela est d'autant plus intéressant ici, qu'en Bretagne, dès le moyen âge, s'était achevée l'évolution qui avait transformé l'esclave en serf, et celui-ci en vilain-franc, et qu'au

Sée (Henri), les Classes rurales en Bretagne du XVI ${ }^{\mathrm{e}}$ siècle à la Révolution. Paris, 1906. 
début du XVIII ${ }^{\mathrm{e}}$ siècle, malgré les charges qui pesaient sur eux, entre les paysans, et les nobles qui le plus souvent, résident, nulle tension n'était à signaler.

En Angleterre ${ }^{9}$, au XVIII ${ }^{\mathrm{e}}$ siècle également, la pratique en grand de l'enclosure eut les mêmes résultats de façon encore plus nette. Entre le squire, gentilhomme fermier, et le yeoman, ou petit propriétaire, il y a sans doute cette différence que l'un est noble, et que l'autre ne l'est pas; mais leur situation économique reste très voisine. Une nombreuse population de cottagers vit sur des terrains communaux (common land ou waste land), terres à peu près incultes, sans posséder sur elles aucun titre légal : il ne leur vient pas à la pensée quand même qu'ils ne puissent plus jouir de cette tolérance. Là encore, il y a des cultivateurs plus ou moins aisés, plus ou moins pauvres; l'extrême dispersion et le mélange des parcelles où s'éparpille chaque bien les oblige souvent à une véritable exploitation collective ; mais, en l'absence d'un danger ou d'une oppression, c'est insuffisant pour qu'une classe se détermine. Vers le milieu du siècle parait la classe des grands fermiers pour qui l'agriculture est un placement; ce sont eux qui obtiennent que les propriétés soient réunies, redistribuées, de façon à pouvoir être encloses d'un mur continu, et aussi que le terrain communal lui-même soit divisé. Le yeoman ne peut empêcher que les meilleures terres soient réservées à de plus riches que lui, il perd ses droits de pâture sur les terrains communaux; de leur côté, les cottagers se voient expulsés du sol et de la masure qu'ils habitent, et obligés d'aller mendier du travail de ferme en ferme. Yeomen appauvris et cottagers errants s'aperçoivent cependant qu'une quantité de terres arables sont transformées en pâturages ou en terrains de chasse. Le plus grand nombre d'entre eux n'ont qu'une ressource : aller vers les villes, offrir à la grande industrie naissante la main-d'œuvre dont elle a besoin. Avant qu'ils s'y décident, ils se sentent troublés dans leurs habitudes, peu à peu détachés du sol, insensiblement expropriés, et finalement appauvris par une classe d'agriculteurs plus riches, la ressemblance de leurs vicissitudes et l'identité des causes de leur misère leur apparaît, et cette représentation commune détermine dans leur groupe des sentiments de classe. Ces sentiments sont tout semblables à ceux qu'éprouvent déjà les ouvriers, et les premiers soulèvements de ceux-ci, la destruction des machines où ils voient la menace d'une privation temporaire d'ouvrage, ressemblent aux protestations des paysans qui empêchent l'affichage des actes d'enclosure.

De ces observations il résulterait qu'il n'existe pas objectivement une classe paysanne. Mais au sein de différents groupes de paysans, dans des conditions, et à des époques définies, se dégageraient des rapports conscients de solidarité, à l'occasion de leur conflit avec d'autres groupes. À ces moments mêmes, et dans ces régions, ce sentiment se dépasserait en quelque sorte, et entraînerait dans leur conscience la repré-

Mantoux (Paul), la Révolution industrielle au XVIII ${ }^{\mathrm{e}}$ siècle. Essai sur les commencements de la grande industrie moderne en Angleterre, Paris, 1906. 
sentation d'une classe dont ils ne seraient qu'une partie mieux éclairée sur ses intérêts et sa situation économique.

Toutefois cette hypothèse, bien qu'elle s'appuie sur beaucoup de faits et satisfasse peut-être l'esprit, en implique d'autres qu'on peut trouver hasardeuses. D'abord, est-il d'une bonne méthode, pour reconnaître le contenu et la réelle nature d'une conscience de classe, de l'envisager au moment où elle est surtout remplie de sentiments de révolte, d'accablement ou de colère, ou encore lorsqu'elle regrette et se désespère, et sent que le groupe qui la supporte se dérobe sous elle? Une conscience sociale orientée vers la lutte se simplifie nécessairement; elle n'existe que dans la mesure où elle s'oppose, et elle n'éclaire que les parties d'elle-même qui sont menacées par l'adversaire, ou qu'elle peut tourner contre lui. Une conscience sociale qui voit venir la mort est à la fois défaillante et confuse; elle se représente surtout la débilité de ceux auxquels elle s'étend, leur impuissance et leurs limites; et, en même temps, par une illusion inverse, elle s'attache encore trop exclusivement aux aspects brillants de leur passé, et aux avantages qu'ils vont perdre. Ainsi il ne convient peut-être pas, pour bien connaître les sentiments nationaux des habitants d'un pays, de s'en tenir à ce qu'ils sont au moment d'une guerre, ou après un démembrement et une annexion.

Mais la conscience de classe existe-t-elle, réellement, à d'autres moments, en d'autres circonstances ? Nous nous heurtons ici à une autre hypothèse secondaire, savoir qu'une classe n'existe et ne prend conscience de soi qu'au cas d'un conflit. Si on veut dire qu'en dehors d'un tel cas elle est plus confuse, qu'elle s'exprime mal, et même qu'elle ne s'exprime par aucune démarche collective, qu'il est dès lors très difficile d'en reconnaître l'existence, soit. C'est une thèse claire, et une prétention très scientifique. Sans doute, de ce qu'on ne peut la connaître, il ne résulte point qu'elle n'existe pas. Mais la science n'a pas à s'en occuper, puisqu'elle ne porte que sur les phénomènes sociaux objectifs. Seulement on ne peut se risquer à cette affirmation que lorsqu'on a passé en revue toutes les activités et manifestations collectives, tous les aspects sociaux de la vie des paysans dont nous supposons qu'ils ne forment pas une classe. On n'a pas le droit de s'en tenir aux activités conscientes, aux manifestations explicites, aux aspects dont le caractère social est éclatant. Une conscience collective s'exprime parfois de façon instinctive; quelquefois elle est diffuse, sans qu'elle cesse pour cela d'être réelle. Surtout, ce ne sont pas seulement des communications verbales, écrites, des assemblées, des fréquentations, des relations directes qui la créent. La marque sociale est imprimée sur le sol, dans les institutions, dans les métiers. Les individus peuvent ne s'être jamais vus : il suffit que leur vie, leur activité, leur travail se développent dans ces cadres, ainsi formés et façonnés par la société, pour que leurs pensées s'orientent dans le même sens et subissent des influences semblables. De ce que des hommes sont dispersés, ou forment de petits groupes isolés qui n'entretiennent les uns avec les autres que fort peu de rapports, il ne s'ensuit pas que leurs pensées aussi 
demeurent étrangères. Mais le pays où ils vivent a été défriché et modifié, on y a tracé des routes ; il s'y trouve des maisons et des villes bâties d'après un même plan. Ils y rencontrent à chaque instant des vestiges d'une collectivité qui l'a occupé avant eux, et, par là au moins, ils s'y rattachent. Pour qu'il en fût autrement, on devrait imaginer des tribus issues de souches diverses, qui auraient toujours vécu dans de petites îles, sans jamais se voir et se parler, et s'y seraient installées à l'origine sur un terrain vierge. Les paysans d'un même pays ne remplissent pas ces conditions. Il faut alors démontrer que ces empreintes d'une activité sociale plus ou moins ancienne n'ont pas gravé dans leurs pensées l'idée de leur situation commune et de leur solidarité, et ne les ont pas ainsi rapprochées en une conscience de classe.

\section{II \\ La technique du travail agricole}

$\underline{\text { Retour à la table des matières }}$

Envisageons les métiers agricoles. Parmi leurs conditions et leurs éléments, certains, peut-être, sont sociaux, c'est-à-dire ne s'expliquent point par la seule nature, mais par les inventions et les traditions humaines. Ils pourraient alors exercer une action sociale sur les hommes. D'autre part, s'opposant à certains caractères des métiers industriels, ils tendraient à séparer le groupe de paysans de la classe ouvrière.

Nous devons nous débarrasser de beaucoup de conceptions littéraires, esthétiques et morales, et nous persuader que, dans nos jugements sur les occupations rurales, nous nous laissons trop souvent dominer par nos sentiments sur les conditions de la vie paysanne.

D'abord le fait de travailler le plus souvent en plein air n'a rien de social, puisqu'il dérive de la nature du travail dans tous les temps et en tous les pays, et d'ailleurs n'est point particulier aux paysans : les débardeurs, les terrassiers, les couvreurs travaillent en plein air; dans les peignages, les trieurs de laine opèrent sous des hangars ouverts, comme les agriculteurs dans les granges lorsqu'ils battent le blé sur l'aire; dans la grande industrie, dans les mines, la métallurgie, le travail en un endroit découvert est 
loin d'être exceptionnel. Au reste, une bonne partie des travaux agricoles s'exécutent entre des murs et sous un toit (la fabrication des fromages, la mouture du blé, le pressurage des raisins, etc.). - Dira-t-on que les agriculteurs sont, par leur travail, en rapports plus directs avec la nature, que le cultivateur qui remue le sol, fauche les épis et les herbes, cueille les fruits, que le bûcheron qui abat les arbres, le berger qui garde ses moutons, le laitier qui trait les vaches saisissent les produits au moment où ils viennent d'apparaître ? Le plus souvent (sauf lorsqu'ils défrichent des landes incultes), ce n'est pas exact. La terre sur laquelle s'exercent leurs efforts n'est pas vierge: elle s'est trouvée depuis longtemps transformée dans sa superficie, dans son relief et son aspect, dans ses propriétés aussi, par les hommes d'autrefois. Les arbres et les animaux ont été, au cours des âges, l'objet d'une lente domestication. Toute la série des travaux agricoles, en leur diversité, ne résulte pas de la seule nature, mais, pour une bonne part, de l'activité organisatrice des sociétés. L'agriculteur ne crée pas ces divisions et cette spécialisation, il l'accepte, et il la subit déjà comme une nécessité sociale. D'ailleurs il ne se distingue pas essentiellement, sous ce rapport, de l'ouvrier. En fait, celui-ci n'est pas toujours, ni même le plus souvent, le travailleur parcellaire qui remplit une besogne sans savoir à propos de quoi. Il lui arrive de s'intéresser à l'objet qu'il transforme, d'en reconnaître l'origine naturelle. Le travailleur de la laine se rattache par ce sentiment au tondeur, le travailleur de la soie à l'éleveur de vers à soie. Entre le mineur, le carrier, et le paysan qui débarrasse une terre des pierres et des racines, et la défonce, ou y creuse des rigoles, il n'y a pas de différence quant à la matière de leur labeur. Les ouvriers qui surveillent une peigneuse, et ceux qui conduisent une batteuse, les fabricants de fromage qui font cuire le lait écrémé, et les encolleurs qui, dans les filatures, font cuire la colle où passeront les fils de la chaîne, les vendangeurs qui transportent la récolte dans des paniers jusqu'aux charrettes, et les ouvrières qui transportent dans des paniers la laine cardée ou peignée d'un atelier ou d'une machine à l'autre, non seulement font à peu près les mêmes gestes, mais travaillent sur des produits également naturels, ou du moins parvenus à un degré aussi peu avancé d'élaboration. On peut parfaitement considérer, et le paysan considère les bêtes comme un ensemble de machines d'un rendement déterminé. Au reste, le charretier est un ouvrier, la charcuterie et la boucherie sont des industries. On ne pourrait pas tracer une ligne de démarcation précise entre ouvriers et paysans en s'appuyant sur le caractère animal, végétal ou minéral des produits : les travailleurs de la terre ne forment pas, comme tels, une catégorie distincte.

Il ne faut pas se figurer, non plus, qu'ils ont le sentiment, à la différence des ouvriers industriels, d'accomplir des travaux qui ont dû exister de tout temps et qui ne répondraient pas à des besoins nouveaux et modernes; car «du temps qu'Adam bûchait, Ėve filait »..., et aussi loin que remonte la mémoire des hommes, on trouve des forges. C'est, pour le lettré, non pour le paysan, que ces différences importent. Il ne faut pas croire encore que le travail agricole déforme davantage le corps humain, et 
lui impose, en tout cas, son empreinte plus fortement que le travail industriel ${ }^{10}$ : il y a, à l'intérieur de l'industrie, et même d'une industrie, des différences d'aspect physique au moins aussi marquées que de l'agriculture à l'industrie.

Le paysan, en général, n'est pas plus en contact direct avec la terre que l'ouvrier avec la matière qu'il façonne: les outils, les instruments, les machines s'interposent entre l'homme et les choses dans les deux cas. Ces instruments ont un aspect nettement social, surtout sous deux rapports. - En premier lieu, ils imposent au travailleur, l'obligation de certains gestes dans un ordre et avec une rapidité déterminée. Est-il exact que la machine, dans l'agriculture, ne puisse pas être «servie» comme elle l'est dans l'industrie, mais doive être constamment "dirigée »? L'agriculteur dispose-t-il, par rapport à ses instruments de travail, d'une indépendance plus grande que l'ouvrier? Les machines jouent assurément un plus grand rôle dans l'industrie que dans l'agriculture: si la machine à battre à vapeur peut être employée, et avec avantage, dans les petites exploitations comme dans les grandes, il n'en est pas de même de la charrue à vapeur, inférieure à la charrue à traction animale dans beaucoup de cas. Dans nombre de métiers industriels, dans les mines, dans le bâtiment, les machines n'ont pas encore révolutionné les conditions techniques du travail. Toutefois, dans les parties si considérables de la grande industrie où les machines se sont introduites le plus avant, l'ouvrier, soit qu'il surveille et répare, soit qu'il mette en train et alimente, est obligé de se plier au rythme général de la production, qui s'exécute en quelque sorte en dehors et au-dessus de lui, mécaniquement; l'agriculteur, au contraire, ne serait pas ainsi dominé, dirigé, entraîné par des forces d'un jeu régulier, et qui ne produisent tout leur effet que si le plus souvent on les livre à elles-mêmes. - Mais peut-être est-ce là une illusion, peut-être le travail de l'agriculteur est-il également rythmé, et pour des raisons du même ordre : la lenteur plus grande n'exclut pas la continuité. On oublie que le laboureur, lui aussi, se borne en somme à alimenter ou mettre en train, et le moissonneur à recueillir les produits de toute une série d'opérations accomplies par les agents naturels. Celles-ci, comme dans l'industrie quand on introduit les machines, peuvent, suivant le climat, la fertilité du sol, les accidents de la température, ou en raison d'amendements qui sont l'œuvre des hommes, s'accomplir plus ou moins vite et avec plus ou moins de perfection. Évidemment l'analogie n'est pas exacte en tout point : elle l'est du moins dans la mesure où elle rend compte du caractère simultané et rythmique des travaux agricoles (en tout cas des plus importants).

Xénophon dit: (En grec dans le texte). «La pratique de l'agriculture entraîne le corps : le rend capable de tout ce qui convient à un homme libre... elle apprend à supporter les froids de l'hiver et les chaleurs de l'été... elle astreint ceux qui cultivent la terre de leurs mains à un exercice qui les rend plus vigoureux... quel autre art habitue mieux à courir, lancer, et sauter ?» (Économique, V, 8). Rapprocher ce passage de celui que nous citons plus bas, (p. 119). 
On pourrait nous objecter que le trait essentiel par où diffèrent la production industrielle et la production agricole c'est que la première est mécanique, la seconde organique. On pourrait surtout nous reprocher une confusion. Dans l'industrie aussi il $\mathrm{y}$ a des agents naturels, très distincts des machines : la force hydraulique, la vapeur, l'électricité, la chaleur, que nous nous bornons, à l'aide de nos dispositifs, à dégager et à diriger. Sans doute c'est une ressemblance entre l'agriculture et l'industrie, que l'une et l'autre soient obligées d'utiliser les forces de la nature. Mais les utiliser à l'aide de machines, comme dans l'industrie, ou à l'aide d'instruments et d'outils mus par des hommes, c'est-à-dire les concentrer et les faire agir par masses dans le premier cas, les mettre en jeu par une série d'efforts individuels et éparpillés dans le second, ce serait l'opposition essentielle, qui expliquerait le caractère discipliné et uniformisé des travaux industriels, la liberté et la variété plus grande des travaux agricoles.

Mais ni cette objection, ni ce reproche ne valent contre notre thèse. Il nous est facile de distinguer, en dehors du travail agricole actuel des hommes, dans ce qu'on appelle en général la nature, trois éléments : $1^{\circ}$ les agents naturels, qui ne se confondent pas du tout avec les forces de la végétation et de la vie, et qui sont la chaleur du soleil, l'humidité, les pluies ; $2^{\circ}$ ce qu'on peut appeler les propriétés organiques des plantes et des animaux, c'est-à-dire la faculté que possèdent les semences, dans certaines conditions physiques, de produire des épis, les plantes et les animaux de se reproduire, de croître ; $3^{\circ}$ la distribution et la disposition relativement régulière et rationnelle des terres, en vue d'obtenir la croissance simultanée des organismes de même espèce, en utilisant au mieux l'action des agents naturels : c'est ce dernier ensemble de faits seul que nous comparons aux machines. En d'autres termes, entre les semences, les animaux reproducteurs et les conditions physiques, il faut que s'établisse une adaptation : sans cela une quantité considérable des forces physiques sera dépensée en pure perte, et une quantité considérable de germes ne se développeront pas. Cette adaptation consiste surtout en ce que des parties étendues du sol, composées à peu près de la même terre, sont exposées en même temps aux mêmes actions physiques. Tel n'est pas l'état primitif : il a fallu défricher, dessécher, irriguer, défoncer, amender, fumer; il a fallu, encore, reconnaître quelles portions du sol étaient plus propres à telle culture, et y étaient les plus propres à chaque période (assolements). Mais qu'est-ce d'autre que de diriger et d'utiliser au mieux les agents naturels (en particulier la chaleur et l'eau) ? Or, c'est la fonction même des machines. À l'origine de ces distributions et dispositions, comme à l'origine des machines industrielles, nous trouvons une activité humaine ancienne (inventions individuelles, nées sous la pression des besoins collectifs, et adaptées par la collectivité), bien qu'elles paraissent maintenant à ce point inhérentes au sol qu'on les confond avec celui-ci sous le nom de nature, comme si, spontanément, la terre avait produit ici du blé, là des vignes. Enfin, comme dans le cas des machines (et c'est là que nous voulions surtout en venir), le résultat de toutes les habitudes auxquelles s'est trouvée pliée la vie organique qui nous intéresse, ç'a été une 
concentration de la production dans l'espace et dans le temps. Sur de vastes étendues, ou sur des parcelles très voisines, aux mêmes époques de l'année, les mêmes travaux sont accomplis, le plus souvent par des groupes d'hommes opérant ensemble. Pour chaque espèce de terre qui, dans des conditions identiques, porte les mêmes cultures, l'époque et la durée des travaux est déterminée. Exactement comme dans l'usine, l'agriculteur doit obéir au rythme de la production, qui est indépendant de lui en une large mesure. En raison de cette concentration, comme dans la grande industrie, une quantité de travailleurs doivent faire simultanément les mêmes gestes.

Si on avait compris la vraie nature du machinisme, et ce qui remplit, en agriculture, la fonction de la machine dans l'industrie, on serait arrivé à une conception beaucoup plus large des progrès possibles de l'agriculture, et des transformations éventuelles correspondantes de la classe agricole. Il s'agit moins d'inventer des machines à semer, à herser, etc., que de reconnaître quelles substances chimiques permettront de transformer de vastes étendues de terre, exposées et arrosées de même, en vue de produire sur la plus grande étendue de sol, et avec la périodicité la plus grande, des végétaux utiles de même espèce, ou, encore, de constituer la météorologie en science, et de prévoir le régime des pluies, ou les périodes de chaleur, afin de modifier les cultures de façon appropriée. Sans doute il ne nous est pas donné de créer de toutes pièces les éléments de fertilité de la terre, mais nous pouvons les transporter là où ils opéreront au mieux; sans modifier la température, nous pouvons exposer au soleil ou à la pluie les cultures qui en profiteront le plus. De fait, les machines ne jouent pas un rôle différent dans l'industrie. - Dans les deux domaines, on a commencé par les adaptations les plus naturelles et les plus faciles. Il était naturel de cultiver d'abord, non, comme le disait Ricardo, les terres les plus fertiles, mais les plus vastes étendues qui ne fussent couvertes ou coupées ni par des forêts, ni par des étangs : un tel sol, où se concentrent la chaleur et la lumière solaires, appelait naturellement la culture, de même que les cours d'eau et les mines, où se concentrent des forces physiques considérables, les premières usines. Mais, à mesure que cette adaptation s'étendra à plus de terrains, et gagnera en précision et perfection, à mesure aussi la grande exploitation se développera. Le petit cultivateur, qui ne peut modifier sa culture suivant les circonstances, ni se risquer à des essais incertains, dépense beaucoup trop de forces : sur sa terre mal adaptée, il est comme un petit artisan qui veut continuer à produire avec des instruments grossiers. Il n'en subit pas moins peu à peu l'influence du groupe qui l'entoure. Or celle-ci s'exerce dans le sens que nous avons dit: uniformité, simultanéité et régularité croissante des travaux sur de vastes étendues, concentration croissante de la production, soumission de plus en plus entière du travailleur aux conditions à la fois naturelles et rationnelles de la production. Par là, loin de se distinguer du travailleur d'industrie, il s'en rapproche, 
Mais la concentration de la production, dans l'industrie, s'accompagne d'une spécialisation de plus en plus étroite des travailleurs il n'en est pas de même dans l'agriculture. David ${ }^{11}$ a dit « L'exploitation industrielle recourt à un système de machines spéciales fonctionnant combinément, l'agriculture à des machines à fonctions combinées et fonctionnant isolément. » Nous avons vu que le mot machine. prête à équivoque. Mais retenons la grande industrie, et l'agriculture telle qu'elle est pratiquée d'ordinaire; comparons non plus les machines, mais les travailleurs et leurs travaux. Tandis qu'un ouvrier est, toute l'année, occupé à une même tâche spéciale, les travaux du paysan se renouvellent avec le cours des saisons. Il ne s'agit pas d'une simple nécessité naturelle, qui, par elle-même, ne pourrait suggérer à des groupes de paysans isolés l'idée d'une communauté sociale fondée sur une identité de condition. Cette succession des travaux, ce changement des occupations se présente à eux comme un phénomène social : car le paysan ne se borne pas à s'inspirer de l'aspect de son champ, et de l'état de la température, pour se décider à tel travail; il tient compte de ce que font les autres au même moment, des indications du calendrier, de la division de l'année en mois et semaines, des fêtes fixes et de certains préceptes traditionnels. De tout temps, des dates, des périodes que la pensée populaire a déterminées, et qui tirent d'elle toute leur réalité comme divisions ou points de repère, ont été associées dans l'esprit des hommes avec certains travaux agricoles, ou ont été le signal de fêtes préalables avant la moisson ou la vendange, et de repos ensuite. C'est ainsi que la pensée sociale exprime à sa façon et souligne le rythme nécessaire des travaux agricoles ; mais, en même temps, elle en consacre la diversité. Il ne paraît pas possible que le paysan, lorsqu'il entrevoit ces grandes usines où des ouvriers se rendent tous les jours aux mêmes heures pour exécuter le même travail, ne soit pas frappé du contraste de ces occupations avec les siennes. La règle et l'ordre président aussi à ses travaux, mais elles ne font que marquer les étapes différentes d'un cycle qui ne se reproduit qu'après plusieurs mois, une année (et quelquefois plusieurs). Dans la même journée, il arrive souvent que des tâches variées se succèdent, en relation elles aussi avec les divisions du jour. En ce sens, surtout, toute exploitation agricole serait un véritable organisme aux fonctions diverses et solidaires, sans rien de la monotonie et de la rigidité des opérations mécaniques de l'industrie.

Mais c'est confondre divers aspects de la vie agricole dont ni l'importance, ni la signification ne sont les mêmes. Veut-on dire que, tandis que l'année paysanne est ainsi coupée en périodes réellement diverses, par la succession des saisons et les habitudes sociales qui en résultent, l'année ouvrière échappe à ces influences? Sans doute, dans l'atelier, le travail en lui-même n'en est point, parfois, modifié. Mais est-ce que, derrière les murs ou les fenêtres de l'usine, l'ouvrier ne s'aperçoit pas de la diversité des mois, et en tout cas n'apporte-t-il pas avec lui le souvenir des impressions du

David (Eduard), Sozialismus und Landwirtschaft, 1,1 Band. Die Betriebsfrage. Berlin, Verlag der Sozialistischen Monatshefte, 1903. 
dehors ? Si on écarte cet aspect, qu'il serait sans doute inutile de définir davantage, si on ne retient que la diversité des travaux, pour l'envisager directement, à quoi se ramène-t-elle au juste ? Nous ne voulons pas aborder maintenant le problème complexe de la division du travail, et chercher jusqu'à quel point cette réunion de travaux différents dans les mains d'un même individu est particulière aux occupations paysannes. Peut-être leur diversité est-elle plus apparente qu'effective, et toutes ces opérations se ramènent-elles à un nombre assez limité de mouvements des bras ou des mains (comme d'ailleurs le travail des déchargeurs et manœuvres de toutes catégories) accomplis seulement dans des directions, sur des objets et en des endroits différents ; tandis qu'un travail très spécialisé, celui du tisseur qui alimente toute la journée un même métier, est en réalité très complexe, et oblige à un effort intellectuel, en raison de la diversité des dessins à reproduire, des navettes à changer. Mais la variété des occupations paysannes nous paraît consister surtout en ceci : d'une part, après des périodes de travail accéléré et assez intense, parce qu'il faut profiter du temps, ou saisir le moment précis de la maturité, en viennent d'autres sinon de repos, du moins d'une activité moins fiévreuse, où l'on prend son temps, des travaux d'entretien, des réparations, des amendements conduits à loisir, avec une lenteur prudente et réfléchie ; d'autre part, après des périodes de travaux exécutés en commun, ou qui, par leur simultanéité bien apparente, ont un caractère nettement collectif, en viennent d'autres où le paysan s'occupe chez lui de la basse-cour, du potager, de l'étable, et se livre, à l'intérieur de sa maison, à toutes sortes de menus travaux exécutés isolément. Or, les travaux industriels ont des caractères comparables à ceux-ci et ne sont point, par là, moins divers.

Le plus souvent, dans une industrie, l'activité productrice ne s'exerce pas avec la même intensité durant toute l'année. Sans même parler des exploitations en relation directe avec l'agriculture, qui utilisent ses produits ou préparent ses instruments, et où doivent se refléter les mouvements alternatifs d'accélération et d'arrêt des travaux agricoles, il y a dans une quantité d'industries des mortes-saisons, pour diverses causes : les variations de la température et de la durée des journées (dans le bâtiment), les variations, en qualité ou intensité, des besoins des consommateurs pendant l'année (dans toutes les industries de la confection, dans la fabrication des bicyclettes, etc.) En outre, même pour les produits d'un écoulement régulier et continu, il y a avantage pour l'industriel à resserrer dans une période de moindre durée les travaux de production, pour diminuer les frais généraux. Il y a enfin des périodes de crise, où, pour profiter de la conjoncture, on accroît tellement la production qu'il y a engorgement, et qu'on doit fermer un grand nombre d'ateliers. Que deviennent alors les ouvriers ? Les uns restent à l'usine, à la fabrique, à l'atelier; le travail, moins pressant, est nécessairement ralenti ; ils sont occupés à des réparations, à des travaux d'entretien. D'autres ne sont employés qu'une partie de la journée, ou de la semaine, ou par roulement. Pour certaines catégories d'ouvriers, enfin, le chômage est complet: ceux-ci ou bien cherchent du 
travail ailleurs, et trouvent sans doute à s'occuper de façon intermittente, ou bien ils travaillent chez eux, pour le compte de particuliers, etc. Donc, à considérer le travail industriel sous ses formes collectives, on reconnaît qu'après des périodes de travail intense (avec allongement momentané de la journée de travail, ou avec un système de primes qui conduit à une accélération extrême, et, encore, avec enrôlement de travailleurs de fortune) viennent des périodes qui, pour ceux qui travaillent encore collectivement dans la profession, marquent quand même un ralentissement et comme un relâchement, et qui, pour les autres, marquent le passage du travail collectif à des travaux individuels de diverses sortes.

Le mécanisme de la production industrielle n'est donc pas si bien monté qu'à certains moments ses agents ne doivent le ralentir ou l'arrêter. Sans doute, parfois, quand ces arrêts se produisent de façon inattendue, c'est comme une catastrophe qui laisse les ouvriers sans travail. Le plus souvent, ces à coups et ces irrégularités sont prévus par les intéressés, qui d'avance se préparent des occupations pour cette période de loisir forcé, si bien que, dans ces cas, cette alternance de travaux est un phénomène d'adaptation aussi naturel que la succession des diverses formes du travail agricole. Il est naturel aussi qu'il se traduise de la même façon dans la conscience collective, et qu'il n'y ait pas là un principe de séparation et d'opposition entre la classe ouvrière et les groupes paysans.

\section{III \\ La condition juridique des paysans}

$\underline{\text { Retour à la table des matières }}$

Nous avons distingué le paysan du sol qu'il travaille, du métier qu'il exerce, de l'instrument qu'il dirige: pendant longtemps il s'y est confondu. Le serf demeurait incorporé à la terre, son activité agricole semblait sa raison d'être et comme sa substance, il était rivé à sa bêche ou à sa charrue comme un simple moteur humain sans 
volonté propre ${ }^{12}$. Aujourd'hui, lorsqu'on compare sa situation à celle de l'ouvrier d'usine, on serait plutôt tenté d'insister sur l'indépendance plus grande dont il jouit, et sur la base de cette liberté, qui est la propriété.

On peut considérer à part la situation juridique de ces catégories de travailleurs, et se demander si ce n'est pas surtout en elle qu'on trouverait la raison des représentations dominantes et distinctives de deux classes. - Sans doute, il y a beaucoup d'ouvriers agricoles qui travaillent à la journée et ne possèdent aucune espèce de bien, du moins aucune parcelle de terre qu'ils exploitent. Mais il est légitime de ne pas juger des paysans en général par ces salariés, dont une partie sans doute iront, à l'occasion, dans les villes, se livrer aux bas travaux de l'industrie. On ne peut pas même dire qu'ils constituent une surface de contact et un trait d'union entre les classes ; mais ils passent de l'une dans l'autre, et ne dépendent pas à la fois de l'une et de l'autre. Ils acceptent les tendances collectives du groupe dont ils sont temporairement des membres. S'ils ne sont pas propriétaires, on peut supposer qu'ils ont, plus que les ouvriers des villes, le secret désir et le respect traditionnel de la propriété. - M. Souchon ${ }^{13}$ a proposé de distinguer: « les grandes propriétés, qu'un chef de famille ne saurait songer à exploiter directement sans recourir d'une façon régulière à l'aide du travail agricole salarié ; les possessions moyennes, dont la récolte doit être assez abondante pour nourrir le maître et sa famille, à la double condition que cette famille ne soit pas excessivement nombreuse et que tous ses membres consacrent leur activité aux soins de l'exploitation ; les petites propriétés, qui ne dispensent pas leurs détenteurs de demander au salaire une part de leur subsistance ». C'est la deuxième catégorie qu'il considère, comme la plus représentative de la propriété paysanne en général. Entre les propriétaires paysans qui ne sont que cela, et les ouvriers de l'industrie, l'opposition parait la plus nette : ceux-là ne relèvent pas d'un directeur ou d'un patron, mais exploitent à leur compte, dans des conditions d'entière indépendance; leurs revenus sont répandus de façon irrégulière sur tout le cours de l'année, et non touchés toutes les semaines ou tous les mois; enfin, ces revenus annuels eux-mêmes ne sont pas détermines, mais varient suivant la bonne ou la mauvaise récolte, le prix des denrées, etc. - Sans doute, quand on passe aux autres catégories de propriétaires paysans, et surtout à des paysans non-propriétaires, d'autres traits apparaissent, et ceux-ci s'estompent; mais ils ne s'effacent pas, et, réellement, ils restent au premier plan. Tant qu'on suppose un propriétaire qui travaille lui-même, peu importe qu'il emploie des ouvriers. Théori-

Rappelons que, d'après de Tocqueville, « dans presque aucune partie de l'Allemagne, à la fin du XVIII $^{\mathrm{e}}$ siècle, le servage n'était encore complètement aboli, et, dans la plupart, le peuple demeurait positivement attaché à la glèbe, comme au moyen âge ", mais que "rien de semblable n'existait plus en France depuis longtemps : le paysan allait, venait, achetait, vendait, traitait, travaillait à, sa guise. Les derniers vestiges du servage ne se faisaient plus voir que dans une ou deux provinces de l'est... partout ailleurs il avait entièrement disparu... le paysan n'avait pas seulement cessé d'être serf, il était devenu propriétaire foncier ». (L'ancien régime et la Révolution, p. 33 sqq.)

13 Souchon (A.). la Propriété paysanne. Étude d'économie rurale. Paris, p. 10, 1900. 
quement, on pourra dire qu'il fait valoir un capital; mais, en fait, ce n'est point là sa fonction principale. Il n'est point comparable aux financiers ou hommes riches qui placent leur argent dans la terre, pas même au grand propriétaire qui réside et exploite en régie. Pour ceux-ci, la terre n'est qu'un emploi de leur capital qu'ils préfèrent à d'autres pour des raisons variables. Pour le propriétaire paysan, l'exercice de l'agriculture est une profession; il peut considérer ses ouvriers comme sa famille élargie; l'essentiel de ses revenus doit être employé en améliorations ou agrandissements de son bien : la propriété reste bien fondée sur le contact direct avec la terre. D'autre part, qu'un petit propriétaire, cherche un appoint à ses revenus insuffisants dans un travail salarié, la préoccupation dominante reste son bien: c'est pour ne pas l'aliéner ou l'hypothéquer, c'est quelquefois pour l'agrandir, qu'il va s'employer chez les autres.

Quant au fermier et au métayer, sans doute ils ne possèdent proprement pas la terre qu'ils exploitent. Ils dépendent du propriétaire, en ce qu'ils se sont engagés à lui payer à intervalles réguliers des sommes déterminées, à exécuter des travaux d'entretien, à des amendements. Mais le propriétaire, en général, habite au loin, il n'exerce pas sur le paysan la surveillance à laquelle l'ouvrier est constamment soumis, par les directeurs et contremaîtres : c'est le paysan qui occupe, et c'est lui qui exploite. D'autre part, comme son revenu résulte de ce qu'il ne donne pas au propriétaire, que la part de celui-ci et la sienne proviennent d'un même travail, que la sienne d'ailleurs est plus indéterminée et variable, il est facilement conduit à penser, quand il travaille, qu'il travaille pour son compte, et à considérer la rente comme une taxe prélevée sur le produit de son travail, comme l'ancienne dîme ou le vingtième. - C'est ce qui devait apparaître plus nettement autrefois. En Bretagne ${ }^{14}$ à la fin du XVIII ${ }^{\mathrm{e}}$ siècle, les propriétaires terriens qui tenaient leur propriété en fief étaient obligés de payer des redevances au seigneur, redevances légères, sans doute, mais qui, dans la forme, ressemblaient aux rentes dues par les fermiers. D'autre part, entre le fermage ou le métayage et la propriété subsistaient des formes intermédiaires : le domaine congéable, qui ne garantissait pas le «domanier» contre une éviction (congément) toujours possible, le comptant, mode de location plus voisin encore de la tenure, qui cédait la terre à perpétuité et à titre héréditaire au cultivateur, moyennant une petite partie de la récolte. Dans les formes juridiques elles-mêmes s'exprimait alors la parenté du fermage et de la tenure, puisque l'on passait de l'une à l'autre par ces intermédiaires. - Mais actuellement on trouverait sans doute la même indication dans les coutumes: il importe au propriétaire que le fermier s'intéresse à la terre, qu'il n'ait donc pas le sentiment qu'il ne l'occupe que pour un temps : de là l'habitude de renouveler les contrats et de conserver le même fermier ou le même métayer. Pour le paysan, le propriétaire qui n'exploite pas n'est point le patron, ni le possesseur, mais, encore, plus ou moins, le

14 Sée. Livre cité, p. 263 sqq. 
seigneur ; il n'y a pas, comme dans l'industrie, séparation entre l'ouvrier et l'instrument de son travail.

Toutefois la condition de droit ainsi définie des diverses catégories paysannes est loin d'indiquer suffisamment leurs tendances véritables. Que des ouvriers agricoles peu nombreux, employés régulièrement chez des propriétaires moyens, soient incapables de prendre conscience en commun de l'analogie de leur situation avec celle des ouvriers de l'industrie, et qu'ils se sentent davantage paysans qu'ouvriers, c'est possible et probable. Mais là où ils arrivent en troupe, à l'époque de la vendange ou de la récolte des betteraves, quelquefois de régions assez éloignées, et pour travailler temporairement dans des propriétés importantes, ce qui leur apparaîtra le plus clairement, n'estce point qu'ils n'ont aucun droit de propriété sur une terre où ils ne font que passer, et qu'ils vendent une quantité de travail déterminée contre une somme définie ? Or, ces cas seuls nous intéressent ici, puisque autrement aucune tendance collective ne se dégage.

Dire qu'un ouvrier qui va travailler tantôt à la ville, tantôt à la campagne, ne peut appartenir à la fois à deux classes, c'est admettre que lesdites classes existent et sont bien distinctes, ce qui est toute la question. Or, par cela seul qu'ils exercent soit un droit de propriété, soit l'apparence de ce droit sur le sol qu'ils exploitent, les propriétaires, fermiers et métayers constituent-ils une classe ? - La propriété n'importe ici que dans la mesure où elle élève ses détenteurs à un certain degré d'indépendance économique. Telle est la propriété sur laquelle vit une famille qui en absorbe directement les produits. Mais telle n'est pas généralement la petite propriété paysanne. Obligé de produire pour la vente, le petit paysan est dans la dépendance du marché des produits agricoles : la valeur de ses produits et, par conséquent, la valeur de sa terre est dans un rapport étroit avec l'ensemble de la production agricole et reflète ses variations. Ici encore, écartons les lieux communs, oublions que la terre est comme «le prolongement de l'activité humaine » qui s'y emploie, ignorons que le paysan, depuis longtemps, vit d'elle et sur elle, et qu'il s'y est peut-être attaché. C'est là un principe d'isolement, d'individualisme, et cela ne peut pas fonder une conscience de classe. La terre est, en réalité, l'instrument de production, et c'est le rapport du paysan à cet instrument qui nous intéresse. Or, que le paysan ait la propriété de son instrument de travail, ou bien cela n'a aucun sens, ou bien on entend par là qu'il n'en peut pas être dépossédé par le jeu des forces économiques naturelles, qu'il peut, tout en le possédant et l'utilisant, continuer à vivre de son travail ${ }^{15}$, qu'il trouve donc pour ses produits un écoulement assuré, à des prix qui lui permettent de rentrer dans ses frais.

Proudhon raisonnait de même, à propos des propriétaires de rente 5 0/0 menacés de conversion. «L'État ne peut exiger, sans une juste indemnité, le sacrifice d'un acre de champ, d'un coin de vigne, moins encore a-t-il pouvoir de faire baisser le taux des fermages; comment aurait-il le droit de diminuer l'intérêt des rentes ? Il faudrait, pour que ce droit fût sans injustice, que le rentier pût 
On conçoit que, tant que la situation reste favorable sous ce rapport, lorsqu'elle l'est depuis longtemps et que le paysan n'aperçoit point de raison pour qu'elle se modifie, il ait, en effet, une impression de sécurité et d'indépendance. Le cours de la production comme la régularité des besoins des consommateurs paraissent déterminés par des lois constantes sur lesquelles on se peut reposer. On ne redoute que les fléaux naturels, qu'on subit patiemment. - Mais, en fait, de notre temps il n'en est plus ainsi. D'une part, la production peut être brusquement accrue, et les petits paysans propriétaires voient les prix des céréales baisser sous la pression d'une lourde concurrence ; d'autre part, aux besoins naturels peuvent se substituer des besoins artificiels, sur la constance desquels on peut moins compter. Dans les deux cas, la préoccupation des débouchés passe au premier plan : ce qui fixe l'attention de la masse paysanne, ce n'est plus la dépendance de ses instruments de travail par rapport à elle, c'est sa propre dépendance par rapport à d'autres groupes, à des marchands, à des industriels. Les petits paysans propriétaires de Champagne ou de Lorraine se présenteront aux marchands de grains, non plus, comme les anciens tisserands indépendants aux marchands drapiers, avec la tranquille assurance d'un producteur sûr de bien vendre un produit d'une valeur certaine, mais, comme les tailleurs à domicile aux agents de magasins de confection, résignés d'avance à accepter la rétribution que ceux-ci ont fixée. Les petits paysans propriétaires de Picardie cultivent des plantes industrielles. Toute autre culture n'aurait pas permis à la petite propriété de subsister ou de s'établir en cette province. Leur indépendance est donc toute formelle. Ils représentent plutôt comme une section des grandes usines où ils envoient tous leurs produits, au sort et à la durée desquels leur propre existence est liée. La seule différence entre eux et ces cardeurs et fileurs de la campagne qui travaillaient, pour le compte des tisserands, la laine tondue sur leurs propres moutons, c'est qu'ils ne poussent pas aussi loin le procédé de préparation du produit. Mais ici comme là, bien que dispersés, ils font partie du même ensemble économique que les ouvriers industriels rassemblés dans l'usine où iront leurs produits, et leur terre, comme le travail de ceux-ci, deviendrait une non-valeur, du jour où les machines s'arrêteraient. L'effet du progrès industriel et commercial, si on entend par prolétaires les ouvriers de l'industrie, n'est sans doute pas de «prolétariser » les paysans, mais, en leur faisant prendre conscience de la valeur incertaine et variable de la terre, de les en détacher ; la propriété n'est plus alors une représentation dominante et distinctive dans leur conscience de groupe.

Quant aux fermiers et métayers, il est plus difficile de reconnaître dans leur situation des traits essentiels par où ils ne se distingueraient point, ou ne se distingueraient que dans la forme des salariés de l'industrie ou des ouvriers en général. Ils ne

trouver ailleurs un placement aussi avantageux de ses fonds ». Ou bien alors les rentiers ne sont propriétaires de leur rente qu'en apparence. (Qu'est-ce que la propriété ? Paris, 1841, p. 46.) 
reçoivent pas du maître une rétribution en argent, et leur revenu consiste en des produits naturels qu'ils vendent sur le marché, en le prix de ces produits moins la rente, ou en une moitié ou autre fraction de ce prix. Par là sans doute ils se rapprochent des petits propriétaires. Que les prix baissent, ou qu'on soit obligé de retrancher du prix une part croissante qui revient au propriétaire, n'est-ce pas identique ? Que le cultivateur soit obligé d'abandonner au propriétaire une part de sa production, ou d'accepter du marchand un prix moins élevé pour les mêmes produits, que la rente augmente ou que les prix baissent, dans les deux cas il s'aperçoit que la valeur de sa propriété ou de la terre qu'il exploite, sa valeur pour lui, varie sous des influences extérieures à lui et qui n'ont aucun rapport avec son travail. Cela ne signifie pas, d'ailleurs, que la situation du fermier risque d'être plus dépendante encore, écrasé qu'il peut être entre le propriétaire qui maintient la rente à un taux élevé, et le marchand qui n'achète qu'à des prix très bas. La baisse des prix entraînera une diminution de la rente lors du renouvellement du bail, et le propriétaire aura avantage à ne pas pressurer le fermier, afin que celui ci n'épuise pas la terre et plutôt continue à l'améliorer. Autrement, il ne trouverait plus de fermiers : le cas de l'Irlande où, malgré les exigences des propriétaires, une population nombreuse et sans autres ressources a dû accepter l'exploitation est exceptionnel. En général, plutôt, le fermier est aussi bien placé que le petit propriétaire, parce que le régime du fermage ne convient qu'aux terres assez riches, parce que les fermiers doivent avoir des avances et posséder des connaissances techniques sérieuses. Mais son revenu dépend toujours en premier lieu comme celui du petit propriétaire, des mouvements des prix des denrées.

Le Code civil dit bien que si, pendant la durée du bail, la totalité ou la moitié d'une récolte au moins est enlevée par des cas fortuits, le fermier peut demander une remise du prix de sa location. Mais la baisse continue du prix des denrées n'est pas un cas fortuit ; au cas d'une baisse de ce genre, le fermier est loin de pouvoir reporter sur le propriétaire une part exactement proportionnelle de sa perte. Et, au cas contraire où les prix haussent, le relèvement des rentes ne se produit pas tout de suite, et c'est le fermier qui profite d'abord, et le plus, de cet accroissement. On comprend dès lors que pour lui aussi la préoccupation de la vente (en période où les prix des produits agricoles sont peu stables) devienne pressante, et qu'il sente vivement, plutôt que son indépendance partielle par rapport au maître du sol, sa dépendance étroite par rapport au marché.

Ce qui complique bien notre étude, c'est qu'à la différence des situations juridiques se superposent des inégalités de richesse. De là ce résultat paradoxal : au XVIII ${ }^{\mathrm{e}}$ siècle, en Angleterre, au lendemain des enclosures, les fermiers établis sur les terres des gros propriétaires se trouvèrent plus riches que les squires, gentilshommes paysans, à plus forte raison que les yeomen, ou propriétaires moyens de la période antérieure : en effet, les meilleures terres seules étaient consacrées à la culture, et le reste transformé 
en prairies. Dans la France d'aujourd'hui, sans doute il y a des propriétaires aisés (en Charente, etc.), aussi aisés que les fermiers de Normandie. En revanche, ceux-ci sont plus riches que les petits propriétaires de Champagne ou de Lorraine. Bien qu'ils dépendent juridiquement du propriétaire auquel ils doivent payer une rente, ils semblent plus différents de l'ouvrier d'industrie, et peuvent exploiter avec une liberté plus grande, que tant de petits propriétaires à la merci des marchands de produits agricoles, dans les périodes où les prix sont au plus bas.

Cette inégalité de condition et ce paradoxe s'expliquent par la diversité des terres, et les nécessités variables de la culture. Nous sommes peut-être trop portés à nous représenter que les diverses exploitations agricoles se distinguent surtout les unes des autres par leur étendue, et à expliquer cette inégalité même par les circonstances historiques, les traditions, les accidents qui déterminent le groupement et la répartition des hommes. En réalité, dans la mesure où l'agriculture est devenue plus rationnelle, où, aussi, elle est devenue une entreprise capitaliste parmi les autres, les régimes juridiques ruraux reflètent de mieux en mieux la richesse inégale du sol, et ses divers emplois. Là où le sol est très pauvre, le petit propriétaire, par son labeur tenace, lui fait produire assez pour qu'il en vive, mais non plus. Là où la terre est plus riche, et quand même assez morcelée, le propriétaire pourra sans doute encore exploiter directement; mais il s'enrichira, et alors ou bien il achètera de nouvelles terres qu'il donnera à ferme tout en continuant à travailler sur son premier bien, ou lui, ou bien ses enfants, renonceront aux soins de la culture et se contenteront d'une rente. Ailleurs (comme en Normandie) des capitalistes en quête de placements sûrs achèteront des terres qu'ils affermeront. Ces terres, de toute façon, seront de plus en plus louées. Là où les terres seront d'un seul tenant, où la surveillance et la centralisation seront aisées, le régisseur se substituera au fermier. Là où la terre sera un peu moins riche et la population plus arriérée, si bien qu'on trouverait avec peine des cultivateurs expérimentés et disposant d'avances, le métayage conviendra.

Dès lors la situation du fermier varie en fonction de deux facteurs : $1^{\circ}$ en raison de la richesse du sol; depuis le petit fermier irlandais qui meurt de faim et se trouve au niveau des petits propriétaires que leur terre ne nourrit plus ou des ouvriers les plus misérables, jusqu'au gros fermier qui tire du sol assez de revenus pour vivre largement et acheter lui-même de la terre, il y a bien des intermédiaires. Mais le fermier riche n'en est pas moins fermier, et sa richesse ne l'empêche pas de reconnaître que le sol qu'il exploite ne lui appartient pas ; car il ne peut ni le vendre, ni le léguer, ni même compter avec une entière certitude sur le renouvellement du bail. Il ne faut pas le comparer à un tisserand, auquel le marchand de drap loue un métier et livre de la laine en échange d'une somme donnée, pour lui acheter ensuite le drap. Mieux vaudrait se représenter un industriel qui, occupé d'autres affaires, confie à ses ouvriers l'entreprise de tels travaux, et, ne pouvant ni les surveiller, ni les faire surveiller, s'en remet à eux et leur 
réclame seulement une quantité moyenne de produits ou une somme déterminée (tel est le cas d'un propriétaire de voitures qui les loue, à des cochers). On trouverait donc dans l'industrie des exemples d'un tel rapport du fermier au propriétaire ${ }^{16}$. Le fermier est plus qu'un et il s'en apercevra d'ailleurs d'autant plus que le propriétaire s'intéressera davantage à son bien. C'est là en effet le second des facteurs à distinguer ici.

$2^{\circ}$ Le propriétaire de la terre affermée peut lui faire rendre plus ou moins, suivant qu'il la visite plus ou moins fréquemment, qu'il se tient au courant du prix du blé ou du bétail, qu'il surveille ou fait surveiller le fermier, ses achats pour son propre compte, etc. Des fermiers, loin de l'œil du maître, travaillent mollement, ou, s'ils travaillent beaucoup, cachent avec soin le montant exact de leur revenu; mais de même des ouvriers mal surveillés ralentissent la production, ou emploient une partie de leur temps de travail pour leur propre compte. Au contraire, si le propriétaire est attentif, si lui-même exploite directement à côté de sa ferme, et si, d'ailleurs, les candidats fermiers ne manquent pas, l'indépendance du fermier sera tout à fait illusoire : sur son travail et ses gains s'exercera un contrôle aussi rigoureux que celui du contremaître ou du directeur dans l'atelier. On peut même prévoir ceci : à mesure que la technique de l'agriculture s'améliorera, et que les capitaux s'y porteront, à mesure en somme que l'agriculture s'industrialisera, la situation du fermier se rapprochera de celle de l'ouvrier d'industrie, et la marge du revenu qui dépassera la rente sera déterminée avec la même précision et la même âpreté que le salaire industriel. Mais, dès maintenant, il en est souvent, et le fermier se rend compte qu'il dépend toujours du propriétaire qu'il en soit de plus en plus ainsi. C'est dire que son rapport de dépendance par rapport au propriétaire ne peut lui apparaître différent en essence de la relation du salarié à l'employeur. - Pas plus dans sa situation juridique que dans celle du petit propriétaire on ne trouverait de, raisons sérieuses d'une opposition ou même d'une distinction entre les classes ouvrière et paysanne.

Toutefois, l'idée que le paysan, en tant que propriétaire du sol, se trouve séparé de l'ouvrier par une infranchissable barrière, est trop répandue, elle semble s'appuyer sur trop de faits, et ceux-mêmes qui l'ont combattue se sont laissés conduire à de trop hâtives généralisations, pour qu'il ne soit pas nécessaire de l'examiner de plus près. Que le petit propriétaire et le petit fermier, en certaines régions, et surtout en période de crise, se trouvent consciemment dans l'étroite dépendance d'autres agents économi-

Il est vrai qu'en droit les baux à ferme sont considérés comme louage de choses, et non d'ouvrage : mais peut-on, réellement, comparer le fermier au locataire d'un magasin ou d'un atelier? Tandis que le propriétaire n'impose aucunement au locataire l'exercice d'une profession déterminée, le « preneur d'un héritage rural » doit non seulement le « garnir des bestiaux et ustensiles nécessaires à son exploitation », mais encore ne pas «abandonner la culture », « cultiver en bon père de famille », ne pas « employer la chose louée à un autre usage que celui auquel elle a été destinée ». En outre, nous l'avons vu, il subsiste entre le propriétaire et le fermier un rapport de solidarité, au cas d'accidents fortuits qui détruisent la moitié au moins de la récolte, c'est-à-dire des produits. 
ques (industriels, marchands), que, d'autre part, en des pays de culture intensive et industrialisée, les fermiers soient comme des ouvriers très qualifiés, surveillés de plus ou moins près, et rémunérés peut-être largement, mais sans aucun droit ni aucune apparence de propriété, on nous l'accordera. Mais une quantité de propriétaires exploitant eux-mêmes, avec assez de ressources pour traverser les crises et tenir tête aux commerçants, ne dépendent-ils pas du marché de façon bien plus lâche ? D'autre part, le type du fermier peu surveillé, dont on connaît mal les revenus, et qui a réellement le sentiment d'exploiter à son compte, n'est-il pas encore très répandu? Qu'est-ce qui nous prouve que ces catégories ne sont pas les plus importantes, ne représentent pas le mieux et n'influencent pas le plus directement la conscience de la classe paysanne ? Les statistiques ne nous apportent pas d'indications suffisantes sur ce point. Mais le nombre des exploitations de ce genre n'est pas ce qu'il faudrait surtout connaître: seraient-elles moins nombreuses que les autres, par leur prédominance en des régions dont le caractère rural est mieux marqué qu'en d'autres, par leur ancienneté et leur stabilité, ne constituent-elles pas, au regard de l'opinion paysanne, le type autour duquel gravitent d'autres espèces mal consolidées, l'exemplaire dont elles restent des ébauches ou des déformations ? M. Daniel Zolla ${ }^{17}$ recueille précieusement une description idyllique de la petite propriété paysanne en Béarn, telle qu'elle se révéla au voyageur anglais Arthur Young. «Partout on respire un air de propreté, de bien-être et d'aisance qui se trouve dans les maisons, dans les étables fraîchement construites, dans les petits jardins, dans les clôtures, dans la cour qui précède les maisons, jusque dans les mues de volailles et les toits à pores... Cela seul suffit à prouver que la possession du sol est le stimulant le plus énergique à un travail rude et incessant, et telle est l'étendue, la force de ce principe, que je ne sais pas de moyen plus sûr de mettre en valeur le sommet des montagnes que de les partager entre les paysans. » Si telle est la vertu de la propriété paysanne, si d'ailleurs on constate que, loin de disparaître, elle se consolide ${ }^{18}$, et qu'un plus grand nombre d'hommes y participent, ne faut-il pas s'attendre à ce qu'entre les populations rurales et industrielles les différences s'accentuent?

Mais la notion de propriété paysanne reste confuse. Est-il exact, comme le pensent beaucoup de conservateurs, que le paysan propriétaire travaille avec plus d'acharnement et aussi plus de goût parce qu'il est attaché au sol où il incorpore son

Zolla (Daniel), livre cité.

Critiquant la proposition de Marx, que «dans la sphère de l'agriculture, la grande industrie agit plus révolutionnairement que partout ailleurs, en ce sens qu'elle fait disparaître le paysan, le rempart de l'ancienne société, et lui substitue le salarié », M. Bourguin remarque que dans la population agricole active, en France, pendant que les salariés diminuaient de 394.000 (tombant de 3.452 .000 à 3.058.000), les exploitants indépendants augmentaient de 144.000, passant de 3.460.000 à 3.604.000. En Allemagne, même phénomène (bien que le nombre des indépendants y reste notablement inférieur, de plus du double, à celui des salariés). En Hongrie, la proportion des indépendants est de 66,6 0/0, et au Danemark de 83,7 0/0. Le collectivisme et l'évolution industrielle, p. 218, note.) 
labeur ? Cette conception est bien sentimentale. Il se peut plutôt que le paysan aime le sol parce que c'est la seule occasion pour lui de travailler, de tirer un produit de ses efforts. S'il fait preuve d'une ténacité et d'une énergie exceptionnelle, c'est qu'il doit vaincre plus de difficultés, avec moins de moyens, et que c'est une question de vie ou de mort d'aboutir quand même. Enfin s'il ne proportionne pas son activité à la rémunération qu'il attend, c'est qu'il est relativement isolé, c'est qu'il a moins de besoins et d'exigences, parce que tous ceux qui ont un caractère social sont, chez lui, aussi limités qu'il se peut. Mais si la propriété a de tels résultats, lorsqu'il y a nécessité extrême, isolement et bas niveau de vie, il n'est pas du tout démontré que le propriétaire paysan qui gagne bien sa vie sur une terre assez fertile travaille plus, parce que propriétaire, que s'il était fermier, ou journalier intéressé au bénéfice, ni dès lors que, par son travail propre, il gagne plus que ceux-ci.

C'est ce qu'ont sans doute méconnu, de leur côté, quelques socialistes; ils n'ont accepté d'assimiler aux ouvriers que les petits propriétaires qui tirent de leur champ à peine de quoi ne point dépérir. En ce cas «le petit champ est l'outil (disons: un des outils) du paysan, comme la varlope est celui du menuisier et le bistouri celui du chirurgien. Le paysan, le menuisier et le chirurgien, n'exploitant personne avec leur instrument de travail, n'ont pas à redouter de se les voir enlever par une révolution socialiste ${ }^{19}$ Seuls les propriétaires paysans moyens sont exclus de la classe ouvrière, en attendant qu'ils soient éliminés par l'évolution économique. - Mais c'est attribuer une trop grande importance, et une réalité qu'elles n'ont pas nécessairement dans la conscience sociale, aux classifications théoriques. Il y a aussi dans la classe ouvrière des travailleurs qui profitent de la rareté de la main-d'œuvre, ou d'une prospérité exceptionnelle dans une branche d'industrie, qui, encore, plus qualifiés que d'autres, obtiennent de plus hauts salaires : sont-ils à exclure de ladite classe? Mais entre les propriétaires moyens et petits la différence est du même ordre. Bien plus, un petit patron qui travaille autant qu'un ouvrier, avec un très petit nombre d'auxiliaires, surtout s'il n'emploie ceux-ci que temporairement, sera-t-il, ou non, à considérer comme un ouvrier? L'exclure catégoriquement serait sans doute bien arbitraire. Ce n'est donc pas son indépendance relative, considérée abstraitement, qui importe ici. Il en est de même du propriétaire qui, travaillant comme un paysan, emploie quelques journaliers et domestiques.

19 Lafargue, la Propriété paysanne et l'évolution économique. 


\section{IV \\ Vie urbaine et vie rurale}

$\underline{\text { Retour à la table des matières }}$

Nous avons évité jusqu'ici d'examiner des types intermédiaires ou mixtes, qui participent à la fois des caractères du paysan et de l'ouvrier. Il aurait été trop commode de démontrer, par eux, qu'on passe insensiblement d'une classe à l'autre. En réalité, précisément parce qu'ils sont exceptionnels, nous ne pouvions nous y arrêter d'abord. Mais ils n'en sont pas moins très intéressants. Les comparant aux membres de la classe ou du groupe auquel ils se rattachent par accident, mais de façon certaine, nous avons chance d'atteindre à l'état pur l'ensemble de représentations ou d'habitudes qui sont communes aux membres de ce groupe, quelles que soient d'ailleurs leurs différences. Surtout, qu'ils ne puissent point faire partie à la fois de la classe ouvrière et de la masse paysanne, ce serait un signe des plus frappants que ces deux ensembles se distinguent l'un de l'autre, et cela nous mettrait sans doute sur la voie du principe de leur séparation.

D'abord, en petit nombre il est vrai, des hommes qui exercent une profession agricole vivent à l'intérieur ou à la lisière d'agglomérations où sont compris surtout des ouvriers, des artisans, des petits commerçants. Nous ne parlons pas ici des propriétaires fonciers qui dépensent leurs rentes dans les grandes villes. Mais des jardiniers, et nombre d'ouvriers agricoles travaillent à proximité des villes où ils ont leur logement, et se livrent à la culture maraîchère dans la banlieue.

Il ne paraît pas que l'agriculteur ainsi transplanté échappe aux influences urbaines et reste lié par quelque solidarité tenace à ceux qui exercent le même métier que lui en des villages éloignés. Le rapport de ses services avec les besoins qu'en ont les habitants des villes lui apparaît directement; d'autre part, c'est dans la ville qu'il dépense le produit de son travail : il se considère sans peine comme un rouage indispensable de celle-ci, au même titre que certains ouvriers ou artisans aussi peu nombreux et aussi nécessaires. Surtout, comme ses revenus sont supérieurs à ceux de la campagne, son niveau de vie et ses besoins ne diffèrent pas de ceux des ouvriers au milieu desquels il vit. À côté de lui, certains groupes de travailleurs passent à la campagne plusieurs 
mois de l'année, et, rapprochés les uns des autres, assez frustes en raison de leur origine et de la rudesse de leur travail, gardent à la ville des habitudes et une mentalité paysannes. Nombre de terrassiers se contentent d'un lit dans un dortoir, et mangent en plein air, à midi, des aliments peu raffinés. Ils réalisent, jusque dans les grandes agglomérations, les conditions de vie de la campagne. Les agriculteurs établis à la ville sont plus profondément « urbanisés », parce qu'ils participent à la vie organique de la cité.

De même, et inversement, il y a dans les villages des artisans : en certaines régions où la population est peu agglomérée, où les maisons s'éparpillent, c'est même l'unique raison d'être des villages que de grouper, autour du clocher et de la mairie, les marchands et ouvriers dont tous peuvent avoir besoin à intervalles. Mais, tant que ces villages gardent de faibles dimensions et un caractère agricole, entre le maréchal ferrant, le menuisier, le maçon qui y habitent, et les paysans qui s'adressent à eux, n'y a-t-il pas plus de rapports et une plus réelle communauté de sentiments et de coutumes qu'entre ceux-là et les ouvriers de même profession groupés à la ville ? La différence est si faible que ces ouvriers sont le plus souvent, en même temps, des agriculteurs, qu'ils cultivent un petit champ, se livrent à l'occasion aux travaux ruraux. Ils sont très peu spécialisés, nécessairement : le maréchal ferrant exerce aussi le métier de forgeron et de serrurier, et le menuisier, de charpentier, d'ébéniste. De même que leur niveau de vie, le prix de leur travail est moins élevé que dans les villes, parce qu'ils n'ont pas d'autres exigences que leurs clients habituels.

Pour marquer le mieux la limite entre groupes ouvriers et les paysans, il faudrait donc s'attacher aux agglomérations qu'ils constituent, où ils vivent et où ils habitent; la différence entre eux se ramènerait à celle qui subsiste entre la ville et le village, entre vie urbaine et campagnarde.

Toutefois une telle opposition reste imprécise. Se ramène-t-elle à une différence de niveaux de vie? Mais le taux des salaires exigés et obtenus par une catégorie de travailleurs, la quantité et l'espèce des besoins qu'ils peuvent ainsi satisfaire serviraient surtout pour déterminer, à l'intérieur de la classe ouvrière comme de la masse paysanne, toute une série de subdivisions. Pour distinguer seulement classe ouvrière et masse paysanne, on ne peut sans difficulté s'en tenir là. Passons sur l'extrême complexité d'un tel calcul, et les obscurités où on serait enveloppé. En quoi un niveau de vie est il supérieur à un autre ? Quelle serait l'unité de mesure? On caractériserait peut-être le niveau de vie ouvrier par la prédominance des besoins sociaux sur les autres; mais n'est-ce pas seulement une catégorie de semblables besoins que développe la vie urbaine, et des besoins sociaux d'une autre espèce ne se manifestent-ils pas avec plus d'intensité chez le paysan ? Il faudrait alors trouver le principe de cet attachement à des objets différents, dans les deux classes. Or ce n'est pas en s'en tenant au chiffre du revenu ou des dépenses qu'on y parviendrait. Souvent le revenu ou les dépenses 
seraient plus élevées pour telle catégorie de paysans que pour tel groupe d'ouvriers, et ailleurs l'inverse ; quelle conclusion en pourrait-on tirer? En résumé, il se peut qu'à l'intérieur d'une classe le rang social de certains groupes se puisse déterminer par le seul chiffre de leurs revenus (il se peut aussi qu'il n'en soit rien, et qu'il faille considérer plutôt l'emploi qu'ils donnent à ce revenu, ou qu'il faille, combiner l'un et l'autre). Mais ce n'est pas la différence de richesse, à supposer qu'on la puisse connaître, qui explique la séparation entre nos deux groupes paysan et ouvrier.

Il n'est pas nécessaire de descendre dans le détail de la vie paysanne, d'inventorier leurs meubles, leurs vêtements, de décrire leurs repas, de distinguer en ces faits ce qui est social de ce qui est individuel, de dégager des diversités régionales les traits communs à toute la classe. Il y a, dans les conditions de vie des paysans, certains caractères assez simples et homogènes, continuellement présents à la pensée des hommes, objectifs, parce qu'ils constituent la base matérielle rigide et stable de leur existence, et sociaux, parce qu'ils dominent toutes leurs relations. C'est le mode de leur groupement, de leur établissement, et de leur habitation.

N'est-ce point cela qui exerce sur la vie tout entière du paysan l'action la plus continue et la plus irrésistible? N'est-ce pas ce qui détermine la fréquence et la facilité, l'étroitesse aussi de ses rapports avec les gens de sa famille (domestiques et parents), avec ceux qui exercent le même métier que lui, et avec les autres? C'est en cela que s'exprime encore le besoin qu'il éprouve ou n'éprouve pas de séparer nettement ses travaux et sa vie domestique. Et c'est ce qui mesure enfin le mieux le degré de son indépendance par rapport non pas au sol, mais au groupe établi sur le sol et à l'exploitation collective où il est compris.

$1^{\circ}$ De plus en plus la vie urbaine consiste en l'existence au milieu de groupes très agglomérés, tandis qu'au village les familles sont assez dispersées. Ce n'est pas ici une simple différence de degré. On peut assigner la limite où, au sortir d'une grande ville, commencent les faubourgs campagnards, et lorsqu'on compare ces régions d'après leur densité kilométrique, on passe sans transition, ou presque, des villes petites, mais qui restent telles, aux véritables villages, si étendus soient-ils. Et cela s'explique : on passe de maisons auxquelles de petits jardins peuvent être attenants, mais à titre d'accessoires, à des fermes dont la raison d'être sont les pâturages et les champs au milieu ou à proximité desquels elles s'élèvent.

$\mathrm{Au}$ reste les maisons campagnardes se distribuent suivant les modes les plus divers ; quelquefois elles s'alignent le long des routes, en rubans dont on cherche la fin (comme dans la Meuse), ou elles s'éparpillent extrêmement et s'isolent l'une de l'autre (en Flandre, dans la Basse-Bretagne). Suivant que le sol est très morcelé, ou se découpe en vastes propriétés d'un seul tenant, les maisons sont agglomérées, pour permettre 
au propriétaire de visiter facilement ses diverses parcelles à partir d'un point à peu près central, ou dispersées, les bâtiments se trouvant au centre du domaine unique. Ce dernier cas est celui de la Provence et du Tarn-et-Garonne, pays de petite propriété non morcelée, du pays basque encore où, malgré le Code civil, les propriétés se sont divisées le moins possible (le centre de la commune ne comprend que l'église, quelques auberges, de petits commerces et la maison d'école), de la Flandre française. C'est l'inverse, pour les raisons opposées, dans le Cambrésis, dans une partie de la Picardie, en Champagne où la propriété est particulièrement découpée (sauf dans la Brie champenoise), dans la Meuse, dans la plaine des Vosges, où les domaines d'un seul tenant sont exceptionnels, dans la Beauce et le Loiret. D'autres raisons sont aussi à invoquer : dans la Savoie montagneuse, les maisons tendent à se disperser parce que, la terre étant peu fertile, chaque famille a besoin pour vivre d'un domaine étendu; il en est de même en Basse-Bretagne. Dans la plaine savoyarde, les maisons tendent à se grouper au bord de la grande route; c'est que les neiges interrompent souvent les communications, et que les chemins seuls sont déblayés.

Or, si le résultat essentiel de la dispersion des maisons était l'isolement relatif auquel elle condamne le paysan, il faudrait admettre toute une série de degrés dans cet isolement. Entre la ferme perdue en un repli du sol, au milieu de vastes domaines, et le village proprement dit, la différence serait aussi profonde qu'entre celui-ci et la petite ville où l'espace n'a pas été trop ménagé. Comment d'ailleurs distinguerait-on sous ce rapport la rue urbaine de la rue villageoise, aux façades continues, qui prolonge directement celle-ci, comme il en est bien des exemples ? En réalité l'isolement n'est pas dans le sens des tendances paysannes : c'est plutôt pour eux un état pénible et une cause d'ennui. Si l'homme cultivé cherche et trouve la solitude à la campagne, le paysan s'efforce d'y échapper. Séparé des hommes des villes, il est en contact plus fréquent peut-être et plus intime que l'ouvrier avec ses voisins immédiats et sa famille.

Ce qui frappe plus que l'isolement relatif des maisons campagnardes, c'est l'absence d'un ordre et d'une organisation apparente, dans la façon dont elles se distribuent. Les ruelles des villages, la direction des routes, l'éloignement des bâtiments, l'emplacement des maisons situées loin du chemin, tout cela semble l'effet du hasard. Sans doute il n'en est rien. Mais, pour un citadin, la maison se suffit à ellemême ; elle représente peut-être le bureau ou le magasin, mais avant tout l'habitation, c'est-à-dire l'endroit, où l'on loge; et les maisons des villes sont disposées principalement en vue de faciliter leur accès et leurs communications, avec toute la symétrie et l'économie qui conviennent. Pour un villageois, la maison est avant tout le centre de l'exploitation: il tient beaucoup moins compte, pour en choisir l'emplacement ou l'orientation, des maisons déjà construites ou à construire, que des parcelles ou de la terre qu'il possède. Le village résulte ainsi d'une série de bâtiments qui répondent, à des besoins et convenances très diverses, et qui se juxtaposent ou non, qui s'harmoni- 
sent ou non, suivant, que ces besoins concordent ou se heurtent, que les convenances des uns sont ou ne sont pas celles des autres. Les villageois ont bien des occasions et des intérêts qui les rassemblent : biens communaux, fêtes, etc. Ils cherchent parfois à remédier aux gênes causées par le mélange des parcelles et l'incohérence des bâtiments : il y a des servitudes. Mais ils n'envisagent point le village comme une unité qui les domine et à laquelle ils doivent s'adapter, comme des citadins trouvent des maisons et des logements qu'il leur faut accepter. La maison villageoise est le plus souvent la propriété de celui qui l'habite ; elle lui a été transmise par ses parents ; par ses dimensions, son importance, elle représente le mieux l'étendue et, la valeur de ses biens. Surtout, il ne pense pas sa maison indépendamment de ses biens. - Aussi la conscience collective, en de tels groupes, est-elle beaucoup plus diffuse. Des mineurs installés dans un coron, propriétaires de leur maison, restent quand même très solidaires, parce que les maisons se touchent et qu,elles ont été construites suivant un plan. Mais comme la maison du paysan est, à ses yeux, liée à sa terre, alors même qu'elle touche la maison voisine, elle en est éloignée de toute la distance qui sépare les terres qui s'y rattachent : de même que la terre du voisin limite sa terre et lui est une barrière, de même la maison du voisin lui apparaît comme un domaine fermé, un territoire étranger. Que ces sentiments soient très enveloppés, ils n'en existent pas moins. Leur effet est de conserver au village un aspect inorganique et désordonné, où s'exprime, sinon l'isolement et l'indépendance des paysans, du moins le relâchement du lien social dans les groupes ruraux.

$2^{\circ}$ Non seulement la situation de la maison du paysan est ainsi déterminée par l'emplacement de son bien, morcelé ou non; mais, le plus souvent, sa disposition intérieure dépend des occupations habituelles du propriétaire. Voici encore un trait par où la vie campagnarde se distingue le plus nettement de la vie urbaine. À la ville, le logement de l'ouvrier est presque toujours séparé de l'atelier où il travaille (nous reviendrons sur certaines exceptions). Il est même rare qu'on y trouve ses instruments, ses outils, et à première vue on pourrait ne pas reconnaître si c'est le domicile d'un très petit employé ou d'un ouvrier. Il en est tout autrement à la campagne.

N'insistons pas sur quelques cas extrêmes, vestiges de formes de vie en voie de disparaître. Voici, par exemple, la description d'une maison de modestes cultivateurs dans les Hautes-Alpes ${ }^{20}$. On y entre au rez-de-chaussée par un couloir voûté : il ouvre d'un côté sur une écurie qui occupe presque tout le rez-de-chaussée (les habitants vivant surtout de l'élevage, on sacrifie tout aux bêtes). La cuisine est très petite. Au

20 Les descriptions qui suivent sont tirées de l'Enquête sur les conditions de l'habitation en France, entreprise parle Comité des travaux historiques et scientifiques, publiée par les soins de M. de Foville. $1^{\mathrm{er}}$, volume, 1894 (épuisé); $2^{\mathrm{e}}$ volume, 1899. Bien qu'elles soient de valeur très inégale sur beaucoup de points (par exemple sur le prix des loyers, etc.) les renseignements purement descriptifs que nous en tirons, envoyés par des habitants des régions considérées, offrent toutes garanties d'exactitude. 
premier étage, il y a une ou deux pièces où on loge durant l'été. Plus haut encore sont les granges et greniers, assez vastes, avec un balcon ouvert où on dépose les denrées qu'on a dû engranger trop vite et qui doivent sécher. L'hiver, de fin octobre au début d'avril, la famille entière habite l'écurie voûtée, avec les animaux. Dans un coin, sur une aire en terre battue, se trouvent une table, un banc, des chaises, un dressoir avec quelque vaisselle et des ustensiles de cuisine. Un poêle brûle, nuit et jour, de l'anthracite. Entre les lits sont les moutons et les chèvres, au milieu les veaux, dans un coin éloigné le porc. - En Basse-Bretagne, écuries et étables ne sont pas seulement dans le même corps de bâtiment que les chambres ou la chambre d'habitation, mais, même aujourd'hui, il n'y a pas toujours de séparation intérieure : rarement c'est une simple claie à hauteur d'homme, plus souvent une cloison avec porte de communication. On change souvent, après un nettoyage sommaire, une étable en habitation. Les porcs ont leur crèche isolée; mais, en beaucoup d'endroits, ils ont libre accès partout. - Dans la région de Langres (Haute-Marne), l'écurie communique toujours avec le logement; à côté de la porte est un lit occupé soit par un domestique qui surveille le bétail, soit par un des enfants de la maison. Dans la Brie Champenoise, très souvent la maison communique avec l'étable. Dans la plaine des Vosges, il n'y a pas de séparation entre le logement et les locaux qui servent aux récoltes et aux animaux : même toit et communications nombreuses; les domestiques couchent: les femmes à la cuisine, dans une sorte d'armoire fermée pendant le jour, les hommes à l'écurie, séparés des animaux par une simple cloison. Le sol de la cuisine est souvent couvert de terre et de fumier. Cette promiscuité des bêtes et des gens ne se rencontre sans doute point partout : en Provence, dans le Tarn-et-Garonne, l'écurie, bien qu'attenant à la maison, en est nettement séparée ; on n'y entre que par une porte cochère extérieure. Dans le Loiret, le Nivernais, il en est de même, comme dans la Beauce. La région du Haut Morvan (pays de transition entre le Nivernais et la Bourgogne) contient de vieilles maisons où il y a, dans un coin, une porte de communication avec l'étable, et des maisons modernes où, comme dans le Nivernais, cette porte n'existe plus. Du moins, l'homme, dans sa maison, vit souvent au milieu des produits et instruments agricoles les plus divers. Comment est distribuée, par exemple, une maison provençale? Au rez-de-chaussée se trouvent l'écurie (qui contient un mulet, une chèvre, et sert de remise) et la cuisine (qui sert de salle à manger et de salon). Au premier étage, il y a quatre portes : l'une donne sur une pièce qui sert de débarras pour les sacs de blé, les figues, les melons, les olives; la seconde chambre, avec ouverture au midi, ce qui la rend plus claire, et qui contient assez de meubles, est réservée aux femmes ; la troisième, encombrée par des sacs, des graines qui sèchent, etc., est celle du maître; la quatrième est le grenier à fourrage, situé au-dessus de l'écurie, et où couchent les garçons. Dans le Lot, le rez-dechaussée sert ordinairement de cave et de bergerie ; on habite le premier étage. Dans les chalets de la région montagneuse en Savoie, au rez-de-chaussée est l'étable pour le bétail, où on met aussi les provisions d'hiver, les outils, et où on ménage un petit atelier quand le propriétaire, travaille l'hiver à un métier ; au premier étage sont disposées la cuisine, avec un fourneau autour duquel on se réunit, et tout autour les 
chambres à coucher; dans les combles on entasse les écorces, la paille, le fourrage. À travers toutes ces diversités qui s'expliquent par les usages locaux, et les nécessités imposées par les différentes cultures et leurs combinaisons variées, par l'altitude encore et la température ordinaire, ce qu'on retrouve toujours c'est l'absence d'une séparation nette entre les pièces, les meubles, les produits qui concernent la vie domestique ou la profession.

Alors même que l'habitation se distingue des bâtiments d'exploitation, elle leur est subordonnée. Quelquefois c'est la place qui manque : si on ne couche plus personne dans la grange ou à l'étable, on met des lits sous l'escalier, dans tous les recoins. Dans la Meuse, tout est sacrifié au bétail et aux récoltes : l'écurie, la grange et l'entessoir (remise du blé et de l'avoine non battus) occupent au moins les deux tiers des bâtiments. Les chambres ne sont pas grandes, et on met plusieurs lits dans chacune : les domestiques et les enfants y sont répartis, tandis que les parents couchent à la cuisine. Dans le Finistère, en $1901^{21}$, le plus grand nombre des ménages composés de six, sept ou huit personnes (et, bien plus nettement encore, des ménages moins nombreux) habitaient une seule pièce. - Quand l'espace est moins ménagé, dans les exploitations assez importantes, la situation de la maison dépend de celle de la grange, de l'écurie, des pâturages. Ce qui caractérise, par exemple, la maison du Cambrésis, c'est que le pignon donne sur la rue et n'a pas d'ouverture ; la porte d'entrée et la façade se trouvent sur la cour; au fond se dresse la grange, le bâtiment essentiel : il importe que le maître puisse surveiller à toute heure le personnel et le bétail. De même, la ferme picarde ${ }^{22}$ consiste en une suite de bâtiments rangés autour d'une cour intérieure en un quadrilatère parfaitement clos. La pièce principale en est la grange, qui occupe tout le côté du bâtiment en façade. La maison d'habitation est soudée à l'ensemble : elle fait face à la grange et est contiguë aux étables et aux écuries, avec lesquelles elle communique souvent par une porte intérieure.

Ainsi les préoccupations du métier dominent et pénètrent toute l'existence campagnarde. C'est peut-être ce qui contribue le plus à séparer les paysans, du moins les diverses familles paysannes, les unes des autres, à empêcher l'entier développement de leur conscience de classe. Lorsque, comme à la ville, les ouvriers une fois sortis de l'usine peuvent l'oublier, la rue où ils se retrouvent, les maisons où se distribuent leurs logements sont en quelque sorte des cadres organiques où ils se rapprochent, se mêlent et se confondent. Mais comme le paysan n'a pas le sentiment d'échapper ainsi à son métier, comme son habitation même en est toute pénétrée, la séparation des exploitations et celle des habitations sont les deux aspects d'un même fait général. Sans

Résultats statistiques du recensement général de la population en 1901. Tome III (Publications de la Statistique générale de la France).

22 Demangeon (Albert), la Picardie et les régions voisines, Artois, Cambrésis, Beauvaisis. Paris, Colin, 1905. 
doute, depuis la masure de l'ouvrier journalier jusqu'à la ferme modèle qui a l'aspect d'un petit manoir, avec des pièces de réception où l'on n'entre qu'exceptionnellement, on noterait bien des intermédiaires. Mais le genre de vie ne change pas profondément, à mesure qu'on s'élève d'un niveau à l'autre. En Basse-Bretagne ${ }^{23}$, exception faite pour les domaniers, on nous dit que le niveau de vie des paysans de toutes les catégories est assez voisin : la classe rurale se distingue nettement des habitants des villes; mais, à l'intérieur de cette classe, il n'y a guère de subdivisions : paysans, propriétaires, fermiers, domestiques vivent sur un pied d'égalité, et, des uns aux autres, les conditions de l'habitation diffèrent assez peu. À un moindre degré, il semble qu'il en soit de même dans toutes les régions. En effet, pendant qu'ils exercent leur métier, aux heures où ils sont absorbés par le travail, les hommes prennent le moins conscience de la différence de leurs situations sociales, et peuvent le moins se confronter, se comparer et se classer. Or la préoccupation professionnelle est toujours présente à la pensée du paysan : c'est ce qu'exprime sa maison, où l'habitation ne se distingue pas des bâtiments d'exploitation, et c'est ce qui empêche le développement dans les groupes ruraux, au même degré que dans la population urbaine, d'une ou de plusieurs consciences de classe.

Chez certains artisans de l'industrie, il est vrai, le domicile et l'atelier sont parfois rattachés aussi jusqu'à se confondre. Dans le quartier de la Croix-Rousse, à Lyon, où les tisseurs de soie ou canuts sont installés de longue date, le métier détermine la distribution et les dimensions du logement. On est frappé tout de suite de la hauteur de la pièce principale, qui sert à la fois d'atelier et de salle à manger : c'est qu'au-dessus du métier se dresse la machine Jacquard : plus celle-ci est haute, plus le travail est facile. Pour fixer la machine, le plafond est divisé par des poutres en une série de conduits le long desquels on la fait glisser. Il n'y a de fenêtres que d'un seul côté, pour éviter les faux jours ; mais ces fenêtres sont nombreuses, deux au minimum, trois en général, quelquefois quatre et cinq, et très vastes. Les dimensions de la pièce varient suivant le nombre des métiers. Elle est divisée en deux par une cloison. La plus grande place est laissée à l'atelier. La partie comprise entre la cloison et le mur du fond est elle-même divisée en deux dans le sens de la hauteur par une cloison horizontale. Audessous on fait la cuisine; quelquefois on fait la cuisine dans l'atelier, et, dans cette pièce, on met un lit: c'est le cas des ménages les plus modestes. Au-dessus est la « soupente », où l'on monte par une échelle, et dans laquelle couchent le compagnon et l'apprenti ou les enfants. Quand le ménage est relativement aisé, il y a encore, à côté, une pièce toute en longueur, avec, du côté opposé à la fenêtre, une alcôve ; quelquefois cette pièce n'a pas de fenêtre et prend jour sur l'atelier. Sans doute c'est là un exemple très particulier: l'industrie lyonnaise a eu de bonne heure un caractère régional, et se rattache à l'industrie domestique pratiquée dans tout le Lyonnais par les

23 Vallaux (Camille), la Basse-Bretagne. Étude de géographie humaine. Paris, 1907. 
paysans montagnards ; la classe des canuts représente d'ailleurs une forme transitoire, et, tend à disparaître avec le développement de la grande industrie. Toutefois, ces conditions de vie se retrouvent à un degré inégal, partout où l'artisan indépendant subsiste. Il y a toute une partie de la classe ouvrière qui ne se représente pas comme deux lieux distincts celui du travail et celui du domicile, et dont la vie domestique reste encore engagée dans la profession. Ce ne serait donc pas un trait propre à l'ensemble des paysans, et qui permettrait de les opposer aux ouvriers de l'industrie. Admettons qu'au début les conditions de la vie industrielle se soient modelées sur celles de l'existence paysanne, qu'on retrouve alors, en dépit de l'évolution, des traces de cette parenté primitive dans certains métiers très voisins encore de leurs origines. Il importe peu. Comme ces artisans sont par hypothèse compris dans la classe ouvrière, ils serviraient alors de transition et de moyen terme entre celle-ci et la classe paysanne.

Mais l'étroite connexion du domicile et de la grange, des bâtiments d'exploitation, etc., chez le paysan, a une toute autre valeur que le rapprochement, chez l'artisan, de l'atelier et du logement. Celui-ci est, en effet, accidentel et accessoire, celle-là reste essentielle. La place du logement pas plus que de l'atelier de l'artisan n'est guère déterminée par la nature même de son travail. Il peut avoir avantage, pour des raisons de clientèle, à cause de la proximité d'une gare, d'une usine, ou en raison du bon marché des logements, à s'installer en telle région et en telle rue ; mais cela lui laisse une grande latitude; il n'est pas lié à une ville, ni à un quartier. Il peut avoir avantage, pour des raisons d'économie, à loger et travailler dans le même local ; mais, dès que l'exploitation grandit un peu, le logement tend à se distinguer et à s'éloigner de l'atelier, et la commodité du travail est loin d'en être diminuée. Le paysan, au contraire, ne peut pas s'établir où il veut, mais doit rester presque au contact de sa terre ; il ne s'inspire pas, lorsqu'il s'installe, et tandis qu'il demeure au même endroit, de préférences qui pourront changer, et de circonstances parfois passagères. Au fond, ce lien entre le domicile, les bâtiments d'exploitation et les cultures n'est que l'expression d'un fait plus général, qu'on a appelé d'un terme vague : l'attachement au sol, et qu'il importe maintenant d'analyser.

$3^{\circ}$ L'extrême diversité des régions où sont installés les paysans, en un pays tel que la France; les différences de caractère et de bien-être qui s'y rattachent, c'est ce qui frappe d'abord : on se demande comment appliquer un même nom à tous ces groupes disparates et les grouper en une même classe. Mais tous se ressemblent par un trait: le lien qui les retient dans leur "pays » : c'est ce qu'exprime le mot: paysan. Non qu'ils se caractérisent, en opposition aux ouvriers, par un contact immédiat avec la terre, et qu'ils subissent l'action directe de la nature. Ratzel insiste sur la transformation du sens du mot autochtone : il faut entendre par là non les habitants primitifs d'un pays, mais ceux qui se croient tels. Non seulement le sol n'a pas porté toujours ceux qui l'occupent actuellement, mais il est même peu probable que ceux-ci aient, le plus 
souvent, été attirés en tel endroit parles conditions naturelles, configuration, fertilité, etc.

Il faut accepter le fait que les habitudes contractées par eux détournent les paysans de chercher ailleurs de meilleures terres et un travail plus facile. «Dans les Vosges, une population s'est implantée jusque dans les intimes replis du massif. Elle se fit place aux dépens des forêts, sur les flancs inférieurs des vallées, sur les versants où s'attardent les rayons du soleil. Dans les basses, le long des collines, tant qu'on put faire pousser entre les pierres du seigle ou du méteil, s'éparpillèrent les granges, séjour permanent de ces montagnards : jusqu'au-dessus de 800 mètres les dernières granges se hasardent. Puis, 200 ou 300 mètres plus haut, on atteint les chaumes, les pâturages d'été ${ }^{24}$. » De très bonne heure (avant le $\mathrm{XVI}^{\mathrm{e}}$ siècle) les habitants de ces montagnes durent joindre les ressources de l'industrie aux maigres produits tirés du sol: on exploita les forêts; des scieries, des moulins à papier profitèrent de la force des rivières ; des verriers utilisèrent les sables; les tisserands se multiplièrent. De telles conditions de vie sont médiocres ; aussi un grand nombre de ces montagnards s'offrirent à l'industrie moderne en quête de main-d'œuvre; mais bien rares furent ceux qui émigrèrent vers des campagnes plus fertiles et qui manquaient de bras. Il en est de même des populations de la Bretagne : «La lande, les bois, les champs de culture, les espaces vides se fixent dans un ensemble inséparable dont l'homme emporte le souvenir avec lui ». Isolés dans leurs fermes perdues entre les sentiers fangeux et sous les arbres, les Bretons n'éprouvent pas le besoin de solliciter plus loin une nature moins ingrate. Dire qu'ils aiment leur pays en raison de sa pauvreté et des efforts qu'ils font pour le défricher, c'est aussi peu explicatif que d'invoquer la richesse de la Beauce comme raison de l'attachement au sol des Beaucerons : en réalité les uns et les autres sont surtout attachés à leurs habitudes, à la forme particulière de la vie sociale dans leur pays.

Cela est plus remarquable encore, lorsqu'on observe combien de formes de vie diverses, inégales, peuvent subsister très proches, sans qu'il y ait pénétration d'une région à l'autre. Que l'on compare la Beauce et la Gâtine voisine : « Depuis longtemps la grande culture était installée, constituée sur les campagnes de Beauce, que le pays voisin n'était qu'un pauvre terroir semé d'étangs et noyé de brouillards, où s'établissaient au hasard, le plus souvent incapables de payer la rente dont ils étaient grevés, quelques manouvriers misérables. » De même, en Touraine, un sérieux contraste se révèle entre la vie des plateaux et des vallées. Sur les plateaux, le sol est souvent pauvre, coupé de landes. «Le paysan des plateaux offre déjà bien des traits du paysan de l'ouest, isolé dans ses métairies, nourrissant, sous une apparence de douceur, un

$24 \quad$ Vidal de la Blache (Paul). Tableau de la géographie de la France (dans Histoire de la France depuis les origines jusqu'à la Révolution de Ernest Lavisse, Tome I. Première partie). Paris, 1903. De cet ouvrage sont tirées les citations qui suivent. 
esprit de superstition et de méfiance. Au contraire, la vie urbaine et surtout villageoise a pris fortement racine aux flancs des vallées : vie joyeuse de vignerons, auprès desquels les gens des Gâtines et des plateaux semblent de pauvres hères. » Le Morvan, pays dont le sol pauvre est couvert de landes, de genêts, de taillis de hêtres ou de chênes, terre froide, pays de loups, retient une population dont la vie ingrate ressemble peu à celle des cultivateurs ou vignerons des «terres plaines » voisines. La Normandie n'est pas moins riche en oppositions; à côté des plaines et campagnes où de riches fermiers tirent bon parti du sol, le Bocage normand éparpille ses maisons de torchis ou de schiste ; la population a dû s'ingénier, combiner les petits profits, joindre aux ressources de la petite culture celles de la petite industrie. "Autrefois surtout, l'abondance des eaux courantes y avait multiplié les petites forges; il y avait peu de rivières dont les eaux ne servissent à mouvoir les moulins, à préparer des peaux, à blanchir des étoffes, peu de hameaux où ne retentît le battement des métiers. » Dans le pays de Caux voisin, en revanche, une riche agriculture s'est développée; dans les fermes entourées de leurs vergers, espacées entre les pommiers, une population nombreuse s'est longtemps concentrée.

De cet état de fait, les causes sont, en somme, peu définies. Ce qui empêche les paysans des régions arides de se transporter sur des terres plus riches, est-ce le fait que celles-ci sont déjà toutes appropriées? Ils seraient à comparer à ces habitants de la montagne dont on prétend qu'ils y restent parce qu'ils y furent autrefois refoulés. C'est d'autant moins vraisemblable qu'actuellement, en bien des régions, « l'agriculture manque de bras »,que les propriétaires réclament des fermiers et les fermiers des ouvriers, et que les petits propriétaires des régions pauvres auraient eux-mêmes avantage à de telles migrations; cependant ils s'y refusent et préféreraient à la rigueur devenir ouvriers d'industrie. - Est-ce leur propriété qui les retient ? Partout où la proportion des capitaux immobilisés est importante, les changements d'industrie ou de profession deviennent difficultueux et dispendieux : vendre sa terre à un moment où peut-être elle se trouve dépréciée, c'est une issue devant laquelle le petit propriétaire s'arrête et recule. Cela ne les aurait point paralysés, s'ils avaient été assurés de trouver ailleurs de forts gains; si, du reste, le besoin profond d'un tel changement de place s'était développé, n'eût-on pas imaginé et réalisé quelque mode pratique de mobilisation du sol? Mais un tel besoin ne s'est pas déclaré, et les petits cultivateurs ont redoublé d'efforts pour subsister sur la terre de leur pays. - Peut-être faudrait-il invoquer plutôt leur ignorance des conditions de l'agriculture dans d'autres provinces, et une certaine incapacité à se risquer en des chemins neufs, envers de leur patience tenace et laborieuse.

Au reste, nous nous intéressons, non pas aux causes de cette stabilité, mais plutôt aux représentations collectives qui en résultent et ne se retrouvent pas dans la classe ouvrière. Or, quelle que soit leur diversité, ce qui leur est commun, c'est, semble-t-il, 
l'idée d'un rapport direct entre les conditions de la vie matérielle et la nature du pays, c'est, si l'on veut, l'idée d'un genre de vie correspondant à une région, et relativement stable comme les propriétés du sol. On peut même dire que la nature et le sol ne sont pas ici considérés seuls, ni en eux-mêmes ; ce qui passe au premier plan, c'est l'activité normale productrice des membres du groupe qui occupe le pays, activité purement agricole, ou agricole et industrielle à la fois; et le genre de vie, tel qu'on se le représente, mesure simplement et exprime dans le langage le mieux intelligible cette activité productrice.

Insistons sur deux éléments, contenus dans cette notion collective, et qui ne paraissent pas de nature à s'amalgamer de quelque façon aux représentations de classes ouvrières.

D'abord, si on se figure le « pays » comme une unité qui doit se suffire à elle-même, ce n'est pas qu'on l'envisage comme un tout organique, dont les parties se servent et se nourrissent mutuellement. L'individualisme, ici, n'est pas seulement au sommet, mais aussi à la base. Sans doute, dans quelques régions avancées, des germes d'organisation solidaire se laissent signaler. L'agriculture du Jura paraît avoir une origine artificielle. Là « naquit, sans doute au Moyen Âge, sous l'influence des églises ou des seigneurs qui cherchèrent, par des franchises, à y attirer des colons, un type intéressant de vie pastorale ». Les ressources des pâtis communaux se combinent avec les prairies. Isolés dans leurs montagnes, souvent à plus de 800 mètres, occupés chez eux, pendant l'hiver, d'industries variées (boissellerie, tabletterie, plus tard horlogerie), ils constituent de petites sociétés concentrées auxquelles convient la pratique des associations ou fruitières. Il y a, ailleurs, d'importantes coopératives agricoles. En tout cas, cette organisation est sporadique et embryonnaire. Presque partout, l'idéal du cultivateur reste de vivre sur ses produits, de se suffire, de développer la production domestique aux dépens de l'économie d'échange. L'absence de division du travail paraît bien la règle. C'est au contraire l'exception dans les villes. Là, l'individu produit presque toujours pour les autres, et a besoin de se procurer les marchandises nécessaires auprès des autres. La ville, pas plus que le quartier, n'est une simple unité de juxtaposition. La raison même du groupement urbain, c'est que les individus qui s'y rapprochent ne pourraient, par eux seuls, créer tous les objets dont ils sentent le besoin. - Il ne faut pas penser que les villages sont déjà des organismes du même genre. M. Vidal de la Blache oppose l'ouest et l'est de la France, comme les paysans et les villageois: dans l'ouest, les fermes sont disséminées entre les closeries, pâturages, étangs et flaques, et isolées les unes des autres ; les habitants ne se rencontrent guère qu'aux jours de fête ou de foire, mais vivent chacun à part durant les longues saisons pluvieuses. «L'ouest est une masse compacte, où, sur une étendue de plus 60.000 kilomètres carrés, règnent des conditions relativement uniformes d'existence. » Dans l'est, au contraire, en Lorraine, en Bourgogne, en Champagne, en Picardie, la population rurale est agglomérée autour du clocher. "Si borné qu'y soit l'horizon, si affaiblis qu'y 
parviennent les bruits du dehors, le village compose une petite société accessible aux influences générales. » Mais nous avons vu que cette agglomération, qui s explique, en général, par le morcellement des terres ou la rareté de l'eau, n'est pas une organisation et que, si les maisons sont voisines, les hommes demeurent séparés par leurs intérêts et leurs préoccupations, qui ne se rattachent point aux mêmes parties du sol et n'ont rien de solidaire. Cela ne les empêche pas, d'ailleurs, de développer une conscience et des représentations de forme collective ; mais ce qu'ils se représentent ainsi collectivement comme le pays, c'est une série d'individus bien distincts et indépendants les uns par rapport aux autres, et auxquels leur rapprochement dans l'espace ne communique qu'une unité accidentelle.

Il est vrai qu'ils conçoivent ces individus comme semblables par leurs coutumes et leur genre de vie : ainsi seulement peut se former la représentation d'un "pays ». La Beauce, nous dit-on, est « l'expression d'une forme de sol et d'existence dont la notion très nette existe dans l'esprit populaire ». Plus précisément, c'est l'expression d'un rapport entre les conditions du travail et le genre d'existence. Or ce rapport est représenté aussi dans la conscience de classe ouvrière, et ne peut ne pas l'être; mais il apparaît bien impossible qu'il le soit au même sens, qu'il soit interprété de même. Pour le paysan, ce qui doit mesurer le niveau et déterminer l'espèce de son genre de vie, c'est, directement, la productivité de son travail, dans les conditions où il s'exerce. Si la terre qu'il travaille produit peu, ou produit moins, il limitera ou diminuera ses besoins ; si elle produit plus, ou beaucoup, il les développera et leur laissera plus de jeu. D'ailleurs, en prévision des mauvaises récoltes, et parce qu'il sait, par expérience, que la productivité du sol ne peut être accrue par le seul travail que dans une mesure assez faible, il sera porté à l'économie, à la prévoyance et à la sobriété ordinaire. - On peut douter qu'il en aille de même pour les ouvriers. En particulier l'ouvrier de la grande industrie ignore, en général, quelle est la valeur de l'entier produit de son travail, puisque ce travail ne vaut que par sa combinaison avec d'autres efforts productifs de nature diverse. Son niveau de vie parait déterminé par des coutumes et sous des influences qui ne s'expliquent point par sa fonction économique, mais peut-être par le milieu social où il vit hors de l'usine, et, soit qu'il travaille davantage, soit qu'il obtienne un meilleur salaire, c'est son niveau de vie habituel qui fixe en une large mesure les conditions de travail qu'il accepte, subit ou réclame. - Mais l'artisan indépendant règlet-il ses dépenses sur des conditions de travail qu'il trouve constituées et invariables, aux quelles il doit adapter son genre de vie ? N'y a-t-il pas aussi dans la productivité de son métier de l'élasticité, de l'indéfini, si bien que, par ses efforts et son ingéniosité, il peut en tirer plus de ressources, et fixer d'avance le niveau des dépenses où il veut s'élever? Les conditions du travail ici sont moins naturelles, c'est-à-dire dépendent moins des propriétés d'un sol et d'un climat, que sociales: suivant le nombre des clients, l'importance de leurs besoins, la concurrence, etc., le métier sera plus ou moins productif; or, sur les conditions sociales on a prise, on peut s'y adapter plus ou moins 
adroitement, et à la rigueur en changer, en transportant son métier ailleurs, en passant d'un métier à l'autre, de la petite industrie à la grande.

On peut dire que, quelle que soit leur situation, les ouvriers de l'industrie vivent plus agglomérés que les paysans, et, hors de l'usine ou de l'atelier, dans les rues ou les maisons, développent une vie sociale indépendante de la profession. Ils doivent donc être portés à formuler, en des représentations collectives, la qualité et la mesure des besoins dont ils réclament la satisfaction; ces représentations une fois constituées expliqueront en partie l'intensité de leur travail (et de leurs revendications). Mais, de telles représentations collectives ne peuvent guère surgir au sein des masses paysannes. Ils sont trop isolés, par l'éparpillement de leurs maisons, par les nécessités techniques de leur labeur, qui rivent l'une à l'autre leur vie domestique et leurs démarches professionnelles. Au reste, même sans ces obstacles, ces représentations ne pourraient subsister, parce qu'elles demeureraient inefficaces; que les paysans de la Bretagne ou de la Champagne se représentent une vie plus plantureuse, manifestent des besoins plus nombreux et plus complexes, qu'importe, puisque, demeurant sur leur terre, ils ne pourraient en tirer davantage. Ils ne peuvent se représenter un niveau de vie que comme le résultat, et non le principe, de leur besogne productive. C'est parce que, sur une étendue de sol plus ou moins vaste, la productivité du travail agricole est la même en moyenne, que les conditions de vie y sont pareilles. Là encore on ne trouverait pas le principe d'un dessein ou d'une organisation collective.

$$
* * *
$$

Résumons les résultats de notre étude des groupes paysans. Nous nous demandions quel pouvait être leur rapport à la classe ouvrière, et apercevions trois hypothèses : ils s'opposeraient comme classe à celle-ci, ou ils n'en seraient qu'une partie ou un prolongement, ou enfin ils n'existeraient pas comme classe.

Or, nous croyons avoir établi qu'à supposer qu'une conscience de classe existe parmi les ruraux, elle les porterait à reconnaître d'abord et surtout leurs relations étroites avec la classe ouvrière (relations si intimes qu'ils pourraient prévoir d'avance qu'ils ne feront plus un jour avec celle-ci qu'une classe unique). Par leurs opérations économiques, comme par leur situation juridique, les paysans de plus en plus s'identifient avec les ouvriers de l'industrie. Ni l'objet, ni la technique de leurs travaux ni le développement inégal du machinisme, ni la diffusion de la propriété paysanne, ni les modes particuliers de contrats que représentent fermage et métayage ne peuvent être l'objet de représentations collectives qui opposent les deux ensembles. Il y a solidarité 
entre le développement de l'agriculture et de l'industrie au point de vue technique, il y a communauté d'intérêts, en ce qui touche l'application ou l'abrogation de certaines règles juridiques, entre les ouvriers et les paysans; à mesure qu'ils prendraient mieux conscience de ces rapports, l'un et l'autre ensemble tendraient à se reconnaitre une même classe. - Sans doute, il y aurait dans le développement de la grande industrie, dans le contre-coup de la « révolution industrielle» tel qu'il a été senti par les campagnards, des raisons d'antagonisme, mais des raisons passagères. Quand l'existence d'un groupe (ou de beaucoup de groupes, tels que ceux que forment les paysans) repose sur des conditions traditionnelles, qu'il leur est attaché au point de multiplier ses efforts et de consentir de gros sacrifices pour n'en point changer, alors qu'un autre groupe s'en est pleinement émancipé, qu'il en consolide de tout autres, et qu'il l'atteint dans ses sources vives en lui prenant un nombre croissant de ses membres, il semble inévitable qu'il y ait opposition entre l'un et l'autre. Mais de telles crises se produisent aussi à l'intérieur de l'industrie, il y a des antagonismes de ce genre entre telle et telle branche, sans que cela divise durablement la classe ouvrière : d'une part l'équilibre doit forcément se rétablir; d'autre part les conditions qui rapprochent sont non seulement plus durables, mais plus profondes que celles qui opposent. -Seulement, que la classe paysanne se fût affirmée en s'opposant, ou qu'elle se fût dégagée comme partie d'un tout dont elle se serait sentie de plus en plus solidaire, cela impliquait que l'ensemble des paysans pouvait se poser comme classe. Or il nous a paru qu'il était constitutionnel à la conscience collective paysanne de demeurer diffuse et inorganique. Les conditions d'existence des paysans, leur éparpillement, effectif alors même que leurs habitations s'agglomèrent, la prédominance de la vie domestique sur la vie sociale, et, mêlée à la vie domestique, la préoccupation constante de la profession, enfin l'adaptation et l'accoutumance au sol, à sa productivité, et au genre de vie qui en résulte, ce sont autant de forces de dispersion, autant de principes de particularisme. Pour que naisse une conscience de classe, peut-être faut-il que la vie sociale soit assez intense, c'est-à-dire assez organisée, c'est-à-dire, encore, assez dégagée de la nature, et des relations mécaniques et matérielles que le travail impose aux hommes. C'est sans doute ce qui caractérise la vie urbaine. À la campagne, les hommes sont encore trop, pendant toute la journée, confondus avec les choses; le travail des champs se prolonge, alors même qu'il est terminé, en représentations et préoccupations trop constantes, qui envahissent toute leur vie, pour qu'il en soit ici de même. La masse paysanne et l'ensemble des ouvriers des villes s'opposent non point comme deux classes, mais comme deux genres de vie. C'est ce que nous comprendrons mieux, quand nous aurons défini la classe ouvrière. 
Livre I : les limites et l'unité de la classe

\section{Chapitre II}

Les conditions techniques et juridiques du travail ouvrier

La classe ouvrière et les autres groupes sociaux qui vivent à ses côtés dans les grandes villes sont-ils séparés par des barrières nettes ? Entre les ouvriers qualifiés et les petits employés du commerce et de l'industrie ou les fonctionnaires subalternes, on peut croire que la limite est facile à marquer, et les fonctions, sans doute, n'ont point de ressemblance ; mais est-ce la fonction qui importe surtout ici ? De même, les petits commerçants et les ouvriers ne se mêlent-ils pas plus qu'ils ne s'opposent les uns aux autres ? Ce sont là des questions que l'on peut réserver. Elles seraient résolues si la classe ouvrière elle-même existait comme unité collective, si, parmi tous ces agents de la production industrielle, dont nous ne connaissons encore que la définition économique, se développait une conscience de classe assez enveloppante, organique et impérative, pour s'étendre jusqu'à ces limites, et pour surmonter les forces possibles de décomposition et de diversité. Les ouvriers qui sont ainsi aux frontières de leur classe subiront d'autant moins l'influence attractive des groupes voisins qu'ils se 
rattacheront eux-mêmes à un corps collectif plus substantiel; et les membres de ces groupes maintiendront d'autant mieux les distances, et se tiendront moralement d'autant plus à l'écart des ouvriers les plus qualifiés que ceux-ci leur apparaîtront plus solidaires de la classe ouvrière.

Il est vain de chercher à établir l'existence ou l'absence d'une conscience de classe ouvrière en s'en tenant aux manifestations diverses de ceux qui croient qu'elle existe et qui prétendent la représenter. De ce que le mot lui-même est employé, plus fréquemment, de ce qu'on parle plus souvent au nom de la classe ouvrière, même de ce que certaines institutions ou organisations où n'entrent que des ouvriers ont acquis une existence durable et légale, il ne résulte pas que cette classe existe. Des individus, ou des groupes ouvriers ${ }^{25}$ peuvent avoir avantage à croire, ou à persuader les nonouvriers, ou les ouvriers eux-mêmes, qu'il y a une classe ouvrière. L'État, ou une élite ouvrière, peut se préoccuper de constituer et développer une telle classe. Si, dans la nature sociale des divers groupes économiques où se répartissent les ouvriers, se cachent des obstacles à cette fusion ou à cette unité, si ces obstacles sont infranchissables, la classe ouvrière restera une fiction, et une telle conscience de classe tout illusoire. - Il n'est d'ailleurs guère possible d'établir, par quelque méthode scientifique, que lesdites manifestations ont une valeur sérieuse, qu'elles en acquièrent une plus grave de jour en jour, qu'elles émanent de la classe entière, et non d'un de ses groupes, ou de quelques-uns de ses membres. Il faudrait non seulement relever les cas où elles se produisent à propos (car elles peuvent se produire par artifice), mais encore tous ceux où, devant se produire, à supposer que la classe existe, elles ne se produisent pas. Naturellement on y échouerait. C'est là d'ailleurs une objection générale que soulèvent toutes les explications historiques fondées sur des démarches individuelles, ou dont le caractère collectif est incertain ; on croit suivre un courant d'opinion, une évolution des mœurs : en réalité, on cherche à deviner et on imagine plus qu'on ne démontre. Seules, certaines institutions qui résultent de l'effort et de l'activité commune de toute une collectivité, ou de ses représentants véritables, peuvent servir de signes objectifs de la pensée collective.

Nous ne sommes pas quand même impuissants à aborder ce problème. D'abord, si l'on peut relever des états de conscience collectifs qui s'opposent à la croyance en l'unité de la classe ouvrière, si ces états ne sont pas obscurs, ne se ramènent pas à des illusions, mais se trouvent en relations certaines avec des données objectives, nous arriverons à un résultat non nul, mais négatif, et, de toute façon, scientifique. S'il se

25 Cela n'empêche pas que ces personnes ou ces groupes ne représentent sans doute en fait les intérêts véritables des ouvriers, surtout en ce qu'ils s'efforcent de les amener à développer et identifier en eux une conscience de classe peut-être encore embryonnaire. Mais, une fois cette conscience élargie et éclairée, rien ne prouve que son contenu correspondrait aux conceptions et tendances de ces personnes ou de ces groupes. Peut-être en ont-ils eux-mêmes le sentiment, et conservent-ils à dessein, pour cette raison, une imprécision relative dans leurs formules doctrinales ou d'action. 
découvre toutefois que ces états de conscience sont des interprétations ou expressions inexactes des faits, ou qu'en eux-mêmes ils sont fictifs, c'est-à-dire qu'ils n'existent que dans la pensée de ceux qui croient les constater, le résultat ne serait ni nul, ni positif, mais non négatif non plus : on pourrait alors admettre que rien ne s'oppose à ce qu'une conscience de la classe ouvrière s'organise. Et il se pourrait enfin que l'étude des données de fait, de la condition de fait des ouvriers conduisît à cette conclusion : la classe ouvrière doit prendre conscience de son unité sous tels et tels rapports, et elle y parviendra quand les circonstances l'obligeront à se définir. Vraiment, ce serait déjà un grand pas que de révéler la fragilité des cloisons qui en apparence la décomposent.

\section{I \\ La classe ouvrière et les industries}

$\underline{\text { Retour à la table des matières }}$

Définir l'ouvrier : l'homme qui travaille de ses bras à la production industrielle, c'est relever un caractère qui permet de le distinguer des autres hommes. Mais rien ne prouve qu'il se représente à lui-même de façon si abstraite, et que ce qui passe au premier plan, dans l'idée qu'il se fait de sa fonction, ne soit pas l'espèce particulière d'activité qu'il exerce et d'industrie où il est employé ${ }^{26}$. Or les recensements nous

26 M. Paul Pie, dans son Traité élémentaire de législation industrielle, écrit : « Est ouvrier au sens juridique du mot quiconque exécute un travail manuel (vieux français manouvrier) pour le compte et sous la direction d'un patron ou de ses préposés, quelle que soit la nature de l'établissement dans lequel ce travail s'exerce (usine, atelier, magasin ou chantier) quel que soit également le taux ou le mode de paiement du salaire. Sont donc ouvriers ceux qui exercent un métier, c'est-à-dire un art mécanique ou manuel, pour le compte d'autrui, ainsi que les individus embauchés comme auxiliaires pour un travail manuel simple ne comportant point d'apprentissage (hommes de peine, terrassiers, manœuvres et autres gens de travail). Doivent au contraire être qualifiés commis ou employés tous les auxiliaires du commerce et de l'industrie qui, bien que placés par leur contrat sous la dépendance du patron, sont préposés à des travaux présentant un caractère d'ordre plutôt intellectuel que matériel... Ils n'exécutent point de travail mécanique comme les ouvriers, ils ne sont point au service de la personne comme les domestiques : leur rôle, à quelque degré de la hiérarchie qu'ils soient placés, consiste à seconder le patron dans son commerce, et, à ce titre, le contrat qui les unit à l'employeur, bien que constituant un véritable louage de services, se nuance en quelque sorte d'une idée de mandat. Cette différence s'accuse nettement dans l'organisation intérieure de la fabrique. Le fabricant a auprès de lui, dans ses bureaux, toute une hiérarchie de commis et «employés qui reçoivent les ouvriers, chefs d'ateliers et autres, et leur distribuent le tra- 
apprennent combien il y a de professions ouvrières différentes; et la diversité même des produits laisse supposer une différenciation professionnelle très avancée parmi les ouvriers. - Il est évident, d'ailleurs, que les classifications des recensements sont établies au nom de tout autres idées que celle de classes sociales. On se préoccupe de distinguer toutes les modalités du travail, et en même temps de les rattacher suivant leurs ressemblances techniques. Plus les subdivisions sont nombreuses, plus le recensement est adéquat; mais des catégories professionnelles à ce point restreintes, et composées quelquefois d'un très petit nombre d'ouvriers dispersés dans l'espace, ne correspondent à aucune réalité sociale. - Les ouvriers qui se groupent dans un même métier (au sens étroit) ont manifesté déjà une tendance à se rapprocher et à s'isoler en certaines organisations (fédérations de métiers). Ce faisant, ils n'ont peut-être obéi qu'à leur intérêt, à ce qu'ils croyaient leur intérêt, et à une tactique de défense professionnelle. Il ne s'ensuit pas que, sous d'autres rapports, ils développent une conscience collective particulière. En effet, la notion de métier reste complexe. D'abord, l'ensemble d'activités qu'on réunit sous le nom d'un métier est souvent à la fois très limité, et très variable : très limité, en particulier, s'il s'agit de travaux très spécialisés, et très variable en raison des modes divers et successifs de la division du travail. Mais d'autre part, à côté de cet aspect technique, de sa place dans l'ensemble des facteurs d'une production industrielle, le métier acquiert et garde quelque temps une signification sociale : il est plus ou moins difficile que tels autres, il implique un apprentissage plus ou moins long, il procure un salaire plus ou moins élevé. Or, si on ne s'en tient pas aux divisions et subdivisions multipliées à l'extrême des recensements, si l'on cherche à constituer des groupes de métiers plus étendus, à la fois larges et consistants, on est livré à l'incertitude des appréciations individuelles. On risque ou bien de se guider sur des caractéristiques extérieures, de réunir des métiers semblables par quelques côtés, mais exercés en des milieux ouvriers et au sein d'organismes industriels des plus différents, ou bien d'oublier qu'un métier exercé principalement en une région, en une industrie, et qui comprend beaucoup plus de membres que tous ceux qu'on exerce dans la même région ou la même industrie, peut devenir le centre et le principe d'union de tous ceux-ci, malgré leur diversité, si leurs intérêts sont solidaires. Donc, si l'on ne s'en tient pas aux groupements trop limités et dont l'isolement est trop accidentel, que sont les usines ou les bassins miniers, et à l'intérieur desquels ne peuvent se développer des «consciences sociales » distinctes et durables, on ne peut s'arrêter aux métiers, dont les limites sont bien mouvantes et parfois arbitraires, il faut aller jusqu'aux industries. - Au reste, pour deux raisons, c'est bien par là qu'il convient de commencer l'étude. D'abord, si des métiers analogues se distinguent surtout par leur exercice en des industries différentes, si la différence des industries est le principal obstacle à leur rapprochement, nous l'apprendrons en reconnaissant à quel point les ouvriers d'une même industrie tendent à former un groupe social distinct. D'autre part,

vail. Ces ouvriers qui participent à, la direction intellectuelle de la fabrique, fût-ce pour une part infinitésimale, ne sauraient être confondus avec les ouvriers.» (P. 632-633.) 
le métier, groupe bien plus limité et éparpillé, risque d'opposer une bien moindre résistance à la formation d'une conscience une de la classe ouvrière, que certaines industries, à la fois très localisées et très importantes.

C'est par la matière travaillée que se définissent les industries. Nous retenons celles du textile, des métaux, et des mines. Étant donné le nombre considérable d'ouvriers qu'elles groupent, leur part dans la production totale, et surtout leur concentration en des régions relativement peu étendues, si certaines industries sont capables de développer, dans les groupes qui y prennent part, une conscience collective distincte d'une conscience de classe ouvrière en général, ce seraient d'abord celles-ci.

De fait, la différence des matériaux sur lesquels s'est exercé l'effort des hommes paraît bien autrefois avoir entraîné entre ceux-ci des différences d'aspect et de mœurs qui se sont reflétées dans la conscience des autres comme dans la leur. Peu nous importe que l'hérédité soit ici intervenue ou non, que des propriétés typiques se soient, comme on le dit bien obscurément, « clichées dans la substance cérébrale » des travailleurs de telle ou telle espèce. Il est probable qu'il n'en est rien, et que si le fils d'un forgeron ou d'un mineur devient souvent forgeron ou mineur, cela tient à de tout autres raisons. Il reste que, dans l'opinion populaire, le forgeron entre sa forge et son enclume, avec son visage brûlé et ses membres d'athlète, le mineur, pionnier et prisonnier des galeries souterraines, qui travaille comme un esclave dans les carrières, le fileur et le tisserand, dont le rouet et le métier évoquent des images campagnardes et patriarcales, se détachent en relief comme des figures traditionnelles et bien distinctes. Sans doute, depuis plus d'un siècle, cela a beaucoup changé. Les mineurs ne remontent plus le charbon dans des paniers, sur leur dos, par des échelles; ils ne rampent plus le long des galeries, enveloppés de la tête aux pieds de draps humides, avec une perche qui supporte à l'extrémité la lumière, pour faire exploser le grisou. Dès le XVIII ${ }^{\mathrm{e}}$ siècle, les forges deviennent des entreprises importantes où les fonctions se différencient : il y a des charbonniers, des fondeurs et des marteleurs; ce sont les maréchaux ferrants qui évoquent encore le forgeron d'autrefois. Enfin, dans les filatures et tissages modernes, on ne retrouve plus trace des mœurs et occupations à demi campagnardes des anciens ouvriers de la laine ou du coton. Malgré tout, même si l'on oublie tout le passé, on aperçoit que, dans les usines et entreprises d'aujourd'hui, l'essentiel de ces particularités subsiste. Si l'outillage s'est perfectionné, si les machines ont été introduites, ce sont toujours les mêmes matières qu'on extrait ou qu'on élabore. Comme autrefois, l'ouvrier reste avec elles en contact direct et continu. Il subit toujours l'influence de la diversité des opérations qu'appellent ces différents produits. Dans sa pensée doivent s'associer étroitement l'image du groupe professionnel dont il est membre, et de la matière où se heurte sans cesse leur effort. 
Entre le mineur et la mine surtout ce lien parait solide. Bien que l'aérage soit bien meilleur, l'entrée et la sortie bien plus faciles qu'autrefois, les conditions de travail du mineur continuent à frapper l'imagination populaire. La houille est cachée dans les entrailles du sol, on ne l'en peut-détacher qu'au prix de gros efforts physiques. Et, sans doute, on discute sur les conditions du travail dans les mines. Certains notent « l'amour du travail souterrain qui se transmet de père en fils dans les familles de mineurs, la répugnance qu'a le mineur à abandonner le travail du fond pour se porter vers un autre métier, l'empressement avec lequel le jeune ouvrier reprend le pic dès qu'il rentre du service militaire ${ }^{27} »$; est-il vrai qu' « en cette région de taupes, la population est tellement accoutumée qu'elle se plait à cette obscurité et méprise la lumière céleste? » Mais voici d'autres témoignages : "Couché sur un côté, trempé de sueur, sur le mur humide souvent, mouillé quelquefois, le mineur arrache la houille, dans des tranchées de 12 à 20 mètres de hauteur, dans la poussière du charbon, la fumée de la poudre, sans air souvent, quelquefois dans la chaleur : voilà la position du mineur des petites couches. À genoux, ou s'étirant, s'échafaudant quelquefois, jamais dans une position naturelle, toujours dans une situation pénible, voilà la situation du mineur des grandes couches ». Peu importe celte diversité d'appréciations. Il reste que le travail des mines est peut-être, dans toute la grande industrie, celui où la dépendance de l'ouvrier par rapport à la matière de son travail est la plus marquée, non seulement dans ses gestes et ses attitudes, mais dans la durée de son labeur (long trajet jusqu'à la taille, puis travail continu, avec une interruption d'une demi-heure seulement). Nulles cheminées d'usines ne représentent mieux aux yeux du travailleur la nature de sa tâche que les montagnes de déchets dressées à l'entrée des puits et qu on aperçoit de très loin ; ce n'est que pour quelques heures qu'après le lavage à grande eau dans la cuve le mineur échappe aux prises du charbon poussiéreux et obsédant. Dans les entreprises métallurgiques, le tableau change. Que la fonte s'échappe du haut fourneau éventré par la pointe du ringard pour se répandre dans des rigoles de sable, que l'acier coule de la poche pleine de métal liquide qu'est le convertisseur, dans les lingotières ou dans les moules, que, du crochet de leur rabot ou de la palette de leur aspadelle, les puddleurs, groupés devant la gueule du four à puddler toujours béante, brassent la fonte avant de la saisir avec des tenailles pour la porter au cinglage, que le lingot d'acier tout chaud soit aplati par le marteau pilon, arrondi et creusé, plongé, tout rouge encore, dans l'eau froide, pour la trempe, l'attention des travailleurs est toujours reportée et leur activité s'exerce sur le métal rendu malléable par l'action du feu. Il est vrai que, de moins en moins, on peut caractériser le travail, dans la métallurgie, comme « le développement d'une grande énergie musculaire en face d'une matière incandescente ». Sauf les puddleurs et aides puddleurs, dont la tâche est demeurée très pénible, les autres ouvriers, grâce aux progrès mécaniques, sont devenus, de producteurs de force, de simples conducteurs de forces. Toutefois, outre les puddleurs, « les fondeurs et aides fondeurs

Benoist (Charles), l'Organisation du travail (la Crise de l'État moderne). Tome I. Le Travail, le Nombre et l'État. Enquête sur le travail dans la grande industrie. Paris, 1905. 
des hauts fourneaux et des aciéries, les lamineurs des tôleries, les forgerons et aides forgerons travaillent encore le métal rouge autour des foyers ardents », et d'autres, « sans avoir à développer autant de force musculaire, sont cependant soumis à la température déprimante des ateliers à feu continu ». Seuls les ajusteurs, tourneurs, raboteurs, monteurs, finisseurs « achèvent à froid l'ouvrage que les autres ont ébauché à chaud ». En somme, leur vie professionnelle est étroitement mêlée à toutes les manipulations auxquelles est soumis le métal, et il ne semble guère possible qu'elle ne soit pas colorée comme par un reflet de toutes ces fournaises. Faut-il dire que, malgré l'habitude, « ils sont là, étonnés quand même et émus au fond, soit de la puissance de l'œuvre, soit de la beauté du spectacle, attentifs, muets, presque religieux dans ce rayonnement? » Sans prêter aux ouvriers des idées apocalyptiques ou trop littéraires, il paraît certain qu'ils ont le sentiment de l'extrême intensité des résistances qu'offre le métal, et qu'il faut vaincre par la mise en jeu de forces mécaniques puissantes, et par des procédés chimiques dont les savants eux-mêmes ne comprennent pas toute la vraie nature. D'autre part, ils savent, par expérience, que le métal en fusion doit être saisi et travaillé au moment opportun, mais qu'il faut aussi se préserver de son contact direct, que toute distraction ou toute maladresse peut dériver sur eux l'énergie redoutable qui s'y trouve enfermée; de là cette attitude en effet muette, immobile, expectante, cette expression grave et tendue des ouvriers du fer, au moment des opérations, et qui laisse sa marque sur leur corps et sur leur visage le reste du temps. Ce n'est plus le forgeron classique au visage ruisselant éclairé de sombres reflets, et qui, lorsqu'il abat son marteau sur l'enclume, semble imposer au métal l'action d'une force surhumaine. Mais, dans l'usine, l'impulsion vient des laboratoires : c'est un déchaînement de forces démesurées, réunies en un étroit espace et au milieu desquelles les ouvriers doivent évoluer avec précaution et sûreté, de façon à leur ménager des issues, à les diriger sur le point où leur effort total doit porter, à les déplacer tout à fait sans presque bouger euxmêmes. Dans ces conditions, en même temps qu'il manifeste sa puissance sur les éléments, l'homme doit prendre conscience de sa faiblesse aussi en face d'eux : c'est ce double sentiment qui s'attache dans l'imagination populaire à la notion d'ouvrier du métal, par opposition à d'autres industries. Le travail dans l'industrie textile met l'homme en contact avec une matière légère et aérienne, malléable et fragile; il exige des aptitudes et présente des difficultés toutes nouvelles. Si l'on s'en tient à la filature et à ce qui la précède, « le travail de la soie se borne à développer et marier les fils de cocons, à les tordre et les retordre ; celui des autres matières exige d'abord un traitement compliqué de division et d'épuration, puis des opérations destinées à juxtaposer les fibres, à les superposer, à leur faire subir des glissements successifs, à réaliser ainsi leur échelonnement régulier et à permettre enfin leur fixation définitive par la torsion ${ }^{28}$ ». Voilà une des branches d'industrie que l'introduction des machines a le

28 Picard (Alfred), le Bilan d'un siècle (1801-1900). Tome IV (Mines et métallurgie. Fils, tissus, vêtements). Voir aussi : Exposition de 1900. Rapport du jury international. Groupe XIII (Fils, tissus, vêtements). 
plus profondément révolutionnées. Ce sont elles, maintenant, qui cardent et qui peignent. Les métiers mule-jenny renvideurs et continus effectuent mécaniquement le dernier étirage des filaments, leur torsion et leur envidage. Dans les ateliers de tissage, ce n'est plus le tisseur qui lance la navette et pousse le battant porte-peigne, et ce n'est même plus lui qui, à l'aide de marches, agit sur les lisses pour abaisser alternativement tels ou tels fils de chaine (ou les tire de bas en haut à l'aide des cordes de semple); l'invention du chasse-navette, de la mécanique Jacquard, et, plus récemment, du métier Northrop, ont petit à petit réduit le travail du tisseur à la mise en marche et à la surveillance des métiers. Mais si ces perfectionnements ont permis d'augmenter de plus en plus la production en limitant la main-d'œuvre, ils laissent l'ouvrier en présence des matières textiles; si les machines accomplissent de façon automatique les mouvements qui étaient autrefois ceux de l'ouvrier, on retrouve dans les chariots mule-jenny et dans les métiers les plus modernes tous les éléments de l'ancien travail manuel. Le fileur et le tisseur touchent à chaque instant les fils qu'ils rattachent ; ils comprennent et suivent tout le jeu des machines qu'ils surveillent. Or, comprendre, c'est à la fois décomposer et reproduire. Malgré leur rapidité accrue (et encore cette rapidité a des limites qui lui sont imposées par la délicatesse de la matière travaillée), ces mouvements doivent se plier aux mêmes conditions de souplesse et de régularité que réalisaient autrefois les fileurs au rouet et les tisserands au métier à bras. Les ouvriers ici n'ont plus, comme les mineurs, à dépenser beaucoup de force physique pour triompher d'une matière dure et lourde; ils n'ont plus, comme les ouvriers des métaux, à exercer, sur une matière dont le contact direct leur est interdit, des opérations variables à l'aide d'instruments et de machines qui remplacent leurs bras, mais qu'ils doivent diriger à leur gré et à leurs risques. La production s'effectue automatiquement et de façon continue sous leurs yeux; mais, comme la matière textile est délicate, il faut à chaque instant suppléer à l'absence de tact dans les machines, les arrêter et rattacher les fils, c'est-à-dire simplement avoir une bonne vue et des doigts agiles. Les ouvriers du textile se bornent à être, dans l'usine, les organes visuels et tactiles de l'appareil producteur. Travail monotone à la fois et absorbant, tels qu'on se représente bien d'ordinaire les travaux de couture, de broderie, etc. ; monotone, car il n'est point coupé par des intervalles d'immobilité qui sépareraient des périodes de labeur plus actif; absorbant, plus ou moins suivant le nombre des broches et des fils étirés qu'il faut tous embrasser d'un regard, ou des métiers vers lesquels il faut alternativement tourner les yeux, mais toujours en quelque mesure. Le ronflement ininterrompu du rouet, le battement continu de la navette dans les anciens ateliers de canuts ont appris de bonne heure aux hommes à associer avec ces métiers l'idée de patience attentive ; la finesse des fils, la légèreté de la laine, la transparence et la faible épaisseur des tissus impliquent que ce travail fut surtout de délicatesse et d'ingéniosité ; d'une visite dans un tissage ou une filature d'aujourd'hui, on n'emporte guère une autre impression. - Ainsi, dans chacune de ces $t$ rois industries, en raison de la diversité des matières qui sont à leur base, il semble que, non seulement des aptitudes techniques distinctes, mais aussi des habitudes de penser et de sentir et des représentations touchant le rapport de 
l'homme avec la nature très différentes se doivent développer chez leurs membres, et que cela doit les détourner de considérer leurs professions ou leurs fonctions comme identiques ou comparables.

On peut penser que, justement parce qu'elle a une base technique, la répartition de la population ouvrière entre des industries différentes, entre des catégories professionnelles, ne saurait rendre compte de la formation de classes sociales, puisque celles-ci sont avant tout hiérarchisées. Chaque industrie groupe des fonctions très diverses, les unes très spécialisées et qualifiées, les autres qui peuvent être exercées par des manœuvres elles détermineraient dans la société des sections verticales, non une diversité de niveaux. - Mais cela n'est pas du tout clair. Il est parfaitement concevable, et il est arrivé dans certaines sociétés, comme il pourrait arriver sous un autre régime social, que les industries comme telles fussent hiérarchisées. On a pu et on pourrait tenir compte de l'utilité de ces industries pour la société (l'utilité pourrait d'ailleurs s'entendre de bien des façons), de leur difficulté, de la répulsion ou de l'attraction qu'elles exercent. Aussi importait-il de reconnaître d'abord, dans nos trois industries, quelles qualités elles impliquent et quelles impressions elles inspirent en général, pour les classer ensuite, s'il y a lieu, de ce point de vue. Les distinctions que nous avons marquées entre elles sont, il nous semble, celles qu'enregistre la conscience collective de chacun de ces groupes et des autres. - Mais sont-elles liées pour cela à des appréciations morales ou sociales qui équivaudraient à des jugements de valeur? Les occasions où de tels jugements pourraient être formulés sont rares. Elles existent et elles pourront se multiplier. Les syndicats des diverses industries, en beaucoup de pays, entrent en rapports, dans les Bourses du travail locales, dans les congrès de l'ensemble des syndicats. Mais il s'agit alors d'essais d'organisation tels qu'il importe surtout d'effacer toutes les oppositions; et rien ne prouve que cette tactique réponde aux sentiments réels des divers groupes professionnels ouvriers. On conçoit encore qu'en régime socialiste la détermination des salaires par la collectivité oblige à une comparaison des tâches, de leur importance et de leur difficulté ; mais les éléments positifs manquent pour déterminer les tendances ou opinions qui se feraient alors jour. De toute façon, il est vraisemblable ou bien que le besoin de classer ainsi les industries n'a pas été assez intense pour que de tels jugements fussent formulés quand l'occasion s'en présentait, ou qu'une telle classification ne répondait réellement à rien.

Parmi les représentations qui se rapportent aux industries diverses, il faut distinguer, en effet, de toutes les autres celles qui expriment le niveau social de leurs membres.

Or le rang social d'un groupe est défini par ses rapports avec d'autres groupes, tandis que tous les caractères sur lesquels nous avons insisté concernent les rapports de chacun des groupes considérés avec la matière du travail, ou, en général, la nature. 
Sans doute, suivant les matériaux et suivant les progrès du machinisme dans les diverses branches, l'activité physique qu'il faudra dépenser ne sera pas la même. Il se peut, encore, que la durée de la journée de travail et la peine que le labeur entraîne (peine qui sera, suivant les cas, la simple fatigue musculaire à la suite d'un dur travail continu, l'épuisement après un effort violent et une trop grande contention de corps et d'esprit, l'étourdissement causé par une attention trop longue et portée sur trop d'objets semblables) ne soit pas la même ou se prête mal à une comparaison.

Mais peu importe. Dans chaque groupe, à la longue, se détermine une notion des conditions de travail au-dessous desquelles on ne veut pas descendre, et que l'on songe sans doute à améliorer, mais que l'on considère quand même comme normales parce qu'on les a acceptées jusqu'ici. Si, dans une industrie, se manifestait d'une façon durable un mécontentement des ouvriers, si ceux-ci se considéraient toujours comme sacrifiés et plus mal traités que les ouvriers de telle autre, ce pourrait être une raison de les classer; il y en aurait qu'on éviterait, d'autres dont on désirerait l'accès, il éclaterait des compétitions. En réalité, sauf en cas d'une crise persistante qui sévit sur une branche de la production, les ouvriers s'habituent aux conditions qu'ils ont reconnu ne pouvoir changer. Ils n'ont pas toujours et même pas souvent choisi l'industrie où ils sont entrés; mais, au bout de quelque temps, tout se passe comme s'ils l'avaient choisie, comme si des aptitudes qu'ils viennent peut-être d'acquérir leur étaient naturelles, comme si, dès lors, ils n'avaient pu trouver un meilleur emploi de leur activité. Si chaque groupe parait bien adapté à sa fonction, si les barrières qui séparent les industries sont tracées par la nature elle-même, si elles paraissent répondre à une diversité d'aptitudes innées, et non avoir été dressées par certains groupes pour fortifier leur position privilégiée, on ne peut reconnaître, entre ces groupes, quelque inégalité sociale. On aura beau dire, au reste, que les ouvriers sont alors victimes d'une illusion, que s'ils pouvaient comparer les travaux, exercer successivement les uns et les autres, de même que dans les séries engrenées et contrastées de Fourier, ils reconnaitraient combien les conditions diffèrent, qu'il s'est développé en chaque groupe une puissance de passivité et de résignation ou d'aveuglement. - Nous nous intéressons non pas à la diversité réelle des situations (qu'il paraît bien difficile d'ailleurs de mesurer directement), mais à l'idée que s'en font les groupes ouvriers. Or, en fait, si certains apportent parfois dans leurs revendications un accent d'âpreté et presque de désespoir, en période de calme ils ne se considèrent point systématiquement comme en une situation inférieure à celle des autres, et, soit amour-propre, soit habitude, ils ne déprécient ni leur industrie, ni leur groupe.

Si maintenant nous examinons de plus près les caractères du travail industriel que nous avons distingués dans chaque branche, nous verrons qu'il est possible d'en dégager une définition sociale du travail ouvrier quelle que soit l'industrie, et qu'il est très 
vraisemblable que cette notion générale occupe, dans la conscience de la classe ouvrière, une place plus importante que les représentations particulières à chaque industrie.

Seul dans la société (avec le paysan), l'ouvrier exerce son travail directement sur la matière inanimée et se trouve, par suite, en contact quotidien avec elle. - Tous les autres membres de la société sont mis, par le fait de leur travail, en relations avec des hommes ou avec une matière humaine, qu'ils exercent des professions libérales, qu'ils soient commerçants ou même employés. Les uns donnent l'impulsion, les ordres, les conseils et les autres les rédigent, les transmettent, en assurent l'exécution ou en surveillent les résultats. Seuls les ouvriers se bornent à recevoir des ordres ou des instructions, et, lorsqu'ils les exécutent, n'agissent que sur la matière, non plus sur les hommes. Ils ne sont pas encadrés de toutes parts dans une société, ils n'ont pas à s'adapter à des hommes au delà de leur activité (C'est-à-dire dans le sens où elle se déploie) comme en deçà (dans le sens d'où leur vient l'impulsion et le commandement). Comme des outils qui, dans leur poignée, portent encore la marque humaine, mais qui sont essentiellement matière dans les parties par lesquelles ils agissent, les ouvriers doivent en quelque sorte se solidifier, se durcir, substituer à leurs contours naturels et humains des lignes plus angulaires, les recouvrir d'une enveloppe à la fois plus rigide et plus rude, sur toute la façade de leur vie qui regarde les choses inertes, c'est-à-dire sur toute leur activité. Un philosophe contemporain a défini l'intelligence : « la faculté de fabriquer des objets artificiels, en particulier des outils à faire des outils ». Nous dirions volontiers que la société, en constituant en elle, ou plutôt en reportant hors d'elle toute une classe d'hommes délégués au travail matériel, a su fabriquer des outils à manier des outils. D'un tel fait, les conséquences sociales, nous le verrons, sont considérables ${ }^{29}$.

Dès maintenant, nous pouvons noter certains traits distinctifs de la psychologie ouvrière, qui résultent de cette familiarité quotidienne avec les objets matériels : une disposition d'esprit de bonne heure plus grave, comme elle se développe dans l'isolement; une pensée à la fois plus lente et plus fruste, une sensibilité à la fois plus

Nous demandons qu'on nous laisse le temps de présenter cette idée, pour nous fondamentale, sous toutes ses faces ; on verra que toutes les exceptions qui viennent à l'esprit se laissent expliquer. Il y a bien, dans la classe non ouvrière, des hommes que leur fonction met aussi en rapport avec la matière ; les artistes, peintres ou sculpteurs ; mais s'ils ne travaillaient que sur commande, si l'on ne supposait pas que leur œuvre n'est du travail que pour une part, et pour l'autre une création où ils ont pris eux-mêmes du plaisir, si en eux on ne supposait pas encore qu'il y a deux hommes, l'un qui exécute (comme l'ouvrier), l'autre qui s'inspire à la fois de son goût et de l'idéal des autres pour concevoir et commander, ils seraient aussi des ouvriers. - D'autre part, il y a des hommes qu'on serait tenté de ranger dans la classe ouvrière, et qui, suivant notre définition, ne s'y rattacheraient pas : tous ceux qui sont préposés aux soins de la personne, garçons coiffeurs, garçons de bain, garçons de café, domestiques : il faut bien reconnaître que leur situation, au regard de l'opinion, est un peu équivoque, et cela vient trop à l'appui de notre thèse pour que nous prétendions les ranger dans une classe ou dans l'autre. 
refoulée et plus émoussée ; plus d'insouciance apparente, peut-être, dans la vie ordinaire, leur sérieux s'étant dépensé dans l'exercice d'un travail qui oblige leur pensée à sortir nettement du cercle social ; à la fois moins de sociabilité et plus de solidarité, c'est-à-dire un certain détachement vis-à-vis de la société et de ses coutumes, et de la sympathie instinctive pour ceux qui, à leur exemple, affrontent la matière.

Telle serait la représentation dominante qui passerait au premier plan dans leur conscience de classe ; il faudrait la supposer suffisamment forte pour que l'unité sociale qui repose sur elle ne se trouve point compromise par des représentations communes à tous les membres d'une industrie (que nous venons d'envisager) ou communes à tous les membres d'un métier (comme nous allons le voir), et assez forte, même, pour les empêcher de naître. Mais elle-même est-elle collective? De ce que les ouvriers contractent ces dispositions générales qui les séparent des autres hommes, il ne peut résulter une conscience de classe que s'ils se représentent bien, la communauté de leur situation sociale sous ce rapport. - Ils en ont sans doute le sentiment. Ce qui pourrait leur faire illusion, les empêcher d'apercevoir, sous cette forme presque abstraite, la définition de leur classe, ce serait une diversité d'organisation ou de régime industriel suivant les industries. Supposons que dans une même industrie, à côté des usines dont le type nous est familier, subsistent des artisans, en relations durables et traditionnelles avec un cercle de clients dont ils reçoivent les commandes, ou encore que se soient constituées des coopératives de production où les producteurs euxmêmes assurent et surveillent la direction de l'entreprise. Cela limiterait l'horizon aussi bien de ces groupes que des ouvriers salariés proprement dits; ils apercevraient entre eux, les uns et les autres, des lignes de démarcation. Les uns (artisans) seraient attachés à une région humainement définie, ville, quartier, village, et, réunissant les fonctions du commerçant et de l'ouvrier, ils ne se considéreraient pas seulement comme l'instrument tourné vers la matière, mais en même temps comme la volonté qui n'est qu'une partie d'un milieu humain, qui réagit sur ce milieu en même temps qu'elle est dans sa dépendance, et qui lui reste en tout cas unie par des liens d'habitude. Les autres (coopérateurs) seraient attachés à une entreprise qu'ils ont fondée et qu'ils dirigent, ils formeraient, en tant que travailleurs d'un même établissement, un groupe solidaire, et non seulement chacun d'eux obéirait mécaniquement à l'impulsion collective, mais encore il contribuerait à la déterminer : il agirait ainsi sur la matière à la fois directement, et indirectement, par l'intermédiaire des forces humaines qu'il contrôle pour sa part. - Mais, dans les grandes industries ici retenues, artisans et coopératives sont bien exceptionnels; on n'y trouve ni « la mine aux mineurs », ni, par exemple dans les filatures et tissages, une organisation patriarcale qui s'efforcerait de perpétuer, sous le régime industriel moderne, les habitudes et manières de penser et de vivre des anciens artisans. En réalité, l'ouvrier de la grande industrie, précisément parce qu'il n'est qu'un instrument d'exécution, ne se trouve en aucun rapport organique ni avec tel 
milieu social localement défini (comme, peut-être, le paysan), ni avec telle usine ou entreprise de direction unitaire.

Il se représente sa situation dans l'usine de toute autre façon que l'employé, par exemple. Celui-ci, par bien des caractères, est réellement incorporé à l'établissement de son patron. Dans les bureaux, il est plus près de celui-ci, il le voit plus souvent. C'est par lui que passent une partie des instructions que donnent les ingénieurs, c'est dans les livres qu'il tient que s'enregistrent tous les résultats de l'entreprise. Dans les rapports directs avec les ouvriers (au moment de la paie), les banquiers, hommes d'affaires, commerçants, bien qu'il ne joue quelquefois qu'un rôle de scribe ou de distributeur automatique, il en vient à se considérer comme le mandataire et le représentant du patron. Enfin, il reçoit un traitement fixe, qui s'augmente, en général, avec l'ancienneté de sa présence dans la maison (et non, nécessairement, avec son travail). Il est naturel, dans ces conditions, qu'il s'intéresse à l'usine, a son histoire, à sa prospérité, bien plus que l'ouvrier.

L'ouvrier, au contraire, porte indifféremment ici ou là sa force de travail ; un chantier ressemble il un autre, et le salaire, la durée de la tâche sont les mêmes, qu'il s'y trouve depuis peu ou depuis longtemps. Le résultat de son travail est confondu et perdu dans le résultat de tous les travaux qui ont collaboré à la même production; il ne peut s'y intéresser que tant qu'il en est encore distinct ; c'est-à-dire qu'il se désintéresse de l'activité totale de l'usine. Les ouvriers ne forment pas des groupes collectifs définis par l'établissement où ils travaillent; c'est le patron, ce sont ses ingénieurs et ses bureaux qui représentent l'usine ; l'ouvrier n'est que l'autre partie contractante, et, au cas de conflit, c'est en ses camarades des autres usines qu'il cherche un appui. L'organisation du travail est telle que ni sur le directeur, ni sur les employés, ni sur la marche du travail, ni sur les autres ouvriers il n'exerce une action quelconque ; il aperçoit donc à chaque instant son isolement par rapport à tous les hommes qui l'entourent, corrélatif de son contact permanent avec les matériaux sur lesquels il travaille. 


\section{II \\ Les métiers et la division du travail}

$\underline{\text { Retour à la table des matières }}$

La nature de la matière travaillée en chaque industrie nous a paru ne point déterminer dans les groupes une représentation sociale correspondante. Par exemple, la notion des ouvriers qui travaillent sous la terre à extraire du charbon n'implique aucune relation sociale définie, ni entre eux, ni de ceux-ci aux autres, et, par suite, n'est pas sociale à notre sens. Faut-il en conclure que les ouvriers n'entretiennent les uns avec les autres, à l'occasion de leur travail, aucune relation d'où naîtrait une représentation collective, qu'ils sont alors en rapports, comme nous l'avons dit, seulement avec les choses, et non avec les hommes?

L'étude de l'organisation industrielle moderne nous apprend que la division du travail, en même temps qu'elle spécialise les agents de la production dans des tâches de plus en plus distinctes, les rattache d'autant plus étroitement les uns aux autres que leurs activités deviennent complémentaires ${ }^{30}$. Or, on a pu soutenir que la vie sociale tout entière repose sur la division du travail (en prenant le mot travail au sens le plus large, c'est-à-dire en entendant par là tous les genres d'activité, militaire, intellectuelle, aussi bien que le travail ouvrier). « En réalité, dit M. Bouglé, la dissemblance aussi est principe d'union. Ce qui est vrai des amis différents de tempérament ou de l'homme et de la femme dans le mariage, est vrai aussi, dans l'ensemble de la société, des coopérateurs spécialisés. Par cela même qu'ils diffèrent, ils se complètent et le ressentent incessamment. La division du travail, en entremêlant leurs fins d'un bout à l'autre de

Pour tout ce qui suit (sur la division du travail) se reporter au livre de Bücher (Karl). Die Entstehung der Volkswirtschaft ( $2^{\mathrm{e}}$ édition), Tübingen, 1898. Voir le compte rendu de cet ouvrage par M. François Simiand (Année sociologique. Deuxième année, 1897-98, p. 440 sqq.), et la Revue générale des théories récentes sur la division du travail, par M. Bouglé (Année sociologique. Sixième année, 1901-02, p. 73 sqq., sur Bücher en particulier, p. 74-85). M. Bouglé adopte la classification de Bûcher; il la rectifie sur deux points, supprimant la catégorie de déplacement du travail (jugée inutile par L. Dechesne, dans la Spécialisation et ses conséquences. Paris, 1901), et ajoutant la catégorie de création de professions (il suit ici O. Petrenz, dans die Entwickelung der Arbeitsteilung in Leipziger Gewerbe, von 1751 bis 1890. Leipzig, 1901) « suscitées par l'apparition d'espèces de biens jadis inconnues » (photographie, fabrication de vélocipèdes, etc.). 
leur vie, rappelle chaque jour à chacun d'eux qu'il ne se suffit pas à lui-même; elle l'habitue à se concerter avec les autres, à régler son activité en fonction de leur activité ; en un mot, à tout instant, elle renouvelle dans son âme le sentiment qu'il est une partie d'un tout, et que son bien dépend de ce tout comme le bien de ce tout dépend de lui... Il est donc avéré que la division du travail ne se développe pas dans un groupe sans tendre d'un individu à l'autre un filet de sentiments sociaux. » Il ajoute, toutefois, que la division des fonctions n'aura ces résultats qu'à condition que « ces fonctions soient aussi exactement adaptées que possible à la diversité des facultés, et, à cette fin, qu'elles soient choisies en liberté »; et cela impliquerait, en définitive, que les conditions fussent égalisées, c'est-à-dire qu'il n'y eût plus de classes. Sous cette forme, la thèse est inattaquable au point de vue de la science : c'est, en réalité, une thèse de morale sociale.

Toutefois rien ne prouve, a priori, qu'entre la division du travail dans l'industrie et la division du travail dans le reste de la société il y ait une différence de nature. Or si son effet, dans le reste de la société, est de créer entre les hommes des rapports de solidarité organique, si elle opère de même dans l'industrie, voilà notre thèse bien ébranlée. L'ouvrier que nous supposions, en tant qu'il travaille, isolé en face des choses, se trouverait alors engagé dans un réseau de relations humaines et en rapports constants au moins avec ses camarades de travail. Comment son travail ferait-il sortir l'ouvrier de la société, puisque, au contraire, l'organisme industriel est lui-même une vaste société très cohérente, puisque les rapports nés entre les hommes qui collaborent à la production constituent entre eux des liens sociaux. Loin de les isoler, l'usine les rapproche; et, en même temps que leurs efforts se combinent, c'est toute une vie sociale nouvelle qui les enveloppe. Telle est la théorie que nous allons maintenant envisager. En quelle mesure et dans quels cas le mécanisme de la production industrielle éveille-t-il chez les ouvriers la conscience de leur coopération ? Il faut s'attendre à ce que ce sentiment, s'il existe, décompose l'ensemble des ouvriers en groupes qui comprendraient toutes les tâches socialement solidaires. Chacun de ces groupes représenterait un métier; et nous n'apercevons d'ailleurs pas d'autre moyen de définir le métier, s'il correspond à quelque réalité sociale. Dans la mesure où les ouvriers se rapprocheraient ainsi en métiers, à l'intérieur desquels (dans l'usine même) des relations sociales existeraient de membre à membre, la classe ouvrière telle que nous l'avons définie tendrait à se décomposer, et son unité s'en trouverait compromise.

Remarquons que la classification la plus précise des divers modes d'association et de division des travaux est l'œuvre de Bücher; or Bücher a pris nettement parti contre la théorie qui explique la diversité des classes par la diversité des professions. Comme nous nous inspirerons de cette classification, il importe d'en indiquer d'abord les traits essentiels. - Adam Smith avait donné trois exemples de la division du travail : l'épingle de la manufacture, le clou du forgeron cloutier, l'habillement du journalier. En réalité, ce 
sont là trois modes distincts de division du travail. La production du drap résulte d'une division des travaux entre des entreprises distinctes: c'est une division de la production; la production des aiguilles résulte d'une division des travaux dans la même entreprise : c'est une décomposition du travail ; la production des clous de fer résulte de ce qu'une profession primitive (forgeron) s'est divisée en professions séparées (forgeron de charrues, de clous) : c'est une spécialisation. Et Adam Smith n'a pas mentionné deux autres cas de division du travail distincts des précédents ; des professions d'abord exercées parla famille s'en détachent : c'est une formation de professions (et d'autres se constituent pour répondre à de nouveaux besoins); de nouvelles professions participent indirectement à des productions jusqu'alors autonomes (la fabrication de machines à coudre en vue de la production des vêtements) : c'est un déplacement du travail. Dans tous les cas qui précèdent, les hommes ont collaboré parce que l'œuvre de production était trop complexe, faisait appel à des aptitudes trop diverses et difficilement réunies; il y avait disproportion qualitative entre le travail et la force limitée de l'homme. - Mais voici d'autres cas où la disproportion entre ces deux termes est quantitative. Il arrive que la force de travail d'un homme soit trop grande pour certaines opérations ; alors se produit le contraire (en un sens) de la division du travail ; l'homme assume plusieurs besognes, afin d'occuper tout son temps et d'employer toutes ses forces : c'est la réunion des travaux. Mais il arrive, surtout, que la force de travail d'un homme soit trop petite pour certains travaux. Alors les hommes s'associent. Tantôt ils sont incapables moralement de travailler seuls : d'où le travail en compagnie. Tantôt ils en sont incapables physiquement, et ils travaillent en groupe, soit qu'ils restent indépendants (comme plusieurs maçons qui bâtissent une maison), soit qu'ils combinent leurs travaux (comme des rameurs ou des batteurs de blé) : le premier cas est celui de l'addition des travaux simples, le second cas est celui de l'enchaînement des travaux. Tantôt enfin c'est une nécessité technique qui les oblige à se grouper (pour la fabrication d'une voiture, par exemple) : d'où la liaison des travaux.

Nous nous demandons quelle signification sociale ont, aux yeux des ouvriers qui se les représentent, les conditions techniques de leur travail ${ }^{31}$. De ce point de vue, chacune de ces modalités de la division du travail (au sens large) n'est pas à envisager à part; plusieurs d'entre elles se peuvent rapprocher, suivant que les rapports sociaux qu'elles paraissent déterminer sont de même nature. - En premier lieu, le fait du travail en un même lieu peut rapprocher (moralement) certains ouvriers en un groupe distinct.

Nous envisageons uniquement ici la forme, et même un seul élément de la forme de l'organisation productive, savoir le degré et l'espèce de la division du travail. Nous supposons un régime d'industrie quelconque (d'artisan, corporatif, capitaliste, coopératif, ou tout autre), et nous n'examinons point d'ailleurs de quelle importance peut être ici la grandeur des établissements et le nombre d'ouvriers qui s'y rassemblent (autre élément de la forme de la production). Sur la distinction entre les régimes et les formes de la production, se reporter à la méthode positive en science économique, par François Simiand (F. Alcan, 1912), p. 157 et p. 172-177. 
Mais quand dira-t-on qu'ils travaillent et qu'ils ne travaillent pas au même endroit ? Le même lieu, sera-ce la chambre où des couturières sont réunies (travail en compagnie), le chantier où des maçons élèvent une maison, l'aire où les ouvriers battent le blé (addition des travaux sous ses deux formes), la forge (liaison des travaux)? Mais quand des ouvriers travaillent dans un même bâtiment, séparés les uns des autres par des cloisons ou des planchers (décomposition du travail), ou lorsque, dans une même usine, des bâtiments voisins, mis facilement en communication, abritent ici les trieurs de laine et les filateurs, là les mécaniciens chargés de réparer les instruments (déplacement du travail), ne dira-t-on point encore qu'ils travaillent « au même endroit ? » Bien plus (puisque nous faisons abstraction du régime de la production, et qu'il n'importe pas que l'ouvrier soit ou non propriétaire légal des instruments de travail et du produit), de ces cas à ceux où des producteurs de la même branche, mais différemment spécialisés, des cordonniers, des selliers, des corroyeurs (spécialisation), ou des producteurs par les mains desquels passe une même matière pour recevoir des façons successives (division de la production), travaillent dans une même rue, dans un même quartier, dans une même ville, ne parvient-on point par transitions insensibles ? L'éloignement n'est pas moindre entre les diverses tailles d'une mine, par exemple, et certains bâtiments d'une même usine qui, pour une raison ou l'autre, sont éparpillés. On ne peut donc guère marquer une limite précise en deçà de laquelle la proximité dans l'espace, et l'idée qu'en ont les ouvriers, contribuerait comme telle à les distinguer des autres groupes. Cette relation doit leur apparaître tout accidentelle, et sans profonde signification sociale. Entre les ouvriers d'un même atelier il peut se créer des liens de familiarité ; mais il n'y a pas plus de raison pour qu'il s'en établisse entre ouvriers qui peuvent être appelés à se rencontrer dans le même atelier, que pour qu'il en soit de même, entre ceux qui peuvent être rapprochés dans le même bâtiment, la même usine, le même quartier, etc., pour ce seul motif. - Mais le rapprochement dans l'espace n'est que l'expression parfois confuse de l'interdépendance des travaux. Les huit modes, distingués par Bücher, d'association et de division des travaux nous semblent se ramener sous ce rapport à trois grandes catégories. On remarque d'abord, dans la société, des professions distinctes en ce qu'elles aboutissent à la production de marchandises nettement différentes (formation de professions), et à côté, des professions voisines, mais différenciées (spécialisation); dans ces deux cas, producteurs et productions sont constamment indépendantes. Si on envisage la société entière comme un organisme producteur, ou encore si on se reporte en pensée à un état où des productions spécialisées ne s'étaient pas encore séparées, on se rend compte de leur solidarité ; mais c'est un point de vue où ne paraît pas s'être élevée encore la classe ouvrière. - En second lieu, il y a des professions dont chacune suppose un ensemble complexe de travaux mis en rapport soit parce que la production d'une marchandise telle qu'une voiture, ou une maison, exige la réunion de pièces ou d'opérations dont chacune répond à un métier (c'est ce que Bücher appelle la liaison des travaux), soit parce que plusieurs élaborations successives et bien différentes sont nécessaires, celles du peaussier, du tanneur et du cordonnier, par exemple, pour le même objet (division du 
travail), soit, enfin, parce que les machines employées à la production par un métier doivent être produites elles-mêmes par un autre (déplacement du travail). Y a-t-il là un principe défini de solidarité professionnelle, qui s'imposerait à la conscience des groupes intéressés? Mais la mise en relation des travailleurs de ces différents métiers, ou plutôt de ces productions diverses, n'est à aucun degré l'œuvre consciente ou un objet proposé au consentement desdits ouvriers. Sans doute les conditions de ces métiers sont en rapports, ces divers métiers se conditionnent les uns les autres en quelque mesure. Quand, au milieu du XVIII ${ }^{\mathrm{e}}$ siècle, on eut inventé la navette volante, le travail du tisserand s'accéléra avant qu'on eût trouvé le moyen de produire du fil en quantité correspondante. D'autre part, une grève dans un de ces métiers immobilise ceux qui en sont le plus directement solidaires Mais ce n'est guère qu'à de tels moments de crise, c'est-à-dire assez rarement, que ces rapports deviennent sensibles, et que les ouvriers de métiers ainsi dépendants sentent que, dans l'organisme social, ils représentent les parties d'un même système. D'ordinaire, ceux qui sont préposés à la direction s'aperçoivent seuls et ont seuls le souci de ces agencements. $\mathrm{Si}$, pour des raisons d'intérêt commun, les ouvriers de métiers voisins s'associent parfois, c'est parce qu'en fait ils peuvent dépendre le plus souvent des mêmes patrons, non parce que leurs travaux se complètent et s'adaptent les uns aux autres. C'est sans doute de cette dépendance des métiers que de plus en plus certains entrepreneurs s'inspirent, pour rattacher en une même entreprise des productions solidaires; mais il n'en résulte pas que, dans les ensembles ouvriers ainsi constitués, doive exister de façon continue le sentiment d'une connexité d'intérêts, et de fonctions. - En troisième lieu, et c'est le cas le plus intéressant pour nous, certains métiers ne sont pas seulement solidaires, mais représentent comme les pièces d'une machine qui obéissent au même déclenchement et engrènent l'une sur l'autre. Cela se réalise dans les deux mode appelés par Bücher le travail additionné et la décomposition du travail. Le premier peut être simple, et s'expliquer surtout par la nécessité de gagner du temps en étant plusieurs (des maçons, des mineurs travaillant à côté les uns des autres), ou complexe (enchaînement des travaux) et soumis à un rythme (des forgerons, des batteurs de blé). Le second correspond à l'exemple classique d'Adam Smith, de la fabrication des épingles. « Un ouvrier tire le fil à la bobine, un autre le dresse, un troisième coupe la dressée, un quatrième empointe, un cinquième est employé à émoudre le bout qui doit recevoir la tête. Cette tête est elle-même l'objet de deux ou trois opérations séparées : la frappe est une besogne particulière, blanchir les épingles en est une autre; c'est même un métier distinct et séparé que de piquer les papiers et d'y bouter, les épingles ». On pourrait penser que, de cette «décomposition» à la « division » dont nous avons parlé, et qui a lieu entre métiers solidaires (peaussier, tanneur, cordonnier), il n'y a qu'une différence de degré, que dans l'un et l'autre cas un même objet, une même matière passe par des mains différentes, et qu'il importe peu que l'intervalle dans le temps entre ces opérations, et dans l'espace entre les ateliers, soit plus ou moins grand. L'intervalle importe beaucoup, au contraire, car, qu'il soit réduit au minimum, c'est la condition pour que ces travaux, quoique divisés, soient réellement organisés et engrenés. En 
effet, le travail additionné, la décomposition du travail, et eux seuls supposent un plan, une discipline imposée; les productions différentes ne sont pas obligées de s'adapter les unes aux autres par tâtonnements, en sorte qu'elles risqueraient toujours de ne se plus correspondre ; mais il y a autant de métiers distincts, et une proportion suffisante d'ouvriers pour chaque opération (un même ouvrier, remarque Adam Smith, pouvant en accomplir deux ou trois), pour que le travail, soit continu, et que les uns ne soient jamais obligés d'attendre les autres.

Est-ce seulement quand les machines sont introduites, et à mesure qu'elles jouent un plus grand rôle, que cette continuité et cette implication réciproque des divers travaux devient le plus sensible? Marx a défini la machine-outil: « un mécanisme qui, ayant reçu le mouvement convenable, exécute avec ses instruments les mêmes opérations que le travailleur exécutait auparavant avec des instruments pareils »; il n'y a pour lui révolution industrielle qu'à partir du moment où la vapeur s'applique à la machine-outil. La définition donnée par M. Mantoux ${ }^{32}$ est peu différente : « la machine est un mécanisme qui, sous l'impulsion d'une force motrice simple, exécute les mouvements composés d'une opération technique, effectuée auparavant par un ou plusieurs hommes ». L'une et l'autre formule mettent surtout en lumière la simplification et la concentration du travail productif par la machine. Les conséquences sociales en sont, certes, considérables, et nous en examinerons bientôt quelques-unes. Mais, au point de vue, qui nous intéresse ici, des conséquences sociales de la seule division du travail, les machines modifient cette division en degré plutôt qu'en nature. Puisqu'il n'importe pas ici, en effet, que la force motrice soit fournie par un moteur humain, animal, ou inanimé, et qu'une pompe mue à la main est une machine au même titre qu'un marteau-pilon, la machine a surtout pour effet de mettre en relations plus étroites et plus continues les diverses opérations productrices, d'écarter de plus en plus les causes d'indétermination, de ralentissement ou de suspension qui viennent de ce que le travail humain qui y participe est plus indépendant. Or cette intégration existe, à un degré moindre, mais déjà, dans la manufacture où il n'y a pas de machines, mais où les travaux sont divisés entre ouvriers qui travaillent simultanément. Par suite de celte organisation, le travail tend à devenir plus rapide et «machinal», plus automatique. Chaque ouvrier subit la pression de tous ceux qui l'entourent, il doit suivre leur allure, et cette allure est déterminée en quelque sorte indépendamment d'eux. C'est un rythme collectif, qui s'impose à chaque individu au même titre que le rythme de la machine. Les chants dont, de bonne heure, s'est accompagné le labeur d'ouvriers travaillant par équipes, ont pour rôle de plier leurs efforts à une discipline extérieure, de même qu'un balancier sur lequel ils régleraient leurs mouvements, qu'un chariot ou une plate-forme mue à la vapeur dont ils attendraient le retour. Sans doute ce rythme n'est pas rigide ; mais, s'il se modifie, ce sera d'ensemble, c'est-à-dire par une décision collective(au cas

Mantoux. Livre cité, p. 180. 
où des maçons, d'un commun accord, ralentiraient leur travail) ou par une acceptation ou résignation collective (au cas où, en période de presse, la production s'intensifie). De toute façon, l'initiative et l'indépendance individuelle auront entièrement disparu.

Faut-il admettre que le rapport de continuité où se trouvent ainsi certains travaux se traduit, dans la conscience des groupes, en représentations sinon de classes, du moins de métiers, et, surtout, que ces représentations sont suffisamment nettes pour empêcher ou ralentir la formation d'une conscience une de classe ouvrière ? Faisons abstraction de la nature différente des produits sur lesquels travaillent les ouvriers, de leurs diverses espèces : nous avons vu déjà que, si l'on considère la matière en général (fer, textile, etc.) qu'on élabore, il n'existe point là un principe de différenciation sociale. D'autre part la notion de produit spécial, du produit tel qu'il est livré au client, n'a d'importance pour l'ouvrier qu'en tant qu'elle représente un certain agencement des opérations productives ${ }^{33}$ : quant à l'utilité et à la signification sociale du produit, ce n'est point sur elle que se porte sa réflexion. Un mécanicien ajustera indifféremment les pièces d'un instrument de guerre ou d'une locomotive, un compositeur ne s'occupera pas du sens des pages qu'il compose. De même, il faut faire abstraction des conditions juridiques qui peuvent, en fait, être liées le plus fréquemment à la petite ou à la grande industrie. Pour rassembler beaucoup d'ouvriers et diviser entre eux les travaux, surtout pour substituer les machines à la main-d'œuvre, il faut d'importants capitaux; dans la grande industrie, la séparation de l'ouvrier et de ses instruments de travail, et la prépondérance économique des employeurs sont plus marquées. Ce n'est pas ce qui importe ici. Mais est-ce que, du simple fait que leurs activités sont engrenées, diverses catégories d'ouvriers constitueront un groupe social distinct, qu'on pourra appeler un métier? Il ne le semble pas.

Ce n'est pas à dire que les organisations ouvrières ne se soient pas inspirées parfois de l'unité de la matière, ou de l'unité du produit, lorsqu'elles ont cherché à définir le principe de leurs « fédérations ». Mais elles ne paraissent pas être parvenues à une notion bien nette de l'industrie ; ainsi « la Fédération du bâtiment est constituée d'éléments travaillant de multiples matières, mais contribuant à l'édification d'un même objet, tandis que la Fédération des métaux est absolument le contraire : des éléments ne façonnant que des métaux, mais contribuant à l'édification de multiples objets répandus dans l'ensemble de toutes les industries. " (Raoul Lenoir, Revue syndicaliste, $1^{\mathrm{er}}$ décembre 1908.) Le seul dessein clair est ici de réaliser l'unité, au nom de principes et par des moyens d'ailleurs variables. L'auteur ajoute : «il est indéniable que les horlogers, les lunetiers n'ont aucune relation technique avec un puddleur : il en est de même du lamineur avec l'opticien, du tourneur avec le bijoutier, du mouleur avec le serrurier, du ciseleur avec le forgeron, etc.». Et un adversaire plus résolu de l' « unité » remarque : " la Fédération de la Teinture et Apprêts et celle des teinturiers dégraisseurs font deux ; la Sellerie-Bourrellerie ne veut rien savoir des Cuirs et Peaux ; la Confection militaire a horreur de la Fédération de l'habillement ; la Fédération lithographique n'a pas fusionné avec le Papier, ni avec les Presses typographiques, ni avec le Livre ; les mineurs ne sont entrés dans la C. G. T, qu'en promettant de respecter la Fédération des ardoisiers ; les Transports sont séparés des Transports et manutentions ». Nous n'avons pas à envisager ce problème de tactique résolu différemment par les Fédérations de métier ou d'industrie, et nous nous bornons à remarquer que l'état actuel des organisations ouvrières exprime mal les relations et oppositions sociales réelles entre les diverses catégories d'ouvriers. 
Sombart a défini le métier au sens étroit, c'est-à-dire l'activité productrice de l'artisan dans la petite industrie : « un genre d'activité qui tient le milieu entre l'art et le travail manuel devenu habitude ». C'est dire que l'artisan conserve, dans son métier, quelque personnalité, et que son travail dépend dans une large mesure, en qualité et grandeur, de ses aptitudes et de son initiative. À mesure que l'habitude intervient plus, le travail cesse d'être personnel ; c'est ce qui se réalise quand la division du travail est poussée très loin. Mais alors, l'ouvrier, en tant qu'être personnel et conscient, est beaucoup moins engagé dans le travail productif que l'artisan. À ce moment il y a lieu de distinguer de lui-même (caractérisé par ses besoins, ses goûts, ses opinions et représentations sociales) sa force de travail, marchandise relativement homogène, qui se vend et s'achète à la quantité, et qui, au contact de la matière et des machines, est devenue elle aussi de plus en plus mécanique et matérielle. En ce sens, non seulement les machines, mais tout cet ensemble automatique constitué par des ouvriers dont les activités sont étroitement coordonnées, imposent de plus en plus au travailleur le sentiment de son isolement en face des forces matérielles inanimées. Ce ne sont pas seulement de nouveaux agents matériels, vapeur, électricité, avec lesquels il entre ainsi en rapport; mais, à mesure que ses compagnons de travail obéissent davantage à une discipline fondée sur les rapports naturels des diverses opérations, se plient à un rythme qui est, pour des raisons naturelles, le plus entraînant, à mesure aussi ils en viennent davantage à se considérer mutuellement comme de simples forces mécaniques qui se déterminent et se limitent les unes les autres ${ }^{34}$. Dès lors cette forme de la division du travail, loin de créer entre ceux qui y sont impliqués des rapports nouveaux de solidarité, aboutit plutôt à les éparpiller et à les isoler. C'est ce qu'on exprime quelquefois, en disant que le travail parcellaire, résultat de la division extrême du travail, conduit l'ouvrier à se désintéresser de la marche d'ensemble de l'industrie.

Or, ce n'est point parce que le travail est parcellaire (on conçoit qu'un des maçons qui construisaient les cathédrales se soit toujours représenté le bâtiment dans son ensemble, et que son travail en ait été relevé à ses yeux), ce n'est pas non plus parce qu'il y a division du travail (un travail, même simple, peut exiger du goût et de l'habileté). Mais le travail, devenu plus rapide et mécanique, oblige l'ouvrier à se transformer en un rouage poussé par ceux-ci et actionnant ceux-là. De là un déplacement de l'attention qui se fixe tout entière sur la tâche spéciale à accomplir, et se détourne des autres travailleurs. - Ainsi, loin d'être le principe de représentations sociales originales, cette organisation du travail, là où elle est la plus développée, augmente au contraire le sentiment, commun à tous les ouvriers, de leur isolement en face de la matière.

34 M. Ad. Bücher, dans son livre Arbeit und Rhythmus ( $2^{\mathrm{e}}$ édition, Leipzig, 1899), a montré sur beaucoup d'exemples de «chants de travail » que le rôle du rythme est d'alléger le travail en le rendant plus automatique (succession d'efforts élémentaires séparés par des temps de repos). 
Si les machines ont, en bien des cas, simplifié à ce point le travail manuel et réduit l'ouvrier aux fonctions de mise en marche, de surveillance, de nettoyage, d'alimentation et de déchargement, en raison de leur complication et de leur délicatesse croissante, ceux qui les fabriquent, les montent, les dirigent, les réparent, doivent parfois posséder des connaissances scientifiques et des aptitudes techniques relativement rares, et elles n'ont d'ailleurs pas fait disparaître ni pu suppléer tout à fait certains ouvriers qui s'acquittent de tâches difficiles. On oppose couramment les ouvriers qualifiés et les manœuvres : c'est même la distinction essentielle qui permettrait, pense-t-on, de séparer en deux classes l'ensemble des ouvriers. Qu'en faut-il penser ? - Autrefois, quand les artisans étaient groupés en corporations exclusives, astreints à un apprentissage, obligés de produire un chef-d'œuvre, soumis à des règlements rigoureux, ils pouvaient se considérer, par la nature technique de leur travail, comme socialement supérieurs aux mineurs et carriers, aux ouvriers des salines. Entre leurs spécialités, entre leurs méthodes perfectionnées et traditionnelles de travail, et ces besognes rudes, très voisines de celles des paysans, et qui rappelaient plutôt les tâches des esclaves que les métiers des artisans, il n'y avait guère de transition ${ }^{35}$. Aujourd'hui encore, lorsqu'on passe, dans une fabrique de laine, de l'atelier des trieurs, ouvriers sélectionnés et qui ne se multiplient pas à volonté, à celui des fileurs, où les rattacheurs sont de purs manœuvres, ou, dans une imprimerie, de l'atelier où sont les presses, où les margeurs et déchargeurs se bornent à poser et à ôter des feuilles, à celui des compositeurs et metteurs en forme, on est surtout frappé de la différence de difficulté des travaux. Mais faisons abstraction des salaires : tenons-nous-en aux opérations effectuées. Observons d'ailleurs qu'une quantité de manœuvres sont des femmes, ou des enfants qui deviendront plus tard des ouvriers plus qualifiés. Sans doute, dans une usine, on pourra classer les ouvriers en diverses catégories, suivant leur « qualification » plus ou moins grande ; mais combien fera-t-on de telles catégories? Les ouvriers qui, par leurs aptitudes, s'élèvent presque au niveau des artistes ou des ingénieurs sont peu nombreux ; les manœuvres qui n'ont absolument aucune aptitude spéciale le sont-ils plus? Ce qui leur manque, n'est-ce pas surtout l'occasion de se différencier, si peu que ce soit ? Or, si les ouvriers se «classent» ainsi les uns par rapport aux autres en tenant compte de leurs aptitudes, c'est bien de leurs aptitudes virtuelles, et non des conditions de travail qui leur sont imposées pour des raisons indépendantes d'eux, qu'ils doivent s'inspirer. Ils ne se figurent sans doute pas qu'il naît précisément autant de fondeurs, de chauffeurs, de marteleurs qu'il en faut pour suffire à la production; et ils ne se représentent pas non plus que ceux qui auraient pu exercer des métiers plus difficiles, s'ils avaient eu un apprentissage suffisant, si les places disponibles avaient

Alfred Doren, dans Studien aus der Florentiner Wirtschaftsgeschichte, T. I (1910), remarque que dès le $\mathrm{XIV}^{\mathrm{e}}$ siècle, à Florence, dans l'industrie des draps de laine, la division du travail, déjà poussée très loin, s'accompagnait d'une différenciation sociale très nette, étendue jusqu'aux habitudes de vie. 
été plus nombreuses, si leurs charges, leurs besoins les avaient plus stimulés, aient tout à fait perdu leurs qualités, pour n'en avoir point tiré parti, et que la profession en général modifie l'homme de façon définitive. Au reste, et si l'on sort d'un métier ou d'une industrie, si l'on envisage, comme il est légitime ici (puisque ni dans l'industrie au sens étroit, ni dans le métier au sens large nous n'avons trouvé le principe de formations sociales distinctes) tous les travaux industriels, n'y a-t-il pas une quantité de stades de transition, où le manœuvre, peu à peu, acquiert des habiletés qui rendent son travail plus rapide, plus facile et plus sûr, où l'ouvrier qualifié doit dépenser autant de force musculaire que d'ingéniosité ? N'y a-t-il pas des groupes considérables d'ouvriers, tels que les mineurs, dont on ne peut pas dire précisément s'ils sont qualifiés, ou si leur activité ne se rapproche pas plutôt de celle des terrassiers et des manœuvres?

La difficulté de tracer ici une limite ne serait pas une raison suffisante pour croire qu'on ne l'a point tracée. On pourrait s'inspirer de la longueur moyenne de l'apprentissage nécessaire pour certains métiers ; cela paraît sans doute le signe le plus objectif du degré de qualification d'un travail. Mais, dans l'état actuel de l'industrie, et en raison de ses rapides transformations, l'apprentissage n'est plus la condition nécessaire de l'accès à un métier. Les métiers ne sont plus fermés; dès lors, les patrons peuvent avoir avantage à faire travailler des ouvriers qui, n'ayant pas consacré autant de temps à leur apprentissage, ont de moindres exigences, et qui sont tout juste à la hauteur de leur tâche ; il se peut aussi qu'un travail puisse être exécuté par d'autres ouvriers que ceux qui, jusqu'ici, s'y trouvaient spécialisés. Comme le remarquent les Webb, après avoir constaté que les Trade Unions ont échoué à obtenir une réglementation de l'apprentissage, « ce mode de formation, qui n'est ni démocratique, ni scientifique, ni économique, est destiné à disparaître ${ }^{36} \gg$. En fait, et dans ces conditions, les ouvriers qui ont derrière eux de longues années d'apprentissage ne forment point bloc contre les autres.

On pourrait encore classer les métiers en tenant compte des salaires : on admettrait que les plus hauts salaires vont aux ouvriers les plus qualifiés. Mais, outre que la notion du salaire reçu, c'est-à-dire du revenu, et non du travail, passerait ainsi au premier plan, il n'est pas du tout établi qu'il existe un rapport déterminable et constant entre la difficulté du travail et sa rémunération. Des travaux très difficiles peuvent devenir inutiles, par suite des découvertes techniques, d'un déplacement de la consommation, de l'évolution économique générale. Suivant les pays, un même métier peut être plus ou moins haut sous ce rapport, et les ouvriers de cette catégorie recevoir des

36 Webb (Sydney and Beatrice). Industrial Democracy. ( $8^{\mathrm{e}}$ mille, London, 1906). Chapitre X. The entrance to a trade, p. 454 sqq. 
salaires plus ou moins élevés ${ }^{37}$.- Au reste, on ne pourrait guère citer de cas où une catégorie d'ouvriers ait protesté contre les hauts salaires d'une autre. Tous sentent que la classe ouvrière dans son ensemble profite des exigences accrues de son élite. Sans doute l'unité ouvrière n'est pas apparue toujours pleinement conforme aux intérêts de tous les groupes ouvriers. De l'accroissement indéfini de la main-d'œuvre pendant tout le $\mathrm{XIX}^{\mathrm{e}}$, siècle, et de la concurrence qu'ils se sont ainsi faite, un grand nombre d'entre eux ont souffert. S'ils avaient pu exclure du marché de la main-d'œuvre toute une masse importante de concurrents par le moyen d'une coalition, il n'est guère douteux qu'ils s'y seraient résolus. Mais leur situation à tous était pareille (leur seul bien restant leur force de travail). Au nom de quel principe de distinction les uns pouvaient-ils se grouper contre les autres ? Toutes les fois qu'il l'a pu, un certain égoïsme corporatif s'est fait jour, sous des prétextes variables ${ }^{38}$. Mais de telles réactions, rares d'ailleurs, se sont révélées sans profondeur et sans durée. Ils ont le sentiment qu'un progrès dans une catégorie ne dessert pas les autres ${ }^{39}$. Non seulement il se peut que, dans l'évolution des salaires en hausse, ce soient les salaires des ouvriers qualifiés qui donnent le signal (ils sont en tout cas mieux en mesure que les manœuvres, par un arrêt concerté du travail, d'immobiliser la production). Mais eux-mêmes sentent peut être l'utilité de consolider les avantages acquis «par en bas »; de là leur participation à des grèves de solidarité, où il s'agit d'appuyer les revendications de camarades moins qualifiés; delà vient même qu'ils acceptent des unifications de salaires qui semblent consacrer le principe « à travail inégal (en qualité), salaire égal ».

Par exemple, dans le textile, Brotherton dit : « Les ouvriers du textile anglais, dans presque toutes les branches de l'industrie du coton... comptent parmi les aristocrates du trade-unionisme... Aujourd'hui, dans toutes les régions où s'est étendue l'industrie textile en Angleterre, on trouve les signes les plus évidents de prospérité économique et sociale... Les ouvriers textiles n'auront peutêtre jamais une position plus favorable que celle qu'ils occupent aujourd'hui. » (Revue syndicaliste, mai 1901.) Il indique, dans la branche filature, un salaire moyen de 50 francs par semaine. M. Ch. Benoist indique, en France, dans une usine du coton à Armentières, comme salaire moyen par jour: pour les fileurs (chefs d'équipe), 6 fr. 50 à 7 fr. 40 ; pour les rattacheurs, 3 fr. 60 à 4 francs; dans une usine du coton dans les Vosges : pour les fileurs, 5 francs à 5 fr. 25, pour les rattacheurs, 3 fr. 25 à. 3 fr. 50 (1905). Dans les filatures de laine, à Reims, les salaires étaient, pour les fileurs, 5 francs, pour les rattacheurs, 3 francs à 3 fr. 50 (d'après le secrétaire de la Bourse du travail, en 1909).

38 Contre les femmes : en 1898, dans un congrès corporatif, un délégué déclarait : « la Fédération typographique n'admet pas les femmes dans les syndicats, et il serait à désirer que toutes les Fédérations qui sont assez fortes en fassent autant ». Contre les étrangers : si les ouvriers de San Francisco se sont opposés à l'immigration des Chinois et des Japonais, c'est qu'ils ont eu peur de leur concurrence. Ils ne pourraient s'opposer de même à une immigration d'ouvriers blancs, bien que le niveau de ceux-ci risque d'être très inférieur au leur. Autrefois, en Angleterre (maintenant en Amérique) c'étaient surtout les ouvriers qualifiés qui se groupaient en Trade-Unions pour exclure de leur profession les non-affiliés, et maintenir ainsi les hauts salaires. Telle est aussi la raison principale de leur attachement tenace à l'institution désuète qu'est l'apprentissage.

« Lorsque l'ouvrier de métier à côté duquel le manœuvre travaille appartient aux catégories de ces ouvriers de choix qui sont le mieux rétribués, il est sûr qu'un plus haut salaire de l'ouvrier de métier peut toujours entraîner quelque peu vers la hausse celui du manœuvre. ».(Cornélissen, ouvrage cité). 
Parmi les manœuvres, on ne remarque aucun sentiment d'hostilité et d'envie à l'égard de l'élite ouvrière. Peut-être cela tient-il à ce que tous ces travaux sont manuels, à ce qu'il n'y a, dès lors, des uns aux autres, que des différences de degré. Peut-être les manœuvres comprennent-ils qu'ils ne pourraient pas se substituer purement et simplement aux ouvriers qualifiés. Car ils peuvent comparer les travaux, apprécier leurs difficultés. Dès qu'ils ont reconnu la nécessité des diverses opérations productrices, ils ne peuvent envier ceux qui, en étant chargés, les exécutent convenablement. Tout autre est parfois leur appréciation du travail intellectuel. Celui-ci ne se traduit pas en mouvements dans l'espace, il correspond plutôt à une immobilité relative du corps, il est d'ailleurs peu compatible avec le travail matériel. D'autre part, c'est, en général, un travail de direction et de contrôle. Or, si l'aide ou le manœuvre est souvent associé à un ouvrier qualifié, si, par exemple, dans une filature, les rattacheurs et nettoyeurs sont les auxiliaires inférieurs du fileur, c'est moins à un homme qu'à une nécessité technique qu'ils obéissent, et leur chef d'équipe travaille d'ailleurs lui aussi de ses bras. Le travail intellectuel est, au contraire, nettement isolé et distant du travail manuel; l'ouvrier est facilement conduit à interpréter cet isolement comme de l'hostilité et du dédain. C'est parce que la coupure est trop nette en haut, à la limite qui sépare les employés des ouvriers qualifiés, qu'il ne s'en fait pas une autre en bas. Enfin, il y a aussi un intérêt d'amour-propre, pour les ouvriers inférieurs, à ne point reconnaitre leur infériorité, en s'opposant aux ouvriers manuels qui rehaussent le niveau de la profession, mais plutôt à se laisser confondre avec eux en une masse indistincte.

Tout autre pourrait être l'attitude des ouvriers qualifiés, et il s'est présenté des cas où on a pu, en effet, relever chez eux une tendance à constituer une sorte d'aristocratie ouvrière très fermée. Il ne faut pas se guider uniquement ici sur leur tactique, qui a été variable. Les unionistes anglais de la première période tendaient à se séparer des ouvriers non qualifiés, à leur fermer l'accès de leurs métiers, et s'organisaient pour obtenir des avantages propres et, comme des privilèges. Plus tard, ils ont reconnu que la principale force des ouvriers dans la lutte politique était leur nombre, ils ont encouragé et aidé les organisations d'ouvriers non qualifiés, et se sont étroitement rattachés à ceux-ci. Que, dans les congrès et les journaux corporatifs, il n'y ait pas opposition explicite entre les ouvriers qualifiés et les autres cela peut signifier qu'ils ont reconnu l'utilité de s'unir pour la lutte alors même qu'il subsiste entre eux une ligne de démarcation dont ils conservent le sentiment. Par leurs aptitudes, leur apprentissage, leur exercice, les ouvriers qualifiés représentent bien une élite : pourquoi n'en tireraient-ils point quelque orgueil ? Pourquoi le sentiment individuel, qui est en chacun d'eux, de sa supériorité technique, ne se traduirait-il pas, dans leur groupe entier, en un sentiment de classe? - Mais existe t-il un caractère visible et constant où se matérialise cette supériorité ? Il ne s'agit pas ici de la conformation physique : chaque métier modifie à la longue de la même manière le corps de ceux qui l'exercent, et un observateur pourra, à l'aide de ces stigmates corporels, discerner les professions des travailleurs de façon approximative. Mais ces stigmates ne se peuvent point classer en catégories qui 
correspondraient à la difficulté croissante des métiers et à l'accroissement des aptitudes des ouvriers. Il n'y a pas ici de déformations abjectes ou nobles. - C'est dans l'objet du travail, dans le produit, que se révèle la supériorité technique d'un ouvrier; mais elle n'apparaît que pour disparaître, parce que le produit se perd aussitôt dans la masse des autres, parce qu'à la façon qui vient de lui être donnée d'autres s'ajoutent aussitôt, et qu'il n'est plus possible de reconnaître, dans le résultat d'une œuvre collective, ce qui doit être attribué à tel ou tel. L'artiste et l'ingénieur, alors qu'ils travaillent en collaboration avec d'autres, mettent quand même dans leur œuvre la marque de leur personnalité : leur travail, la partie du travail total dont ils ont été chargés, subsiste distincte, avec ses qualités et ses défauts propres; chacun d'eux, dans de certaines limites, peut faire preuve d'initiative, et, par ses innovations, déterminer une refonte partielle de l'ensemble. Il n'en est pas de même de l'ouvrier qualifié : celui-ci n'a pas à remplir une partie de la toile, en s'inspirant à la fois de l'ensemble et de ses propres pensées ; il doit plutôt tracer certains traits compliqués, poser des touches délicates, qui ne vaudront que par leurs rapports aux autres, qui se fondront dans le reste, et sur lesquels, bien que peut-être ils représentent la partie la plus difficile de l'œuvre, l'attention ne se portera pas. Ce caractère impersonnel de son travail rabaisse l'artisan d'élite au niveau du simple ouvrier. Précisément parce que dans le produit rien ne subsiste qui évoque une personnalité, on se figure que tout en pourrait être effectué par des procédés mécaniques ou par un travail humain machinal et simple, de même que le travail de l'ancien artisan presque artiste s'est décomposé en opérations monotones et faciles. Les conditions de leur travail dans l'industrie moderne déterminent cette appréciation des ouvriers qualifiés ; et, sans doute, eux-mêmes ne se jugent pas autrement. Eux aussi sentent combien est profond le fossé qui les sépare des nonouvriers, et par combien de traits ils se rapprochent des manœuvres, aides et ouvriers non qualifiés, qui travaillent à leurs côtés.

Ainsi, la division du travail et la réunion des travaux, loin de fonder des séparations entre les groupes divers d'ouvriers, tendent plutôt à effacer entre eux toutes distinctions. Le groupement des ouvriers autour de tels ensembles de machines, la mise en rapport de leurs activités pour une production complexe, ne correspond pas à autant de représentations collectives ou de classes ; elle leur fait plutôt prendre mieux conscience à tous de leur isolement en face des forces matérielles. La division des ouvriers en manœuvres chargés de servir les machines et ouvriers qualifiés chargés de les construire ou de les suppléer, qui résulte du progrès de la division du travail, n'entraîne pas une division de l'ensemble des ouvriers en deux classes superposées; elle met plutôt mieux en lumière la nécessité, pour tous les ouvriers qui collaborent à la production, de renoncer à toute initiative personnelle et de s'identifier à des mécanismes partiels sans valeur indépendante. 
Mais toute cette analyse des conditions techniques du travail et de leurs conséquences sociales porte sur la grande industrie. Vaut-elle pour la petite industrie, qui n'est pas une survivance, qui a gagné du terrain sur beaucoup de points, et qui constitue peut-être une pièce nécessaire du système économique moderne ? - Pour étudier la petite industrie, on se reporte volontiers au temps où elle était la plus développée, sous le régime de la production artisane. Il semble qu'alors le travailleur, en même temps, ait eu plus d'indépendance (comme travailleur) et se soit trouvé conduit, à l'occasion de son travail, à envisager plus souvent les hommes, leurs besoins et leur activité. Pour Sombart, c'est bien dans l'attitude morale et dans les dispositions psychologiques des artisans qu'il faut chercher le principe distinctif du métier (Handwerk). Or, l'artisan tiendrait surtout à son indépendance ${ }^{40}$. Le travailleur de métier se suffit à lui-même; il n'est pas artiste (ce sont les artistes de la Renaissance qui se sont fait artisans, et non l'inverse), mais, comme l'artiste, il doit posséder, outre les facultés techniques, une conception d'ensemble de l'œuvre. Sans être non plus un savant au sens moderne, il lui faut les connaissances nécessaires pour la production et pour la tradition du pouvoir productif, ce qui est comme une culture intégrale. Des aptitudes personnelles, naturelles ou acquises, des procédés qui se transmettent, entre lesquels on choisit, qu'on améliore, voilà ce qui passe au premier plan, et non plus le sentiment qu'on n'est qu'une chose, qu'un rouage dont la place et le jeu sont immuables.

D'autre part, pour l'accomplissement même de son travail, l'artisan entre en rapports fréquents avec des hommes dont il ne se borne pas à recevoir et exécuter les ordres. Il propose au client, et, sans doute, il ne lui impose pas, mais il lui conseille telles modifications, tels perfectionnements, dont celui-ci pourrait ne pas avoir l'idée et auxquels l'artisan a pensé au cours de son travail. Entre le maître et le compagnon, il n'y a pas que des rapports de subordination. Celui-ci, parce qu'il travaille aux côtés de l'autre, et parce que la qualité du produit les préoccupe parfois plus et toujours autant que leur quantité, peut, à chaque moment, le consulter, lui suggérer des tentatives, discuter ses conceptions. Entre le travail de l'artisan et celui de l'ouvrier moderne, envisagés dans leur technique seule, il y aurait donc une différence grande : aux démarches matérielles de celui-là se mêleraient toutes sortes de représentations humaines; il $\mathrm{y}$ aurait chez lui plus d'initiative, moins de mécanisme : entre lui et ceux qui exercent des professions commerciales ou même libérales, il n'y aurait pas une ligne nette de démarcation.

Mais, d'abord, la description de Sombart ne s'applique qu'aux cas où, sous un régime non capitaliste, la petite industrie est pratiquée. Même sous le régime corporatif, et avant l'introduction des machines, on trouve une grande industrie dans laquelle

Sombart (Werner). Der moderne Kapitalismus. Leipzig, $1902\left(1^{\mathrm{er}}\right.$ Band, die Genesis des Kapitalismus $1^{\text {er }}$ livre et fin du $2^{\mathrm{e}}$ ). 
l'ouvrier perd une large part de son indépendance. L'étude de M. Doren sur la grande industrie drapière à Florence aux $\mathrm{XIV}^{\mathrm{e}}$ et $\mathrm{XV}^{\mathrm{e}}$ siècles a mis bien en lumière ce point. La corporation y a perdu son caractère primitif, pour devenir un organe d'exploitation, d'administration et de réglementation, au service des grands patrons associés. Les ouvriers ne pouvaient travailler que pour les membres de la corporation; elle les tenait à sa merci, par les prêts de capital, d'instruments et de matières premières, et leur imposait ses tarifs de salaires. Or, si c'est là peut-être un phénomène exceptionnel au moyen âge, il faut reconnaître que maintenant la production artisane indépendante n'est bien souvent qu'une apparence, et que les petits producteurs sont, en grand nombre, dans la dépendance sinon légale, du moins effective, de capitalistes et commerçants plus ou moins groupés.

Peu importe qu'ils se rattachent ou ne se rattachent pas à une entreprise centrale ; par suite de la facilité plus grande des relations, et de la multiplication des entreprises similaires, il s'établit un niveau moyen des salaires et des prix que tous les petits entrepreneurs doivent accepter. La petite production artisane ne subsiste plus que dans les régions et dans les branches d'industrie les plus arriérées ; tantôt le client n'est pas au courant des prix, ne sait pas où s'adresser ailleurs; tantôt il n'y a pas avantage pour de gros entrepreneurs à intervenir, et, en organisant la production, à faire la loi aux petits industriels ; tantôt encore la demande est très éparpillée, ou le travail à la main conserve une supériorité incontestable. Partout ailleurs, dès qu'un niveau des salaires et des prix s'est établi, il faut bien que l'artisan se plie à ces lois générales, fixe en conséquence la durée et l'intensité de son travail, s'astreigne à produire les articles de prix courant qui sont les plus demandés : il renonce, alors, à ces avantages d'indépendance, à ces possibilités de fantaisie, qui distinguaient la technique de son travail.

Les conditions où il s'acquitte de sa tâche s'identifient de plus en plus avec celles où les ouvriers opèrent dans la grande industrie : ce n'est point dans les conditions techniques du travail artisan qu'on pourrait trouver l'origine de représentations de classes distinctives. 


\section{III \\ La notion de salarié}

$\underline{\text { Retour à la table des matières }}$

Ne nous occupons plus de la technique. Considérons les ouvriers dans leurs rapports avec ceux qui leur donnent des ordres ou leur font des commandes. Si l'esclave pour son maître, l'artisan pour le client, le travailleur libre pour l'entrepreneur, le travailleur à domicile pour le grand magasin s'acquittent d'un même travail en de mêmes conditions de temps, de difficulté, de technique, ils ne sont pas cependant dans une situation juridique comparable, et ils s'en rendent compte. Voici tout un autre ensemble de représentations, nettement sociales, qui pourraient varier suivant les conditions, et devenir les centres distincts de plusieurs consciences collectives, où s'éparpillerait la conscience de la classe ouvrière.

Suivant que les ouvriers travaillent directement pour une clientèle, ou pour des entrepreneurs, et, encore, pour de gros, de moyens ou de petits entrepreneurs, pour des sociétés par actions, pour des magasins publics (et bien d'autres modalités sont concevables), se représenteront-ils de même le groupe ou les personnes de ceux qui les emploient, éprouveront-ils pour eux les mêmes sentiments? Souvent il y a peu de distance de l'ouvrier au patron, surtout lorsque l'ouvrier peut à l'occasion devenir luimême entrepreneur. On a noté que, dans le travail à domicile, comme les employeurs ont avantage à n'entrer en relations qu'avec un petit nombre d'ouvriers, ils leur font de grosses commandes : l'ouvrier alors devient lui-même un sous-entrepreneur. Mais, très exploité lui-même, il peut difficilement exploiter à son tour ceux qu'il emploie, et ne doit point leur apparaître sous les traits d'un homme d'une autre classe. Dans la petite industrie indépendante, il se trouve encore que l'ouvrier espère à la longue s'établir (petit horloger, serrurier, etc.). Ici, les conditions sont assez spéciales. L'employeur est parfois le maître, chez qui on apprend le métier pour aller ensuite l'exercer ailleurs, de préférence dans la grande industrie. Parfois (plus rarement) la vieille relation du compagnon au maître subsiste, le compagnon devant devenir maître à son tour. Le plus souvent, l'ouvrier restera ouvrier, mais comme le patron travaille à ses côtés et comme lui, que, d'ailleurs, le nombre des ouvriers est très limité, des rapports plus 
familiers s'établissent de l'un aux autres, comme entre le petit fermier et ceux qui l'aident à la culture. Dès que les ouvriers sont au service d'hommes qui ne travaillent pas eux-mêmes de leurs mains, leur attitude ne doit-elle pas changer? Les voilà en présence non plus d'artisans qui ont eu plus de chance ou d'habileté que les autres, mais que leur genre de vie et leurs occupations habituelles rapprochent des ouvriers : le patron appartient à un groupe social tout autre, où ils n'ont ni l'espoir, ni l'idée de pénétrer. Tantôt, on le connaîtra, et, soit par la surveillance personnelle qu'il exerce sur le travail, soit par son âpreté dans les discussions d'intérêts, soit par sa bienveillance et son humanité, il apparaîtra du moins à ses ouvriers comme un individu, pour lequel on peut éprouver des sentiments définis. Parfois le directeur sera lui-même un employé, au service d'un grand industriel, et qui n'a pas toute la responsabilité de la conduite qu'il tient. Mais, à la place du grand industriel toujours invisible, l'ouvrier pourra se représenter aussi un groupe de sociétaires plus invisibles encore, ou une multitude d'actionnaires. L'on exprime quelquefois cela en comparant, à l'autorité patriarcale du patron d'autrefois, la puissance anonyme du capital d'aujourd'hui. - Sans doute, les sentiments individuels ou particuliers qu'Inspirent aux employés les employeurs sont très variables. L'on trouvera dans la petite production artisane des petits patrons d'autant plus rapaces qu'ils ont eu de la peine à s'élever à ce niveau social, si bien que leurs ouvriers les détesteront plus encore que des patrons nettement bourgeois. Inversement, entre des groupes capitalistes et des collectivités ouvrières, surtout en période d'essor industriel dans les branches concernées, en particulier dans les pays où les employeurs prennent l'initiative de stimuler par des accroissements de salaire l'effort productif des ouvriers (au lieu de se les laisser imposer), des relations amicales peuvent s'établir, surtout si les deux groupes comprennent que leur entente momentanée est pour eux le seul moyen de profiter vite des circonstances exceptionnelles. Sans doute, encore, ce sont là des réactions collectives passagères, et limitées à des groupes restreints. Il n'y a pas de raisons pour que l'une d'elles s'impose durablement à tous les groupes d'une catégorie, pour que tous les artisans, tous les ouvriers de la petite industrie, tous ceux de la grande, tous les employés des sociétés anonymes s'organisent en autant de groupes distincts qu'il y a de régimes de la production. - En tout cas, de tels groupements embryonnaires apparaîtraient si ne se dégageait pas, dans la conscience de la classe ouvrière, sous une forme universelle, la situation caractéristique, où ils se trouvent tous, de salarié.

Mais qu'est-ce que le salaire, pour les ouvriers qui le reçoivent? Admettons que la production artisane ou la petite production, pour subsister dans un système économique où de plus en plus la grande industrie domine, ait dû se plier et s'adapter aux conditions créées par celle-ci. Non seulement sa technique (comme nous l'avons vu) en a été transformée, mais la relation de l'ouvrier à l'employeur a cessé elle aussi d'être le rapport traditionnel du compagnon au maître, pour s'identifier de plus en plus à ce 
qu'elle est dans les grandes usines; le taux du salaire des artisans et ses variations dépendent du taux des salaires dans la grande industrie.

Mais, dans la grande industrie, le salaire est arrêté (il ne s'agit pas ici des lois naturelles qui le déterminent) suivant des règles diverses, à l'intérieur de chaque branche. Dans les mines, «les ouvriers véritablement producteurs, c'est-à-dire les ouvriers occupés à l'abatage du charbon et au creusement des voies, sont payés " aux pièces ", la pièce étant, suivant les cas, ou la quantité de charbon extrait ou le mètre d'avancement de la galerie creusée. Les « ouvriers à l'entretien » sont le plus souvent payés à la journée ; il en est cependant qui sont payés «aux pièces », comme les ouvriers producteurs, quand ils ont à exécuter un travail régulier et de quelque durée ${ }^{41}$. Dans la métallurgie, ces deux manières d'établir les salaires se mêlent de façon très variable. Dans telle usine, « le personnel entier des aciéries est à la tâche ; il en est de même du personnel des fours, sauf les déchargeurs de lingots, qui sont à la journée; à la fonderie, tout le monde travaille à la journée; au puddlage, les maîtres puddleurs, leurs aides, les troisièmes ou rouleurs de boules, les cingleurs, les lamineurs, les rouleurs de fonte, les casseurs de fer sont à la tâche ; le peseur, le machiniste et le pointeur sont à la journée, etc. ». Dans le textile, les soigneuses, fileurs, rattacheurs sont payés d'ordinaire à la journée, ainsi que les ourdisseuses ; les noueuses, rentreuses, les tisseurs, à la tâche,: souvent, les soigneuses (qui surveillent les machines) sont elles-mêmes, payées aux pièces, suivant les conditions et tarifs établis, au moyen de compteurs mécaniques qui mesurent la quantité de travail ou de matière fabriquée: En somme, et à travers une quantité de modalités, les deux types essentiels de rémunération sont bien au temps et aux pièces.

Or, il peut sembler que le travail aux pièces laisse à l'ouvrier deux libertés, la liberté d'accroître (ou de limiter) son gain, d'augmenter (ou de diminuer) l'intensité de son travail, et que le travail au temps ne lui laisse que la deuxième. Dans la mine, en particulier, le prix de la berline est débattu, pour chaque taille, entre le chef de taille et le porion ou le chef porion, qui, ici, représente les employeurs ou leurs délégués (ingénieurs, etc.); on tient compte de la puissance probable de la couche, on traite à forfait pour l'emploi de la dynamite. En faut-il conclure qu' « une assez grande marge est laissée à la volonté, à l'intelligence, à l'activité de l'ouvrier » et qu'il est maître, dans une assez large mesure, d'élever son salaire ${ }^{42}$ ?

Mais on sait que, dans nombre de métiers, les ouvriers sont hostiles au travail aux pièces, et on en voit bien la raison. Quand le salaire est au temps, rien ne prouve au patron que l'ouvrier donne tout l'effort dont il est capable, surtout quand la technique ou l'organisation du travail vient d'être transformée. Instituant le travail aux pièces, ils

Charles Benoist, livre cité.

Benoist, livre cité, p. 220. 
stimulent l'ouvrier, qui va jusqu'à la limite de ses forces pour accroître son gain : une fois cette expérience effectuée, rien n'empêche le patron soit de rétablir le travail au temps, et d'avertir ou de renvoyer ceux qui n'adoptent pas le rythme de travail qui a été reconnu possible, soit, en maintenant le travail aux pièces, d'abaisser le salaire à l'unité, de façon à ce qu'en moyenne le salaire reçu par l'ouvrier soit le même que quand il travaillait au temps. Entre le salaire au temps et aux pièces, la différence serait donc de surface. Le travail au temps implique un minimum d'intensité de travail, et le travail aux pièces un maximum de salaire journalier que l'ouvrier ne dépassera pas ${ }^{43}$. Voilà ce que savent bien les ouvriers. Cela permet de confondre, au point de vue de l'appréciation qu'ils en portent, ces deux modes principaux de rémunération du travail et de définir un premier aspect, négatif il est vrai, du salaire tel qu'il est représenté dans la conscience de leur classe.

L'échange du travail contre un salaire ne ressemble en rien à une opération commerciale. On parle souvent de marché du travail, et on considère couramment le travail comme une marchandise qui a une valeur et un prix. Marx disait que l'ouvrier vend sa force de travail au patron. Malgré tout, l'ouvrier ne peut pas s'assimiler à un commerçant. Supposons qu'un esclave qui vient d'acheter la liberté moyennant une somme d'argent se revende à un autre maître pour une somme moins ou plus élevée : il fera une mauvaise ou une bonne affaire. Mais le travailleur qui vend (si on veut) au patron une quantité de travail donnée n'a pas acheté cette quantité de travail, ne peut donc pas en assigner le prix pour lui. Les Webb ${ }^{44}$ font justement remarquer que, dans toute la série des opérations industrielles et commerciales, le vendeur est, en principe, dans une situation d'infériorité par rapport à l'acheteur qui peut attendre et d'ailleurs connaît mieux les conditions du marché. Or, tandis que le commerçant au détail, le commerçant en gros, le commissionnaire, l'industriel sont tour à tour acheteurs et vendeurs, tandis que le client du premier n'est qu'acheteur, l'ouvrier, lui, n'est que vendeur. Quand l'industriel lui demande son travail pour un prix donné, il, ne peut pas se retourner vers quelque autre et lui demander: combien vous ai-je payé ce produit ou ce service, qu'on veut maintenant m'acheter? Il n'est pas exact, d'ailleurs, de dire, comme Marx, qu'il ne sait pas ce qu'il vend, qu'il croit vendre six heures de travail et qu'on lui en demandera huit ou douze. Sans doute le patron a bien des moyens

Schloss (David), les Modes de rémunération du travail, $3^{\mathrm{e}}$ édition. Traduit par Rist (Charles). Paris, 1902.

44 Webb (Beatrice and Sydney). Industrial democracy. Dans le deuxième chapitre (the higgling of the market, le débat sur le marché), de la troisième partie (Trade Union theory), les auteurs montrent que, dans un régime de libre concurrence et de contrats individuels, le débat sur le marché se décompose en une "chaîne » de marchandages qui mettent en rapports "the manual worker, the capitalist employer, the wholesale trader, the shopkeeper and the customer ». Les deux infériorités essentielles de l'ouvrier, dans son débat avec le capitaliste, sont: $1^{\circ}$ que, tandis que le capitaliste risque seulement de voir diminuer d'une fraction son profit annuel, (l'ouvrier risque la faim ; $2^{\circ}$ que l'employeur connaît la position de l'ouvrier ses besoins), tandis que l'ouvrier ignore celle de l'employeur. P. 654 sqq. 
d'entraîner l'ouvrier, en dehors du travail aux pièces, ou des primes, et, par exemple, par une simple organisation technique différente, en augmentant le nombre ou la rapidité des machines qu'il faut surveiller, peut accroître insensiblement l'intensité de son effort. Mais comme l'ouvrier peut de son côté, à chaque instant, dénoncer le contrat de travail, on ne peut nier qu'il ne connaisse la « valeur d'usage » du service qu'il vend.

Nous convenons volontiers de ceci que le travail a un prix courant, à chaque époque et en chaque région; mais il ne suffit pas qu'il y ait un marché du travail pour que la vente de travail soit un acte de commerce. Les produits présentés sur un marché commercial le sont à un prix différent de celui qu'ils ont coûté au vendeur ${ }^{45}$ : c'est donc sur le marché même, par la vente elle-même, que le bénéfice commercial se réalise. Au contraire, il n'y a qu'un prix pour le travail ; et si un «travailleur » peut réaliser un « bénéfice », c'est seulement soit en s'éloignant du marché, en s'adressant à des clients (ici, soit des clients, soit des patrons) qui ne connaissent pas le prix du marché, soit, sur le marché même, en vendant des produits frelatés ou à faux poids (c'est-à-dire en travaillant mal ou trop lentement), soit, encore, en vendant au-dessous du prix, pour vendre plus et se retirer avec plus d'argent comptant (en travaillant, aux pièces, de façon trop intense), ce qui est «gâter le commerce » et épuiser un stock non indéfiniment renouvelable (force physique). Quant aux opérations qui s'effectuent normalement, sur le marché, elles ne rapportent pas un bénéfice, elles ne sont donc pas de commerce et cela suffit déjà pour distinguer nettement le salaire de beaucoup d'autres modes de rémunération.

Allons plus loin, et demandons-nous s'il y a une représentation sociale, positive cette fois, qui se rapporte au salaire, et soit commune à toute la classe ouvrière. Est-ce celle d'une somme d'argent remise régulièrement à l'ouvrier en échange de son travail, et dont le taux serait fixe au moins pour une période? On ne distinguerait pas alors du salaire les appointements des employés du commerce, de l'industrie, des services publics, les traitements des fonctionnaires, les émoluments et honoraires attachés à l'exercice des professions libérales. L'ouvrier se représente-t-il, en outre, un ou plusieurs principes au nom duquel ou desquels son salaire serait, à chaque moment, déterminé ? Quand un ouvrier entre dans une usine, il se conclut bien, entre lui et son patron, un contrat individuel, mais qui n'est, en réalité, l'objet d'aucune discussion. L'un et l'autre se réfèrent au taux du salaire dans l'usine, pour la profession et à l'époque considérée. Ce taux, d'ailleurs, semble s'être déterminé en dehors d'eux; le salaire est un phénomène social. Comme, d'autre part, nous ne recherchons pas ce que les ouvriers désireraient que le salaire fût, suivant quelle règle ils le voudraient voir

Lorsqu'un cultivateur apporte sur le marché ses produits, la vente n'est un acte de commerce que si elle lui rapporte un bénéfice. Sinon le rapport du cultivateur à l'acheteur n'est pas différent de celui de l'artisan à son client, c'est-à-dire (dans nos sociétés) qu'il revient à la vente de travail au sens où nous l'entendons ici. 
déterminer, peu importe que certains d'entre eux réclament que les salaires soient en rapport avec la difficulté, l'intensité, l'importance de la tâche, ou encore qu'ils réclament le produit intégral de leur travail.

Toutefois, si l'ouvrier accepte ainsi sans mot dire le salaire en vigueur quand il entre à l'usine, une fois qu'il se retrouve au milieu de la collectivité ouvrière, il participe à ses revendications et à ses démarches. Or c'est aux moments où les ouvriers réclament un relèvement des salaires, et le réclament avec assez d'ensemble et de vigueur pour l'obtenir, qu'on aperçoit et qu'ils comprennent eux-mêmes le plus clairement ce;qu'il est pour eux ${ }^{46}$. - Les motifs invoqués pour réclamer une augmentation des salaires sont variés. Le plus général sans doute, celui qui est toujours plus ou moins sous-entendu, c'est l'accroissement du prix de la vie; mais précisément parce qu'il est vague, parce qu'il n'intervient pas plutôt à certaines époques qu'à d'autres, ce n'est pas celui qui détermine la revendication. On cherche un prétexte ou une occasion plus précise, par exemple une prospérité exceptionnelle ou une simple hausse des prix dans l'industrie (dans les mines du Pas-de-Calais, après la grève de 1889, prime de 10 0/0, portée en 1899 à 25 0/0, en 1900 à 30 0/0, en 1901 à 40 0/0, à la suite de la hausse de la houille). Ou, encore, on invoquera les salaires plus élevés payés dans la même industrie, en une autre région, et on réclamera l'unification des salaires : c'est ce qu'on essaie de réaliser quelquefois par l'institution de contrats collectifs appliqués à toute une industrie.

Qu'est-ce à dire, si ce n'est que les ouvriers reprochent alors au patron et tâchent de l'empêcher de les léser de deux façons : il veut profiter seul d'un accroissement des prix non prévu, et dont ils veulent profiter aussi ; et il veut profiter d'une différence interrégionale de salaires qui est à leur désavantage, et qu'ils ne veulent plus supporter dès qu'ils la connaissent. Mais cela prouve qu'il y a pour eux un rapport certain entre le taux du salaire et le prix. Indépendamment de toute question d'équité, puisque, quand les prix haussent, ils réclament et obtiennent que les salaires haussent, c'est qu'ils croient que le salaire peut varier avec le prix, que sa limite possible se déplace dans un certain rapport avec lui. Et puisqu'ils réclament que les salaires soient les mêmes dans toute la profession, c'est que, pour eux, ce rapport implique que, de même qu'il y a un niveau commun des prix, il doit y avoir un niveau commun des salaires.

46 M. Simiand (François) a montré, en discutant l'introduction mise par M. Rist en tête de la traduction du livre de Schloss cité ci-dessus (Année Sociologique, $6^{\mathrm{e}}$ année, 1903, p. 501 sqq.), que si les ouvriers, lorsque les salaires sont menacés d'une réduction, invoquent la règle « à travail égal, salaire égal », cette règle est surtout pour eux un principe de défense intéressée. Sans doute, il y a, derrière leur résistance, une conception de ce qui est juste pour eux ; " c'est que le salaire ne baisse pas pour des causes indépendantes de l'individu, c'est pour chacun le droit au même salaire aujourd'hui qu'hier pour le même travail... » Ce n'est donc pas à ces moments, où les ouvriers invoquent des raisons de justice, ou se retranchent derrière leur intérêt, où ils manifestent comment ils trouvent juste que, ou ils veulent que le salaire soit établi, qu'il faut rechercher comment ils pensent que le salaire est établi en fait. C'est aux périodes de hausse. 
On retrouverait donc, en toutes ces représentations collectives du salaire, l'idée d'un rapport quantitatif entre deux choses, dont l'une, le prix, est une quantité, dont l'autre, le travail, doit être aussi une quantité. Maintenant, est-il possible, et est-il d'ailleurs utile ou nécessaire d'aller plus loin; et de supposer, dans la conscience ouvrière, une représentation formelle de cette dernière quantité (le travail) elle-même ? Remarquons qu'il s'agit, ici, uniquement de représentations, c'est-à-dire d'opinions et de croyances. Peu importe le fond des choses ; peu importe que le travail soit réellement, en soi, une quantité. Le travail est loin d'être une substance homogène. Laissons de côté la difficulté de comparer quantitativement les travaux des métiers différents ; mais l'heure de travail du milieu, ou de la fin de la journée, de la fin de la semaine, n'est pas la même que celle du début ; et, suivant l'âge, suivant la région, le climat, la saison, etc., le travail n'est pas non plus le même. Parler, comme Marx, de la quantité de travail socialement nécessaire pour effectuer tel objet, s'efforcer de mesurer tous les travaux à l'aide d'une unité, en temps de travail, c'est construire une théorie qu'il ne sera jamais possible de vérifier, et qui ne rejoindra jamais la réalité. Mais, nous le répétons, peu importe que le travail soit, ou non, une quantité. Il suffit que la pensée sociale puisse se représenter qu'il est tel, qu'elle puisse par conséquent le mesurer (fûtce au prix d'une illusion, et à l'aide de conventions très arbitraires). L'établissement de tarifs de salaire, leur fixité relative, l'idée que les salaires doivent hausser quand les prix haussent, et le principe de l'unification des salaires sont autant de preuves qu'elle le peut.

Or, cette représentation collective, qui s'impose aux membres de la classe ouvrière, leur fait prendre peut-être le mieux conscience de ce qui les distingue des employés et fonctionnaires, et de ce qui les oppose aux patrons, comme classe. Leur travail étant considéré (à tort ou raison) comme une pure quantité, ils sentent que leur personne alors ne compte pas, qu'elle est aisément remplaçable, et qu'eux-mêmes deviennent des unités dont ni l'âge, ni les qualités, ni les dispositions et sentiments n'importent. Il en est autrement des employés et fonctionnaires ${ }^{47}$. Sans doute les traitements et émolu-

C'est dire que nous n'acceptons pas la thèse ainsi formulée par M. Bourguin: «Ce n'est pas la condition de salarié qui fait le prolétaire, c'est la faiblesse de la rémunération et la précarité de l'existence. L'ébéniste de la trôle qui travaille sans engagement et pour son propre compte, le vannier qui colporte ses produits, les travailleurs ambulants qui exercent les petits métiers de la rue, ne sont, malgré leur situation indépendante, que des prolétaires; et il en est parfois de même pour le professeur, le médecin, l'agent d'affaires insuffisamment occupés et rémunérés. En revanche, le mécanicien de précision et l'ouvrier ciseleur bien payés, le fonctionnaire public et l'employé de commerce qui reçoivent des appointements réguliers, sont de véritables salariés sans être des prolétaires. " (Les systèmes socialistes et l'évolution économique, p. 194. Si prolétaire signifie pauvre, d'accord. Mais l'auteur nous paraît prendre le terme salarié en un sens à la fois trop étroit (car, pour nous, les travailleurs « indépendants » qu'il mentionne reçoivent en réalité un salaire), et trop large (car, comme nous tentons de le démontrer, il y a une différence radicale entre un salaire et un traitement). 
ments sont établis en vertu de règles générales. Mais celle qui domine les autres est qu'à mesure que les employés et fonctionnaires avancent en âge, de toute façon leur situation s'améliore, alors même que leur travail et leurs responsabilités ne s'accroissent pas. Ce qu'on rémunère, est-ce le travail effectivement fourni, est-ce la présence ? Tout se passe comme si l'employé se trouvait intéressé de plus en plus dans l'entreprise ou le service dont il fait partie, et voyait en même temps grandir la part qui lui est attribuée des gains totaux. Il importe qu'on se l'attache, qu'il s'établisse un lien de solidarité entre lui et la maison, et il importe aussi qu'il se pénètre peu à peu de traditions et comme d'un esprit sans lesquels l'entreprise manquerait d'unité et de continuité. Ainsi, et malgré qu'à certains instants de surtravail, ou de stagnation, ils puissent se considérer comme des machines, le plus souvent ils admettent qu'entre eux et leurs chefs les rapports sont réellement personnels ceux-ci le savent bien, et ne manquent pas à l'occasion de faire vibrer la corde sentimentale.

Les ouvriers ne peuvent céder à la même illusion. Bien que quelques patrons, quelques grandes compagnies aient prévu des secours, des indemnités, des retraites pour les ouvriers âgés, bien qu'ils se soient efforcés d'attacher à l'usine les ouvriers par l'institution de maisons ouvrières, ceux-ci ou bien n'ont pas attribué d'importance à ces œuvres, ou s'en sont défiés. Ils savent bien qu'il n'est tenu aucun compte du temps qu'ils ont passé à l'usine, ou dans la profession, que la même quantité de travail, qu'elle soit fournie par l'ouvrier âgé ou jeune, est payée de même, et qu'on remplace sans aucun regret et sans forme un vieux travailleur par un étranger. Non seulement le temps n'ajoute pas à leur valeur pour l'employeur ; leur application et leur habileté ne leur procurent pas un traitement de faveur, une sorte d'avancement au choix. Que le salaire soit au temps ou aux pièces, l'essentiel reste qu'une quantité donnée de produits soit journellement livrée, et que ces produits soient conformes à tels types; l'essentiel est qu'ils soient acceptés. S'ils sont en deçà, l'ouvrier est passible d'amendes ou de réductions de salaires; s'ils sont au delà, s'ils sont plus achevés, mieux soignés, l'ouvrier n'est ni mieux payé, ni félicité. Or, pour les employés et fonctionnaires, les gratifications, augmentations extraordinaires, avancements au choix sont prévus pour récompenser les " excès de zèle ", les services exceptionnels non imposés, les succès sur lesquels on pouvait ne pas compter. C'est que là, dans les services, administrations et bureaux, tout ne se fait pas mécaniquement, les chefs peuvent redouter que s'y introduisent la routine et l'inertie. Il y faut une discipline et une régularité qui n'est pas aussi facile à obtenir que dans l'usine, où les bras sont bien forcés de se plier au rythme et aux mouvements des machines, qui doit être voulue, spontanément poursuivie; il y faut une attention en éveil sur les imperfections, sur les simplifications, sur les solutions aux cas difficiles, qui ne se commande pas, et dont on ne constate pas aussi vite l'absence que la rouille sur un rouage qui grince, ou la malfaçon sur un produit que le client refuse. C'est pourquoi on propose comme modèles et on récompense ceux dont l'activité a été en apparence la plus désintéressée, et le travail, même 
inutile, mais qui dénote une tenace bonne volonté. Presque tous les contremaîtres ont sous ce rapport une mentalité d'employés.

En même temps, les ouvriers sentent que leurs patrons tirent avantage de ce que leur travail est ainsi envisagé comme une quantité : cela leur permet, comme les marchands sur ces autres quantités que sont les prix, de spéculer sur celle-ci. Les patrons de l'industrie ne font pas toujours du commerce ; mais, quand ils en font, c'est sur les différences de salaires, bien plus que sur les différences de prix, qu'ils spéculent. Spéculer, c'est toujours profiter d'un manque d'adaptation, de correspondance exacte, entre les besoins, les tendances, les opinions de deux groupes ${ }^{48}$. Dans le cas du commerce de détail et de gros, c'est évident; si les clients, ou les petits commerçants entraient en rapports directs avec le producteur, les bénéfices du gros commerce s'évanouiraient. Mais il ne faut pas croire que le déséquilibre dont profitent les gros commerçants soit leur œuvre, soit artificiel. Il est dans la nature des choses, ici, dans la nature collective des représentations qui sont ainsi mises en rapport indirectement, et qui se trouvent d'emblée en désaccord. Les commerçants au détail sont trop occupés de leur clientèle, et les industriels de leur production et de leurs ouvriers, pour qu'ils soient capables de rester en contact, et de se réadapter perpétuellement les uns aux autres. Sous ce rapport, il se développe en eux, en tout ce qui touche leurs relations, une attitude plutôt passive ; les uns et les autres ont tendance à admettre et à accepter les prix des commerçants en gros ; en tout cas, si ceux-ci doivent accepter une loi, c'est plutôt celle des détaillants, qui sont acheteurs, que celle des industriels, qui ne sont que vendeurs. Toutefois les industriels, parce qu'ils sont quand même cultivés, avertis, et qu'ils ne forment pas un groupe très intégré, échappent dans une large mesure à cette force d'inertie. Sans doute leur fonction propre n'est pas de fixer les prix ; mais il suffit que quelques-uns d'entre eux aient l'idée et la force de résister aux prétentions des commerçants, pour qu'ils agissent sur les prix, exactement comme les grands magasins, par où le commerce en gros atteint directement la clientèle, peuvent limiter les exigences des détaillants. En réalité, les ouvriers ne se trompent pas, lorsqu'ils considèrent les industriels aussi comme des spéculateurs. Les industriels, comme les commerçants, ne sont pas des individus isolés; ils forment des groupes. Mais comme leur rôle est de s'adapter sans cesse à des conditions variables, l'influence collective du groupe n'est pas irrésistible, et les individus conservent une grande part d'initiative. Leur fonction veut qu'ils soient souples, qu'ils changent vite leurs appréciations et leur attitude. Entre les collectivités davantage passives, plus difficiles à mettre en marche et modifier que sont les ouvriers d'une part, et le public de l'autre, ils se meuvent plus vite et plus librement.

48 Dans notre livre sur les Expropriations et le prix des terrains à Paris (Paris, 1909), nous avons étudié la nature et le rôle de la spéculation, pp. 17 -21 et pp. 317-389. 
La classe ouvrière en particulier, en raison de la faible culture individuelle de ses membres et de la ressemblance de leur condition, est une masse collective bien plus lourde et inerte. Elle s'habitue à certains taux de salaire, à certaines conditions de travail ${ }^{49}$, et ne réclame une amélioration que sous la pression des circonstances, et encore après quelque temps : c'est de cela que l'employeur petit profiter. Nous avons dit que les ouvriers reconnaissent seulement par intervalles avec une clarté suffisante que le salaire est un rapport entre une quantité de travail et le prix. Cette idée, dès qu'elle est assez répandue et consciente, les détermine à réclamer une augmentation des salaires, alors que leur quantité de travail elle-même n'est pas accrue. Mais, en dehors de ces périodes, leur passivité, leur accoutumance à des conditions déjà anciennes, se traduit plutôt dans le sentiment vague que le salaire est surtout en rapport avec la quantité de travail, qu'il mesure la valeur même de l'effort ouvrier ; c'est pour cela qu'en cas de baisse des prix ils opposent une résistance tenace à tout abaissement des salaires ; c'est pour cela surtout qu'ils ne réclament pas leur augmentation aussitôt que la hausse des prix le permettrait ${ }^{50}$. Sans doute, même alors, ils ne se représentent pas très clairement ce qu'est la quantité de travail. S'ils résistent à un abaissement des salaires, ils consentiront à la rigueur, pour le même salaire, à travailler davantage ; si, au cas d'une diminution de la durée de la journée de travail, ils réclament le maintien du salaire journalier antérieur, ils augmenteront au besoin l'intensité du travail. Cela peut être une tactique; l'ouvrier sent qu'il a eu tant de peine à obtenir ce taux de salaire qu'il s'y attache désespérément. Mais cela peut s'expliquer aussi par la pensée confuse que le salaire représente réellement la valeur du travail, comme une quantité qui lui serait attachée, et qu'il faut empêcher qu'on ne fausse cette valeur, en diminuant le prix de la journée de travail. Dans certains cas, ce sentiment collectif fait obstacle aux desseins patronaux. Mais le plus souvent il lui est avantageux. C'est grâce à ce « conservatisme » ouvrier que le patron peut maintenir quelque temps les salaires à un même taux, malgré la hausse des prix, et ne céder aux revendications ouvrières que quand il a tiré largement parti des circonstances. Sans doute, cela lui est plus ou moins possible : guère dans le cas du petit artisan qui exécute, avec des ouvriers habiles, des produits dont il ne peut leur cacher le prix (mais il s'agit alors d'ouvriers très qualifiés et instruits), le plus dans l'industrie à domicile. Mais, partout où il y a salaire, le salarié, tout en tenant à ce que les salaires soient déterminés, et en réclamant parfois l'établissement de tarifs, sent obscurément que, de cette fixité, le patron peut tirer profit, que

49 M. Simiand (François), sur les expériences analysées dans son livre (le Salaire des ouvriers des mines de charbon en France. Paris, 1907), a établi que les objets poursuivis par les ouvriers (comme les patrons), rangés suivant l'ordre décroissant de leur importance pour eux, sont les suivants : continuer d'avoir un même gain, ne pas augmenter l'effort, avoir un gain plus grand, diminuer l'effort.

Après une enquête très objective sur les conditions de vie des ouvriers en Belgique, M. Rowntree conclut que, si les salaires des ouvriers de l'industrie sont très bas en Belgique (à peu près la moitié de ceux qui sont payés en Angleterre) cela tient à ce que « les ouvriers en général ne font pas assez d'efforts pour obtenir la valeur entière de leur travail. " (Comment diminuer la misère? Études sur la Belgique. Traduction française, Paris, 1911). 
cette façon de « quantifier » le travail est un moyen aussi de le cristalliser, de le réduire à n'être qu'une chose, comme les produits en général, sur laquelle on peut spéculer, et non une réalité vivante et personnelle, une activité humaine qui, à chaque instant, change de valeur.

\section{IV}

$\underline{\text { Retour à la table des matières }}$

Résumons les résultats où nous sommes arrivés. Nous nous demandions si l'on pouvait parler d'une classe ouvrière en général, s'il existait un ensemble de représentations communes à tous les individus ou plutôt à tous les groupes auxquels on applique empiriquement la dénomination d'ouvriers, et si d'autres représentations particulières à certains de ces groupes ne passaient pas au contraire au premier plan et n'étaient pas entre eux un principe de séparation. Envisageant d'abord la nature de l'industrie et comparant sous ce rapport les mines, l'industrie textile, la métallurgie, nous observions que l'idée d'une industrie n'est point liée à la notion d'un rang social défini où s'élèveraient ceux qui y participent, qu'elle ne saurait donc fonder une représentation sociale de classe. Passant au mécanisme et à l'organisation technique de la production industrielle, en particulier aux modes principaux de la division du travail, nous trouvions que là où les diverses activités, les diverses phases du travail sont rattachées le plus étroitement et comme engrenées, cette solidarité technique des opérations s'exprime dans la diversité des métiers, dont chacun comprend tout un ensemble de travaux ainsi enchaînés. Mais, loin de rapprocher, de fondre en un groupe indépendant les ouvriers ainsi mis en rapports, cette liaison mécanique de tâches diverses leur impose de plus en plus l'idée d'une machine où ils ne sont que des rouages, et empêche une conscience collective vivante de se développer en chacun de leurs groupes. Retenant enfin une distinction courante, qui résulte non plus de l'organisation industrielle, mais des aptitudes techniques différentes, en rapport d'ailleurs avec elle, nous remarquions qu'outre la difficulté de tracer une ligne de démarcation précise entre les travaux dits qualifiés et les autres, on ne trouve pas plus chez les manœuvres que chez les ouvriers de métier des sentiments d'hostilité ou d'exclusivisme qui opposeraient leurs deux groupes. 
L'analyse même de ces divers points de vue d'où se peut examiner la fonction des ouvriers nous conduisait à dégager ses traits généraux essentiels : quels que soient les matériaux, l'ouvrier est celui qui, dans et par son travail, ne se trouve en rapports qu'avec la matière et non avec des hommes, reste isolé en face de la nature, se heurte aux seules forces inanimées; l'ouvrier est encore celui dont l'activité doit se plier au rythme des machines, dont les gestes doivent se lier et se conformer à ceux de ses compagnons de labeur, de façon à reproduire le jeu mécanique des machines, comme si on ne pouvait dompter la matière qu'en se soumettant à des lois aussi régulières et impersonnelles que les lois naturelles; l'ouvrier est enfin celui qui, manœuvre ou ouvrier de métier, doit s'abstenir de toute initiative, et viser seulement à devenir ou demeurer un outil sûr et bien adapté à une tâche simple ou complexe, mais toujours monotone.

En somme, tout se passe comme si la société, pour agir sur la matière, imposait aux groupes dont elle se sert alors l'obligation de renoncer, dans leur travail du moins et pendant qu'ils l'exercent, à la vie sociale même et aux liens sociaux qui les unissent, de s'isoler, de s'éparpiller et de se figer, de fixer à ce point leur pensée sur la matière à élaborer, sur la machine à surveiller, sur le moment où intervenir, sur le mouvement à exécuter, que tout ce qui est «humain » et surtout tout social leur devienne, pendant tout ce temps, étranger ${ }^{51}$.

Mais cette définition de l'ouvrier n'est-elle pas individuelle et négative ? On conçoit bien que l'ouvrier, dans l'état d'isolement où il se trouve ainsi d'habitude, durant les intervalles où, sans quitter son travail, il peut vaguement penser et sentir, se représente ce qui lui manque, la vie sociale, le contact d'autres hommes et, soit qu'il en souffre, soit qu'il s'y soit accoutumé, prenne conscience alors de sa situation par rapport à la société, et, plus particulièrement, par rapport à ceux qui lui ressemblent. Mais une représentation n'est sociale que lorsqu'elle est dans l'individu en raison du groupe où il plonge, et qui la lui impose.

Or, ce sentiment d'un manque, d'un isolement pénible, plus ou moins remarqué en tous cas, parce que l'individu est habitué à la société et trouve naturel de vivre au milieu d'elle, est social sans doute par là. On peut dire que la société nous impose, en effet, l'idée qu'il nous est naturel de vivre dans son sein, et que, quand nous en sommes

\footnotetext{
Voici un passage de Xénophon, où l'opposition entre le travail industriel et la vie sociale se trouve fortement marquée. «Texte en grec»-《Les arts appelés mécaniques sont décriés. C'est avec raison que l'opinion publique en fait peu de cas. Ils ruinent le corps des travailleurs et de ceux qui les surveillent, contraints qu'ils sont à demeurer assis, à vivre dans l'ombre, parfois même à séjourner près du feu. Or quand les corps s'efféminent, les âmes s'amollissent. De plus rien ne s'oppose davantage à l'accomplissement de nos devoirs envers nos amis et l'État. Aussi les travailleurs manuels passent pour de mauvais amis, et de lâche défenseurs de la patrie ». Économique, IV.
} 
ainsi extraits et comme arrachés, c'est bien une notion sociale qui est à la base de nos sentiments. Il n'en reste pas moins que ces sentiments peuvent être de forme individuelle ou sociale. Ils seront éprouvés individuellement par l'ouvrier à domicile par exemple, comme par un prisonnier en cellule, par ceux encore qui vont à l'usine et en reviennent sans échanger des réflexions avec des camarades sur les conditions du travail. Ils pourront être éprouvés socialement en d'autres cas, lorsque passeront au premier plan, dans la conscience de l'ouvrier, non plus ses impressions personnelles, nées et mûries dans la solitude morale de l'atelier, mais l'opinion et les idées développées dans son groupe.

Cela nous conduisait à examiner, après l'organisation et la technique du travail ou les rapports des ouvriers avec la matière, leurs relations avec les hommes qui les emploient ou leur condition juridique. Ce nouvel ordre de rapports détermine, en effet, des représentations assurément sociales, puisqu'ils sont l'occasion, pour le groupe, de se confronter avec les autres. Dans la mesure où elles se mêleront à celles-ci, où elles se mêleront aux réflexions communes des groupes intéressés sur leurs rapports avec leurs patrons ou leurs clients, les notions jusqu'ici analysées (notions de technique, d'organisation, d'aptitude, d'industrie, de métier) se trouveront acquérir une valeur sociale.

Y a-t-il une représentation juridique ou sociale commune à tous les ouvriers? Les ouvriers de la grande et de la petite industrie ou de la production artisane ne se laissent pas séparer d'après leur attitude générale vis-à-vis des employeurs. Cette attitude semble dépendre plus des circonstances que de leur situation sous ce rapport. Dans la grande industrie, le mode de fixation du salaire peut varier. Mais il ne faut point penser que le salaire au temps et le salaire aux pièces soient à distinguer, et les ouvriers qui les reçoivent de même, parce que dans le dernier cas la rémunération serait plus exactement proportionnée à l'effort. En réalité, la différence n'est qu'apparente. Dominant toutes ces diversités sans réelle portée, la notion de salarié se détache en pleine lumière dans la conscience de la classe ouvrière; c'en est, proprement, le noyau. Le salaire, disions-nous, se distingue d'abord de tous les gains commerciaux en ce qu'il est relativement fixe, en ce qu'il ne contient pas une partie qui varierait avec les circonstances momentanées, avec l'habileté de spéculation ou la chance de l'intéressé ; parmi tous ceux par lesquels passe le produit avant d'arriver au client, l'ouvrier est le seul à ne point spéculer. Mais ce n'est là qu'une caractéristique négative du salaire. Nous avons constaté qu'aux moments où il demande un relèvement de son salaire, l'ouvrier, ou plutôt la collectivité ouvrière a le sentiment qu'il existe un rapport quantitatif (du reste, pour elle, indéterminé) entre le taux des salaires et le niveau des prix. Elle va plus loin ; elle considère (à tort ou à raison) que le travail lui-même est une quantité, par conséquent une chose homogène, matérielle, indépendante de la personne et des qualités propres de l'ouvrier. 
Par là, la situation de l'ouvrier contraste avec celle de l'employé et du fonctionnaire, comme lui non commerçants, mais dont on rétribue, en même temps que le travail, l'ancienneté de service, le zèle d'occasion, les qualités intellectuelles ou morales. Par là, surtout, elle s'oppose le plus nettement à celle de l'employeur, puisque celui-ci spécule sur les salaires, sur la différence entre les salaires et les prix, entre les salaires dans la même industrie en différentes régions, et que ce qui lui permet ce genre de spéculation, c'est la possibilité de traiter comme une quantité pure le travail ouvrier.

Ainsi les deux parties de notre analyse se rejoignent et se confirment. Nous disions que l'ouvrier, isolé en face des forces matérielles, privé, dans son travail, de tous rapports avec des hommes, n'est pas conduit nécessairement à se représenter sa condition comme un fait social, mais peut s'en tenir à l'envisager pour son propre compte, et du point de vue individuel. Mais la notion du salaire et du salarié que nous avons dégagée est par contre une représentation sociale. Isolé, l'individu ne s'y élèverait pas. Il faut qu'il puisse comparer la situation de son groupe, du groupe des ouvriers, à celle des autres groupes. Or de telles comparaisons ne sont possibles que dans une conscience sociale, et ne peuvent s'exprimer qu'en termes sociaux. - C'est pourquoi la conscience de la classe ouvrière comme classe une n'a pas toujours existé, ne s'est peut-être éveillée qu'assez récemment ${ }^{52}$. Entre les ouvriers des corporations et ceux qu'employait la grande industrie naissante dans les premières manufactures ou encore dans les mines, il ne semble pas qu'il y ait eu la même solidarité qu'aujourd'hui entre les travailleurs des grandes usines et des petites entreprises : leur situation juridique ne leur apparaissait pas équivalente. Les ouvriers des corporations, qui avaient chance de devenir maîtres, à une époque où les relations commerciales, nationales et internationales et le gros commerce étaient moins développés qu'à présent, se sentaient appelés à faire eux-mêmes un jour fonction de commerçants. Leurs qualités personnelles et l'ancienneté de leur présence à l'atelier n'étaient pas négligeables aux yeux du maître. Quant aux ouvriers des grandes manufactures et grosses exploitations, manifestent-ils dès cette époque une conscience de classe ? On ne voit pas autour de quelle notion sociale essentielle elle se serait constituée. En tout cas, l'idée du salaire ne parait pas bien dégagée, non plus qu'une conception générale de leurs rapports avec les employeurs. Sans doute, dès les origines, il y a des soulèvements, des protestations

M. Picard (Roger), dans l'article cité (p. 632), indique que les ouvriers dès le XVIII ${ }^{\mathrm{e}}$ siècle, ont déjà tenté de s'associer et de se coaliser contre les patrons, et que «ce sentiment de classe se réveilla » au moment des élections aux États Généraux de 1789. «Les édits de convocation, n'appelant au vote et à l'expression des doléances que les individus constitués en corps, laissaient en dehors de ce mouvement la masse des ouvriers considérés comme des individus isolés. " C'est nous qui soulignons. C'est donc bien parce qu'ils ne sont pas associés, parce qu'ils sont exclus de tous les corps sociaux organisés, et par conséquent de la société, que les ouvriers lui semblent déjà à considérer comme une classe. - Se reporter à l'ouvrage du même auteur : Les cahiers de 1789 et les classes ouvrières (Paris, Rivière, 1910), en particulier aux deux premiers chapitres, pp. 23-47. 
collectives contre les exigences des patrons, mais surtout dans les industries qui étaient autrefois domestiques et artisanes ; et elles sont dirigées plutôt contre les commerçants, gros drapiers, etc., que contre les manufacturiers; ils protestent parce que des commerçants leur achètent leur produit à un prix inférieur au prix ancien. Quand il y a travail salarié proprement dit, surtout dans des industries nouvelles, il semble qu'ils se plient aux bas salaires comme à une loi naturelle, et ne réclament leur relèvement que quand leur misère est trop grande. Pendant la Révolution française, c'est-àdire dans une période de vie collective intense, ils ne réclament guère de relèvements de salaires, mais protestent contre le trop haut prix du pain, et demandent la fixation d'un maximum. Évidemment, la notion du salaire entendu comme un rapport entre une quantité de travail et le prix du produit ne s'est pas encore dégagée ${ }^{53}$.

Elle est devenue de plus en plus nette à mesure que la vie sociale s'est compliquée. D'une part, le développement de la richesse mobilière, l'essor du commerce et de la spéculation ont de plus en plus transformé les conditions de l'industrie, et modifié les tendances et habitudes d'esprit des industriels. D'autre part, les ouvriers de la grande industrie ont représenté de mieux en mieux la classe ouvrière, et imposé de plus en plus à la masse leurs conceptions ordinaires. Il en est résulté une opposition de plus en plus consciente des classes. Car la classe ouvrière a perdu peut-être à la disparition progressive des artisans habiles et presque artistes remplacés par les machines. Mais la formation et l'accroissement de groupes ouvriers étendus et homogènes, leur organisation en vue de discuter les conditions du travail, les expériences de grèves ou d'ententes avec les patrons, à l'occasion desquelles toute une conception de la production industrielle, des rapports entre ouvriers et employeurs, et enfin du salaire s'est dégagée dans la conscience des groupes, l'ont préparée à reconnaître son unité. - Ce n'est en rien notre objet d'étudier l'évolution dans le temps d'une pareille conscience de classe ; mais nous voulions marquer qu'elle existe. Nous devons aussi constater que, dans tout l'ensemble des faits qu'une théorie des classes doit expliquer, il n'y en a sans doute pas de plus important. Il y a des régions de la société où il est plus facile de distinguer des classes, et d'autres où il l'est moins. Il est vraisemblable d'ailleurs qu'en toute nation suffisamment évoluée et complexe diverses consciences de classes tendent à se former. Mais, dans les pays d'industrie, et de notre temps, on ne trouve nulle part un fossé plus profond qu'entre les ouvriers et ceux qui ne le sont pas.

Fin du livre I

M. Picard relève que les ouvriers demandent ou qu'on demande pour eux, à la veille de la Révolution, des salaires « un peu plus équitables », c'est-à-dire « qui se proportionneraient au coût des denrées dans chaque région ». Livre cité, p. 105. 